Metals and Ceramics Division

\title{
Correlation of Process Data and Electrochemical Noise to Assess Kraft Digester Corrosion: Second Year at Spring Grove
}

\author{
S. J. Pawel* \\ D. W. Townley† \\ D. E. Roy $\ddagger$ \\ D. F. Wilson* \\ * Metals and Ceramics Division, ORNL, Oak Ridge, TN \\ $\dagger$ M. J. Schiff and Associates, Claremont, CA \\ ‡Glatfelter Company, Spring Grove, PA
}

Date Published: April 2004

\author{
Prepared for \\ U. S. Department of Energy \\ Industrial Technologies Program
}

Prepared by the

OAK RIDGE NATIONAL LABORATORY

Oak Ridge, TN 37831-6285

Operated by

UT-Battelle, LLC

for the

U. S. DEPARTMENT OF ENERGY

Under contract DE-AC05-00OR22725 
This page

intentionally blank 


\section{PREFACE}

Dimensions and calculated quantities using these dimensions are frequently given in English units rather than in the unified metric system throughout this report. Fundamentally, the vessel dimensions (feet and inches), the measurement locations associated with the digester (feet and inches), wall thickness measurements (inches and mils), and corrosion rates (mils/y) provided by, or determined at, the mill are recorded and discussed in English units. As a result, and because it is the common nomenclature for mill personnel and the anticipated audience of this document, these units will be retained for primary use in the report. In the few instances in which measurements were originally made using the metric system, that nomenclature is retained. Conversion to metric system units depends on the following relationships:

$$
\begin{aligned}
& 1 \mathrm{mil}=0.001 \mathrm{in.}=0.0254 \mathrm{~mm} \\
& 1 \text { inch }=25.4 \mathrm{~mm} \\
& 1 \text { foot }=0.305 \mathrm{~m}
\end{aligned}
$$


This page

intentionally blank 


\section{CONTENTS}

\section{Page}

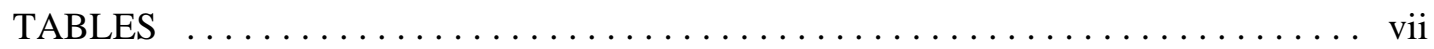

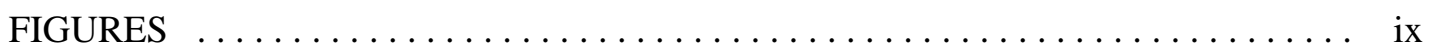

ACRONYMS AND SYMBOLS $\ldots \ldots \ldots \ldots \ldots \ldots \ldots \ldots \ldots \ldots \ldots \ldots \ldots \ldots \ldots \ldots \ldots \ldots$

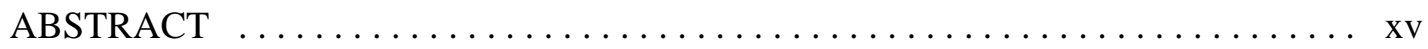

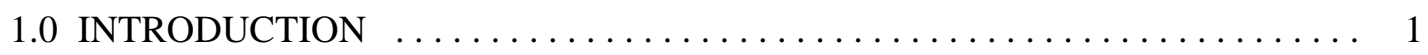

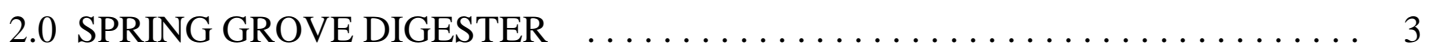

2.1 PROBE AND COUPON PLACEMENT ................. 3

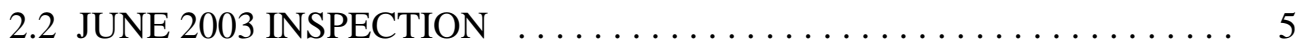

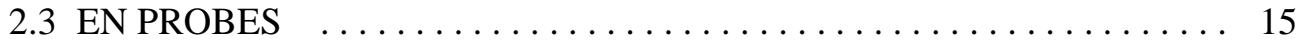

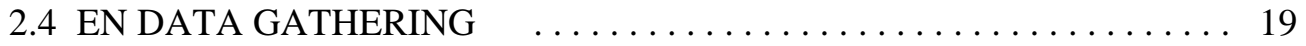

2.5 STEEL COUPONS ON DUMMY PLATES $\ldots \ldots \ldots \ldots \ldots \ldots \ldots \ldots$

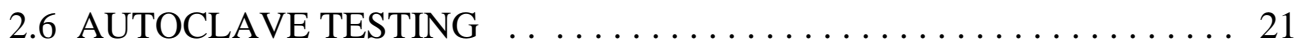

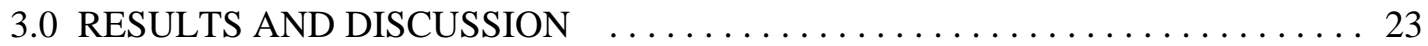

3.1 EN DATA ANALYSIS AND INTERPRETATION $\ldots \ldots \ldots \ldots \ldots \ldots 23$

3.2 POST-TEST EVALUATION OF ELECTRODE MATERIALS $\ldots \ldots .25$

3.3 GENERAL ECN CHARACTERISTICS $\ldots \ldots \ldots \ldots \ldots \ldots \ldots \ldots \ldots$

3.4 REPRESENTATIVE EN DATA $\ldots \ldots \ldots \ldots \ldots \ldots \ldots \ldots \ldots \ldots \ldots \ldots \ldots \ldots$

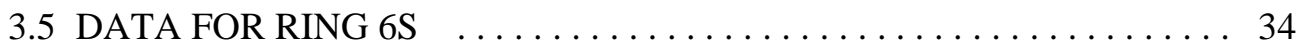

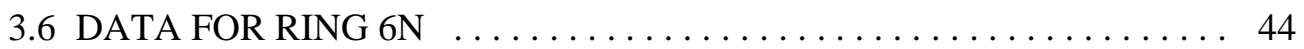

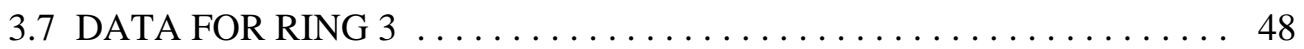

3.8 DATA FOR THE FLASH TANK $\ldots \ldots \ldots \ldots \ldots \ldots \ldots \ldots \ldots \ldots$

3.9 PROCESS DATA CORRELATION $\ldots \ldots \ldots \ldots \ldots \ldots \ldots \ldots \ldots \ldots$

3.10 RESULTS FROM STEEL PANELS ON DUMMY PLATES . . . . . 54

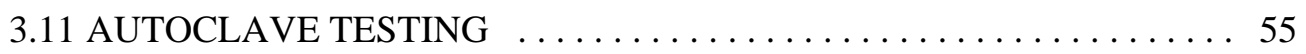

4.0 CONCLUSIONS $\ldots \ldots \ldots \ldots \ldots \ldots \ldots \ldots \ldots \ldots \ldots \ldots \ldots \ldots \ldots \ldots \ldots \ldots \ldots \ldots \ldots$

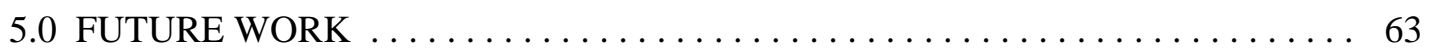

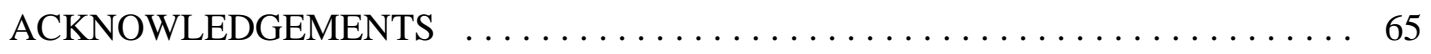

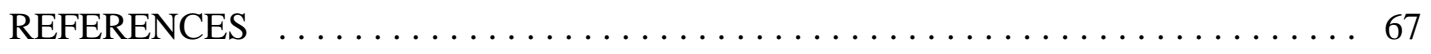


This page

intentionally blank 


\section{TABLES}

Table

Page

1 Position/location of electrochemical noise probes in the Spring

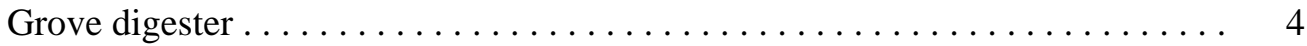

2 Composition of overlay materials (weight \%, average of at least nine determinations). No Si was detected for either overlay with the alloy analyzer. Ferrite number determined by average of 20 determinations with a calibrated magnetic gage $\ldots \ldots \ldots \ldots \ldots \ldots \ldots \ldots$

3 Comparison (wt\%) of the test panels attached to dummy plates at the extraction level and exposed to the process for one year $\ldots \ldots \ldots \ldots \ldots 21$

4 Comparison of corrosion rates (mils/y) calculated from the sum of the absolute values of current averages on five-minute intervals for the 309LSi and 312 stainless steel overlay probe materials. List includes data for the 309LSi from year \#1 at Spring Grove for

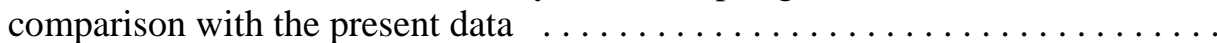

$5 \quad$ Corrosion rates (mils/y) calculated from weight loss of coupons exposed to synthetic liquors in autoclaves for 14 days at $165^{\circ} \mathrm{C}$

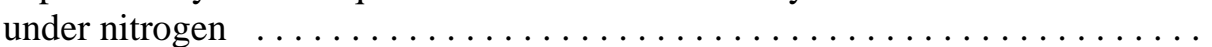


This page

intentionally blank 


\section{FIGURES}

$\begin{array}{lll}\text { Figure } & \text { Page }\end{array}$

1 Schematic of the Spring Grove digester and probe locations . . . . . . . . . 4

2 Views of the new dummy plate with steel coupons attached. Top: one of two blank plates with test panels attached. Bottom: close-up view of test panels with different heat treatments. Note that the stainless steel nut and bolt have been welded together on the end to prevent loosening during operation $\ldots \ldots \ldots \ldots \ldots \ldots \ldots \ldots \ldots \ldots$

3 Three views of a small diameter section of center pipe removed from the digester in June 2003. Note the parallel rows of pits separated by relatively smooth areas. Pits here are generally 40 mils deep and slightly elongated in the longitudinal direction rather than being hemispherical. The white scale marker is $3.5 \mathrm{~cm}$ long $\ldots \ldots \ldots \ldots \ldots$

4 Large diameter section of the center pipe with a single row of

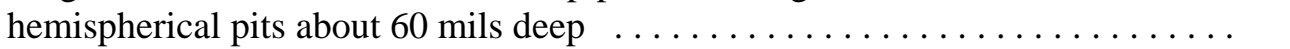

5 A gouge on a large diameter section of center pipe. The gouge shown here is oriented about $45^{\circ}$ to longitudinal and is about 60 mils deep

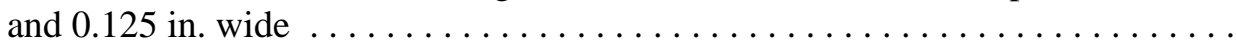

$6 \quad$ Transition piece (ring 17) and the round seam weld H18 at the June 2003 inspection. Localized corrosion at this location was not previously documented. Pits near the white scale marker $(3.5 \mathrm{~cm}$

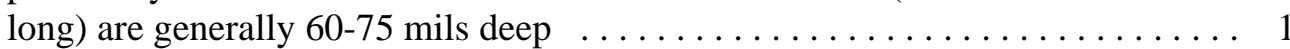

7 Views of the ring 13 surface during the June 2003 inspection. Top: oceans-and-islands pitting on a relatively fine/close spacing. The flashlight beam spot improves contrast between the elevated surface (bright, "island”) and the recessed (dark, “ocean”) positions. Bottom: close-up view of a relatively large "island” at the bottom of ring section 14. In both photos, the white scale marker is $3.5 \mathrm{~cm}$ long

8 Views of ring section 12 at the June 2003 inspection. Top: general appearance, showing shallow pits in a mostly unattacked surface. Bottom: some pits appear to have agglomerated in patterns suggesting the location of a former bracket just below the $\mathrm{H} 13$ seam weld. The white scale marker is $3.5 \mathrm{~cm}$ long $\ldots \ldots \ldots \ldots \ldots \ldots$

$9 \quad$ Stainless steel blank plate with steel test panels after one year of

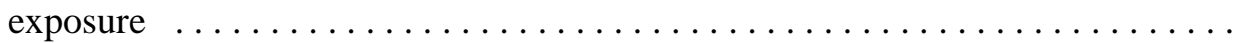

10 Adjustable length dual probe used in the Spring Grove experiment 16 
11 Photomicrographs of the 309LSi overlays. Top: representative of the laboratory applied overlay. Bottom: representative of the 309LSi

field overlay in the digester $\ldots \ldots \ldots \ldots \ldots \ldots \ldots \ldots \ldots \ldots \ldots \ldots \ldots \ldots$

12 Photomicrograph of 312 overlay applied in the laboratory $\ldots \ldots \ldots \ldots \ldots$

13 Post-test cross-sections of type 312 stainless steel electrodes after exposure for one year. Top: from the ring 12 probe. Bottom: from

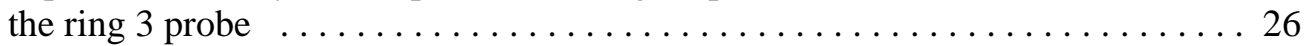

14 Unexposed cross-section of type 312 stainless steel electrode. This specimen was prepared from material remaining following fabrication

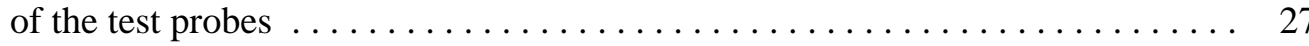

15 As-polished cross-section of the approximate mid-plane of the Ag electrode from the ring 12 probe $\ldots \ldots \ldots \ldots \ldots \ldots \ldots \ldots \ldots \ldots \ldots \ldots \ldots \ldots$

16 As-polished cross-section of the approximate mid-plane of the Ag

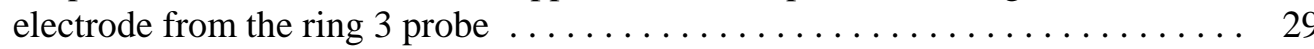

17 As-polished cross-section of the approximate mid-plane of the Ag

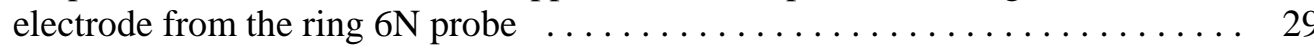

18 As-polished cross-section of the approximate mid-plane of the Ag

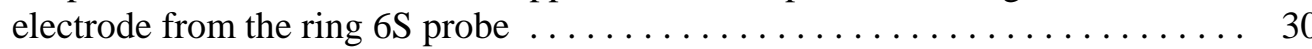

19 Histogram representing the EN potential data for each probe position and electrode material for the period June-September

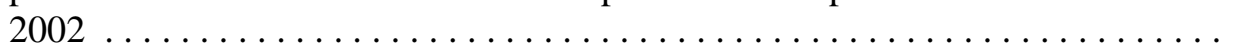

20 Histogram representing the EN potential data for 309LSi electrodes early in the year $\# 1$ experiment $\ldots \ldots \ldots \ldots \ldots \ldots \ldots \ldots \ldots \ldots \ldots \ldots \ldots \ldots \ldots$

21 Representative EN potential data for the 309LSi electrodes in the ring $6 \mathrm{~S}$ probe. The dashed lines represent the $\pm 10 \mathrm{mV}$ boundary around the median potential of $-55 \mathrm{mV}$. .

22 EN potential data along with probe temperature for the ring 6S 309LSi electrode surrounding the October 4 event in the digester

23 Relationship of ring 6S probe temperature and the white liquor flow to the digester surrounding the October 4 event in the operation $\ldots \ldots \ldots \ldots$

24 White liquor flow to the digester plotted with 309LSi potential data for the ring $6 \mathrm{~S}$ probe and the October 4 event in the digester. The dashed vertical lines represent the boundaries of the $~$ zero white liquor flow period

25 Relationship of current and potential noise for the 309LSi electrode on the ring $6 \mathrm{~S}$ probe for the October 4 event in the digester 
26 Probe temperature and 309LSi potential at the ring 6S probe

associated with the October 31 event in the digester $\ldots \ldots \ldots \ldots \ldots \ldots$

27 Relationship of the current and potential noise data for the ring 6S

309LSi electrodes associated with the October 31 event in the

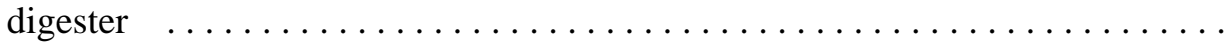

28 Ring 6S probe temperature and white liquor flow plotted together

for the October 31 event in the digester $\ldots \ldots \ldots \ldots \ldots \ldots \ldots \ldots \ldots$

29 Current noise for the ring 6S 309LSi electrodes plotted with the total

filtrate flow associated with the October 31 event in the digester $\ldots \ldots \ldots 42$

30 Potential noise of the 312 electrodes along with the shut-down

temperature excursion at ring $6 \mathrm{~S}$

31 Potential and current noise for the 312 electrodes of the ring $6 \mathrm{~S}$

probe during the shut-down transient $\ldots \ldots \ldots \ldots \ldots \ldots \ldots \ldots \ldots$

32 Representative temperature data as a function of time at the ring 6

33 Representative potential noise for 309LSi electrodes along with temperature data for the ring $6 \mathrm{~N}$ probe $\ldots \ldots \ldots \ldots \ldots \ldots \ldots \ldots$

34 Current and potential noise for the 309LSi electrodes in the ring 6N probe surrounding the early October "event" in the digester

35 Representative current noise for the 312 electrodes plotted with temperature of the flash tank probe

36 Current noise for the February 15 portion of the general current noise recorded in Fig. 35. Data points are coded corresponding to the relative potential associated with each $\ldots \ldots \ldots \ldots \ldots \ldots \ldots \ldots$

37 Potential noise corresponding to the current noise data plotted in Fig. 36

38 Current noise transient associated with a digester upset (temperature excursion) near January $21 \quad \ldots \ldots \ldots \ldots \ldots \ldots \ldots \ldots \ldots \ldots \ldots \ldots \ldots$

39 Coupons used in autoclave testing. Top: A series of A517-70

panels with a 120 grit finish, $45 \mathrm{~min} / 305^{\circ} \mathrm{C}$ scale, and $135 \mathrm{~min} / 305^{\circ} \mathrm{C}$

scale, from left-to-right, respectively. Bottom: A series of coupons

(one of each material and heat treatment) arranged on a piece of all-thread for exposure in the autoclave 
40 Appearance of specimens following autoclave testing for 14 days at $165^{\circ} \mathrm{C}$ in synthetic white liquor solution. Top: specimen rod with all the specimens; the one with no corrosion product is the 304L coupon, and the two Corten A specimens have relatively little corrosion product. Bottom: A285C coupon with the corrosion product partially

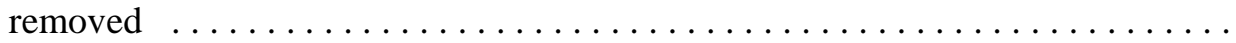

41 Examples of oxide removal patterns to examine potential galvanic effects of the scale during autoclave testing. The dark/blue areas have scale formed in $45 \mathrm{~min} / 305^{\circ} \mathrm{C}$, and the shiny areas have been ground to 120 grit finish 


\section{ACRONYMS AND SYMBOLS}

$\begin{array}{ll}\text { EN } & \text { electrochemical noise } \\ \text { EX } & \text { extraction screens } \\ \text { ID } & \text { inside diameter } \\ \text { LI } & \text { localization index } \\ \text { ORNL } & \text { Oak Ridge National Laboratory } \\ \mathrm{ZRA} & \text { zero resistance ammeter } \\ \mathrm{Ag} / \mathrm{Ag}_{2} \mathrm{~S} & \text { silver/silver sulfide reference electrode } \\ \mathrm{R}_{\mathrm{n}} & \text { resistance noise parameter }\end{array}$


This page

intentionally blank 


\begin{abstract}
Electrochemical noise (EN) probes were deployed in the carbon steel continuous kraft digester at Spring Grove at four locations and at one location in the bottom cone of the associated flash tank for a second consecutive year of a corrosion study. The probes contained dual electrodes of 309LSi stainless steel overlay - representing a field repair material applied to a portion of the vessel - and dual electrodes of 312 stainless steel overlay. Current and potential noise, the temperature at each probe location, and the value of 23 process parameters (flow rates, liquor chemistry, etc.) were again monitored continuously for a period of almost one year. Historical vessel inspection data and post-test evaluation of the probe components were used to assess/compare EN corrosion activity with physical changes in wall thickness and corrosion patterns on the digester shell. In addition, attempts were made to correlate EN activity from each electrode type with process parameters.
\end{abstract}

The results indicate the corrosion conditions aggressive to mild steel persist within the digester, as post-test inspection of the vessel revealed localized corrosion of mild steel in locations previously free of attack. Further, there was evidence that the depth of localized attack of exposed steel had increased in some locations. Nevertheless, the stainless steel overlay in the digester was essentially immune to corrosion, as evidenced by retained surface relief and heat tint associated with the original deposition process. The 309LSi electrodes also appeared visually pristine, and post-exposure metallographic examination of the 309LSi electrode materials revealed no attack. The 312 electrode materials were similar in appearance, but exhibited very minor interdendritic attack over the exposed surface. The silver electrodes in the probes were consumed (to $\mathrm{Ag}_{2} \mathrm{~S}$ ) to variable degree over the course of the exposure indicating a useful life of not more than a year in digester service in this vessel.

Since the stainless steel overlay electrodes were immune to corrosion during the exposure, the current and potential noise activity on these probes is likely related to redox processes on the electrode surfaces. Analysis of this activity as a function of position (and year) in the vessel suggests that redox chemistry/conditions vary by a significant amount on a consistent basis even on opposite sides of the vessel at the same elevation - and that these differences are not identified by process parameters tracked at the mill. These variable environmental conditions (flow, temperature, liquor chemistry) appear to have little effect on stainless steel overlays under 
evaluation, but apparently can be quite corrosive to steel as determined in the initial study in the digester at Spring Grove.

With the exception of start-up and shutdown activity, including brief upsets for "hanging columns” or brief maintenance periods, no regular correlation was observed between tracked process variables and EN activity on any of the probes. In combination with the variable redox activity, this result suggests that the liquor sampling and flow data compiled at the mill do not represent the corrosion conditions in the vessel particularly well. 


\subsection{INTRODUCTION}

This is the third in a series of reports detailing experiments involving the deployment of electrochemical noise (EN) corrosion probes in operating digesters. The initial report [1] included background information about the EN technique and the general goal of the program to assess vessel corrosion in real-time as a function of operating parameters. In addition, the initial report [1] detailed vessel inspection data and the results from a year-long experiment using EN probes made of mild steel in the continuous kraft digester at the Weyerhaeuser Company paper mill in Kamloops, British Columbia.

A second EN probe deployment was initiated in June 2001 in the continuous kraft digester at the Glatfelter paper mill in Spring Grove, PA. The initial set of probes was in place for an entire calendar year, and each probe included both mild steel electrodes (approximating the original construction material) as well as type 309LSi stainless steel overlay electrodes (representing the applied repair choice for a corroded portion of the digester). The results of the first year of data from the Spring Grove digester, along with observations gathered during vessel inspections, were summarized in a second report [2].

In June 2002, the probes in the Spring Grove digester were replaced with almost identical probes, but rather than electrodes of mild steel and type 309LSi stainless steel overlay, the replacements had electrodes representing both types 309LSi and 312 stainless steel overlay. Several factors contributed to the decision to change probes and electrode materials following the first year of exposure. Primarily, the EN data collected during the first year suggested that modest corrosion might be occurring on the 309LSi electrodes (and, by inference, the 309LSi overlay in the digester). To confirm whether or not significant corrosion had occurred on the electrodes, the probes needed to be removed from the vessel and destructively examined. However, decisions regarding replacement probe materials were required several months in advance of the opportunity to examine the exposed electrodes. As a result, type 312 stainless steel overlay was included in the replacement probes as representative of an "upgrade" overlay material compared to type 309LSi. [Type 312 is considered an "upgrade" compared to 309LSi for digester service primarily due to the higher $\mathrm{Cr}$ content of the former - nominally $28-32 \% \mathrm{Cr}$ compared to $23-25 \% \mathrm{Cr}$ for 309LSi.] In addition, it was considered prudent to replace probes following a year of service to examine the teflon probe bodies and silver reference electrode materials for signs of degradation that might compromise extended service of the probe. 
The replacement probes were removed from the Spring Grove digester at the maintenance outage in June 2003, and the vessel was again inspected. The purpose of this report is to document the additional inspection information and EN data gathered during the second year of the Spring Grove experiment, and to compare applicable results with those from the initial year. 


\subsection{SPRING GROVE DIGESTER}

\subsection{PROBE AND COUPON PLACEMENT}

A general description and brief operational history of the Spring Grove digester appears in Ref. 2. For the convenience of the reader, a vessel schematic indicating the EN probe locations is shown in Fig. 1. The vessel is approximately $150 \mathrm{ft}$. tall and $12 \mathrm{ft}$. in diameter, and the relative positions of the EN probes for this experiment are indicated on the schematic drawing. The number associated with each probe was determined from the ring section number of the shell it represents and, in the case of the two probes at a single elevation, the further notation " $\mathrm{N}$ " and "S" describes the relative side of the vessel. The "N" designation indicates the probe on the northeast side of the vessel with approximately the same longitude as the service manway. The "S" designation indicates the probe in the southwest portion of the vessel almost directly across the vessel from the probe at the " $6 \mathrm{~N}$ " location. The probes at ring 3 and ring 12 have the same vessel longitude, which is only very slightly different from the longitudinal position of the probe at ring $6 \mathrm{~N}$.

In addition to the four probes indicated in Fig. 1, a fifth probe was located in the bottom cone of the \#1 liquor flash tank. Due to data gathering limitations - only four sets of probes could be evaluated at any time with the EN instrumentation - and because activity on the probe at ring 12 was essentially nil over the initial year of the experiment, the probe at ring 12 was used only to monitor temperature during the second year of the Spring Grove experiment. Table 1 gives the probe locations along with approximate corresponding elevations in the vessel. 


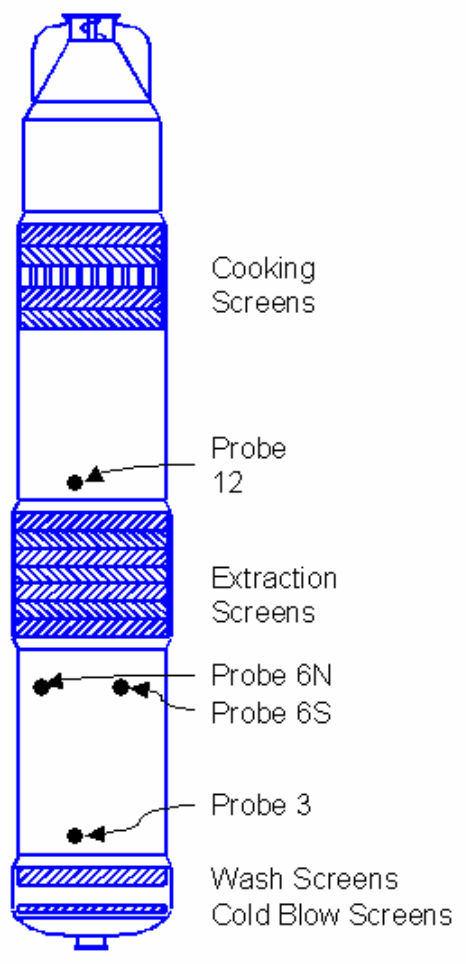

Fig. 1. Schematic of the Spring Grove digester and probe locations.

Table 1. Position/location of electrochemical noise probes in the Spring Grove digester.

\begin{tabular}{|l|l|c|}
\hline Probe ID & \multicolumn{1}{|c|}{ Location/Elevation relative to other components } & $\begin{array}{c}\text { Design Shell } \\
\text { Thickness (in.) }\end{array}$ \\
\hline Ring 3 & $\approx 8 \mathrm{ft}$. above top of wash screens, just above manway & 1.332 \\
\hline Ring 6N & $\approx 6 \mathrm{ft}$. below bottom row of extraction screens, above manway & 1.289 \\
\hline Ring 6S & $\approx 6 \mathrm{ft}$. below bottom row of extraction screens, opposite 6N & 1.289 \\
\hline Ring 12 & $\approx 8 \mathrm{ft}$. above top row of extraction screens & 1.438 \\
\hline Flash Tank & $\approx$ mid-slope in bottom cone of vessel \#1 & 0.375 \\
\hline
\end{tabular}


In the June 2002 outage, five rows of mild steel blank plates associated with the extraction screens were replaced due to severe corrosion [2] over the service life (2-5 years, depending on the specific row). The replacement blank plates were fabricated of $304 \mathrm{~L}$ stainless steel. In an attempt to examine the possibility that residual oxides such as mill scale influence corrosion of mild steel in the digester environment, and in particular might contribute to the pitting pattern commonly observed on digester steels at/near the extraction screens, a number of mild steel panels heat treated to simulate mill scale were attached to two blank plates that were installed on opposite sides of the vessel. Panels with dimensions 5 in. $\mathrm{x} 5$ in. $\mathrm{x} 0.125$ in. thick fabricated from three different types of mild steel and given a range of heat treatments in air were affixed to the blank plates with stainless steel hardware and teflon shoulder washers to isolate the test panels from the blank plate and attachment hardware. Figure 2 is representative of an array of test specimens attached to a blank plate awaiting installation. Additional details regarding the coupons, materials, and heat treatments appear in a subsequent section.

\subsection{JUNE 2003 INSPECTION}

This section summarizes observations made during the June 2003 inspection of the digester vessel. The first few paragraphs are dedicated to the center pipe, which was removed for replacement. Subsequently, observations from inside the vessel organized from the top of the vessel toward the bottom are recorded. In all cases, changes in appearance compared to previous inspections are highlighted. Inspection details from June 2001 and June 2002 appear in Ref. 2.

Despite approximately 40 years service with only minimal required maintenance, it was determined by Glatfelter personnel that the mild steel center pipe (through which process liquor is added at specific locations in the vessel via an annular piping arrangement) would be replaced at the June 2003 maintenance outage. While the center pipe did not exhibit signs of imminent failure when it was removed, the high corrosion rate detected on the steel shell in the vicinity of ring 6 (prior to the overlay campaign) in combination with the existing pitting pattern on the center pipe suggested replacement as a conservative approach. Further, due to the relatively minor cost differential with mild steel in 2002, the material of construction for the replacement center pipe was upgraded to $304 \mathrm{~L}$ stainless steel. 

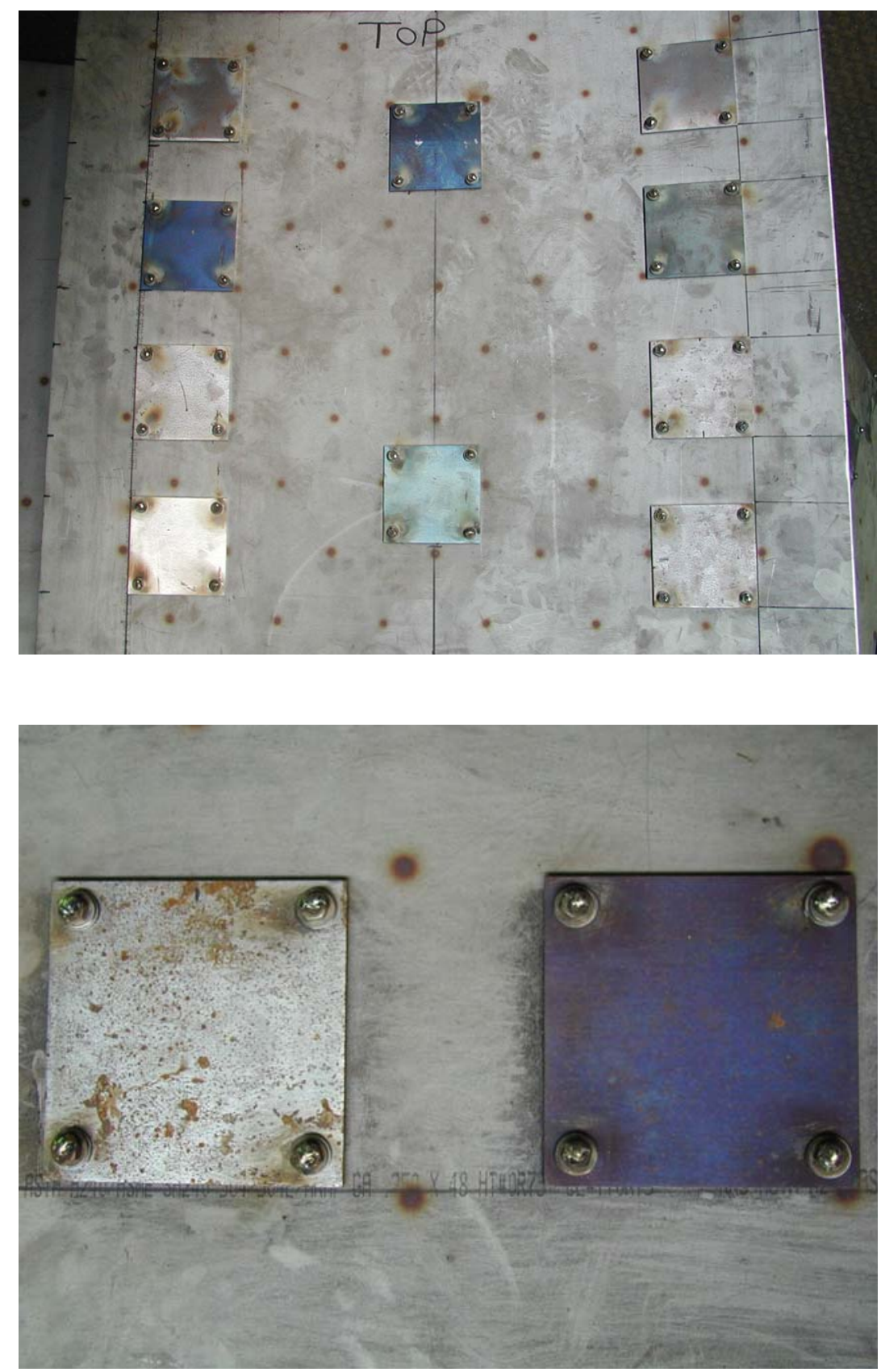

Fig. 2. Views of the new dummy plate with steel coupons attached. Top: one of two blank plates with test panels attached. Bottom: close-up view of test panels with different heat treatments. Note that the stainless steel nut and bolt have been welded together on the end to prevent loosening during operation. 
Figure 3 shows a series of photographs of the center pipe after removal from the digester. These photographs highlight the localized corrosion that has been observed on the center pipe in the last few inspections. In particular, note that the pits on the small diameter sections of the center pipe surface appear to be oriented as least generally in longitudinal rows separated by remarkably smooth and unattacked regions. As estimated with a pit-depth gage, the majority of the pits shown in Fig. 3 - and on other areas of the center pipe following its removal - are nominally 40 mils deep (compared to estimates of 20-25 mils deep as a generality for this manifestation of pitting in the previous annual inspection). However, small clusters of pits in the range 60-75 mils deep were noted on the large diameter sections of the center pipe in previous inspections, so it is not obvious if the pitting at any specific location has become significantly deeper over the last few years. It does appear, however, that the extent of pitted areas has spread somewhat.

Figure 4 shows a perfectly longitudinal row of single pits, more hemispherical in shape than most as well as slightly deeper ( $\sim 60$ mils), on a large diameter section of the center pipe. In other locations, this section of the pipe exhibited clusters of pits in longitudinal rows similar to that shown in Fig. 3, but in this location, the single row of pits is the only significant blemish on an otherwise smooth section.

In a few locations on the large diameter sections of the center pipe, gouges like the one in Fig. 5 were observed. Typically, the gouges were aligned approximately $45^{\circ}$ to longitudinal, and, like the example in Fig. 5, were about 60 mils deep and 0.125 in. wide. Similarly oriented gouges were documented in past inspections, but there is no practical method to determine whether this particular gouge was previously examined. 


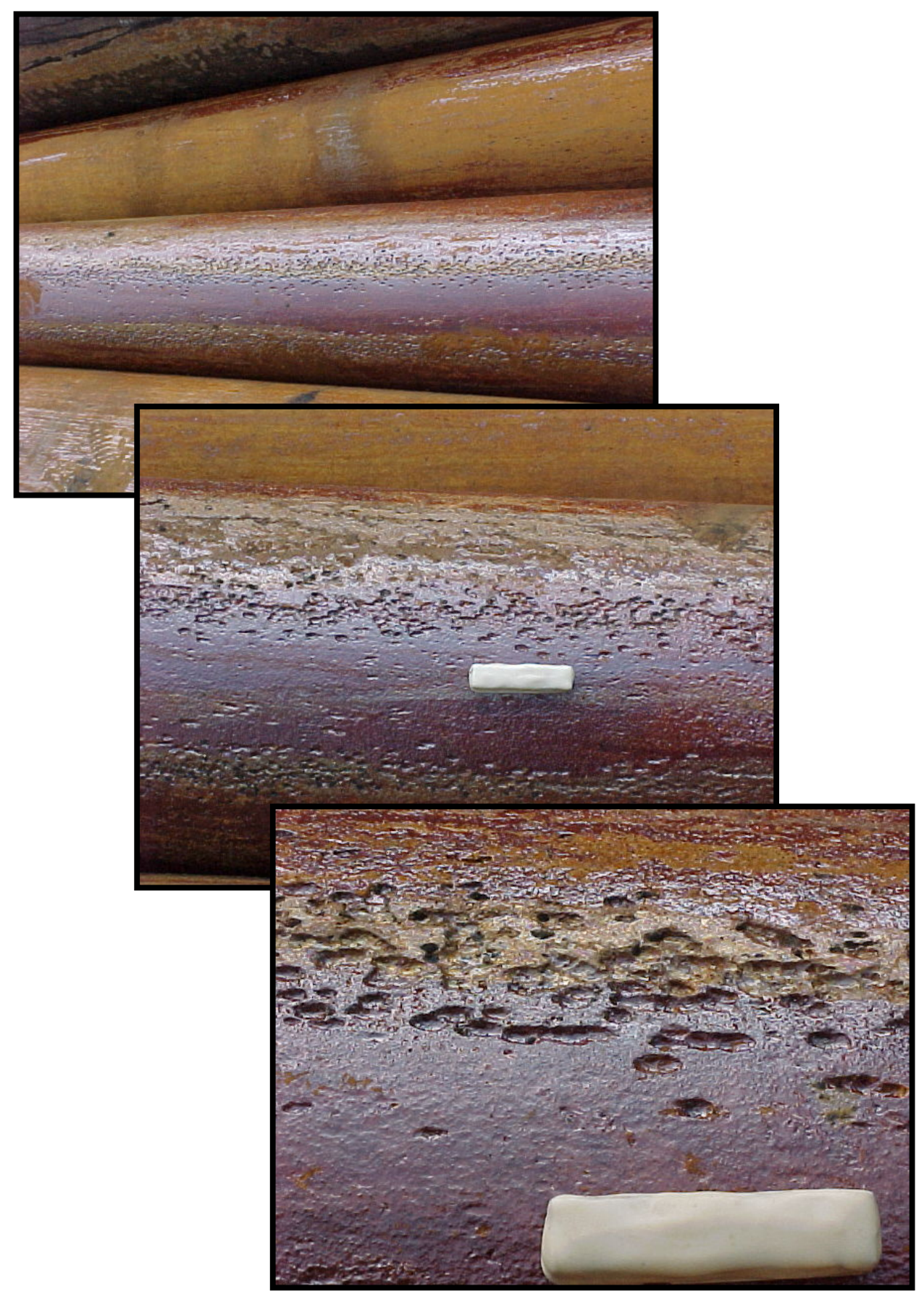

Fig. 3. Three views of a small diameter section of center pipe removed from the digester in June 2003. Note the parallel rows of pits separated by relatively smooth areas. Pits here are generally 40 mils deep and slightly elongated in the longitudinal direction rather than being hemispherical. The white scale marker is $3.5 \mathrm{~cm}$ long. 


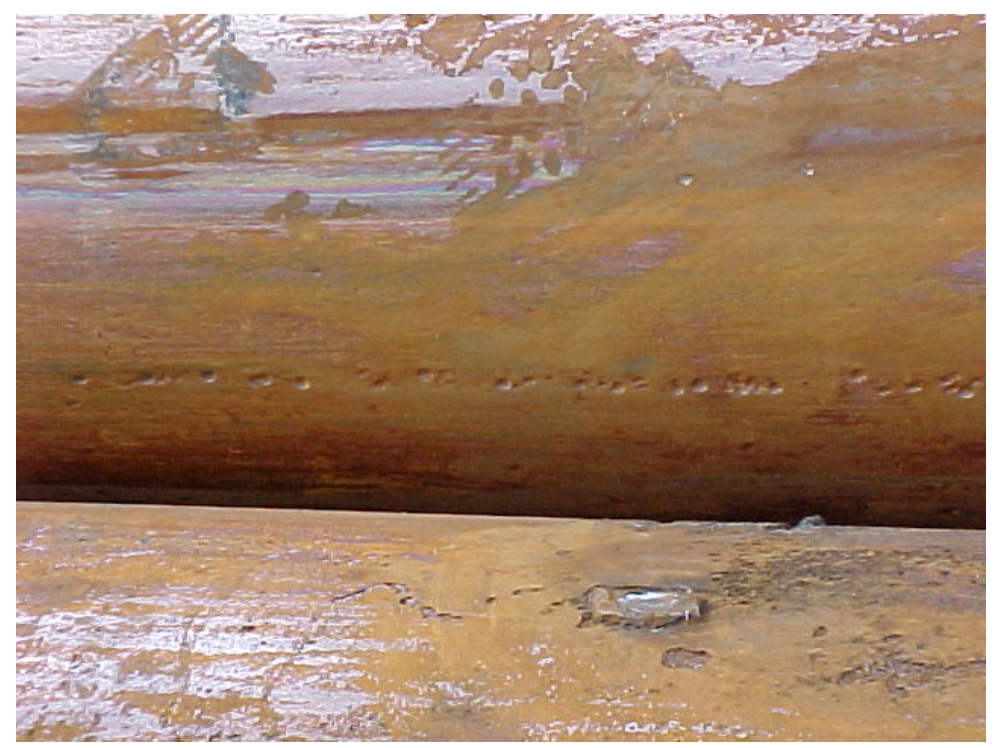

Fig. 4. Large diameter section of the center pipe with a single row of hemispherical pits about 60 mils deep.

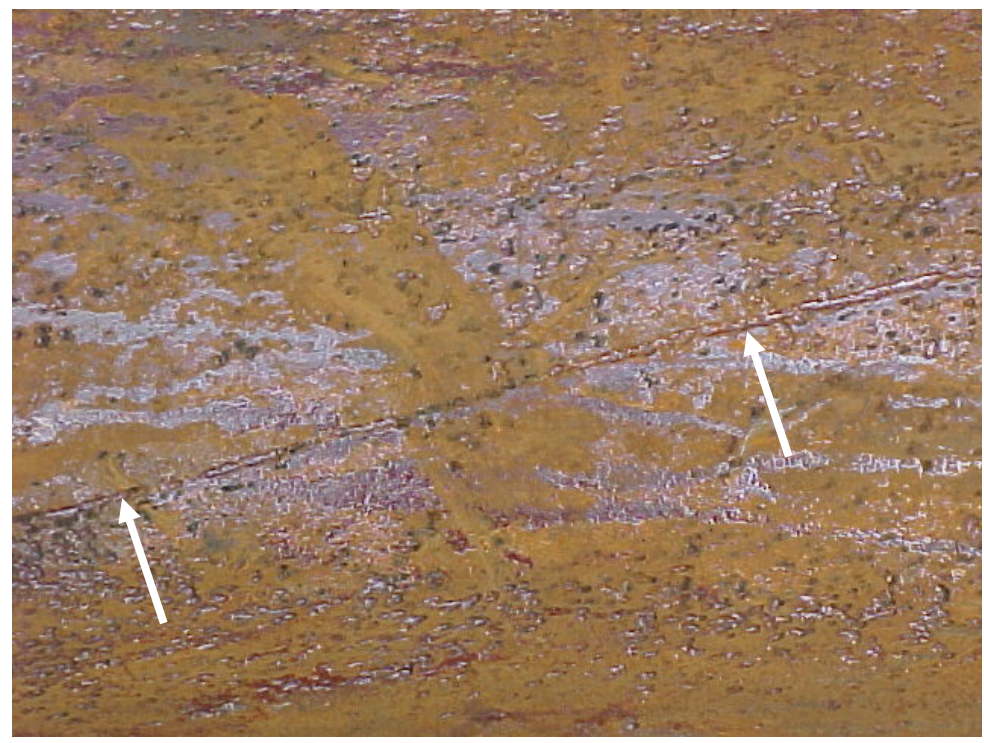

Fig. 5. A gouge on a large diameter section of center pipe. The gouge shown here is oriented about $45^{\circ}$ to longitudinal and is about 60 mils deep and 0.125 in. wide. 
Only a limited amount of the internal surface (ID side) of the center pipe could be examined, but no pits and/or gouges like those shown in Figs. 3-5 were observed on the internal surfaces. This result suggests that subtle details of the environment (flow, chemistry) or handling (fabrication, installation) are able to influence localized corrosion of the external surfaces but not the immediately adjacent internal surfaces of the annular array of center pipe material.

Another result of the June 2003 inspection is evidence that localized corrosion has spread over the prior year to higher regions in the vessel than previously observed. For example, in previous inspections, the vessel ID was largely smooth and unattacked above the cooking screens, with only minor exceptions noted on the transition piece from the shell to the top dome. These exceptions were shaped like "L" brackets, and appeared to be locations where grinding was once used to remove an attachment. However, in the June 2003 inspection, isolated pitting in the range of 60-75 mils deep was observed just above the cooking screens at the round seam designated H18 (transition piece immediately above the cooking screens) as shown in Fig. 6. The round seam at this location (the horizontal weld toward the top of Fig. 6) appeared to be in excellent condition, with a uniform crown above the shell surface and little or no indication of general wastage or pitting. It is possible that previous inspections of this area were hindered by residual black liquor, or failure to inspect/view the topmost position in the vessel with the "sky-climber" inspection platform, but the consensus of Glatfelter personnel is that localized corrosion of this type was not previously detected at this location. 


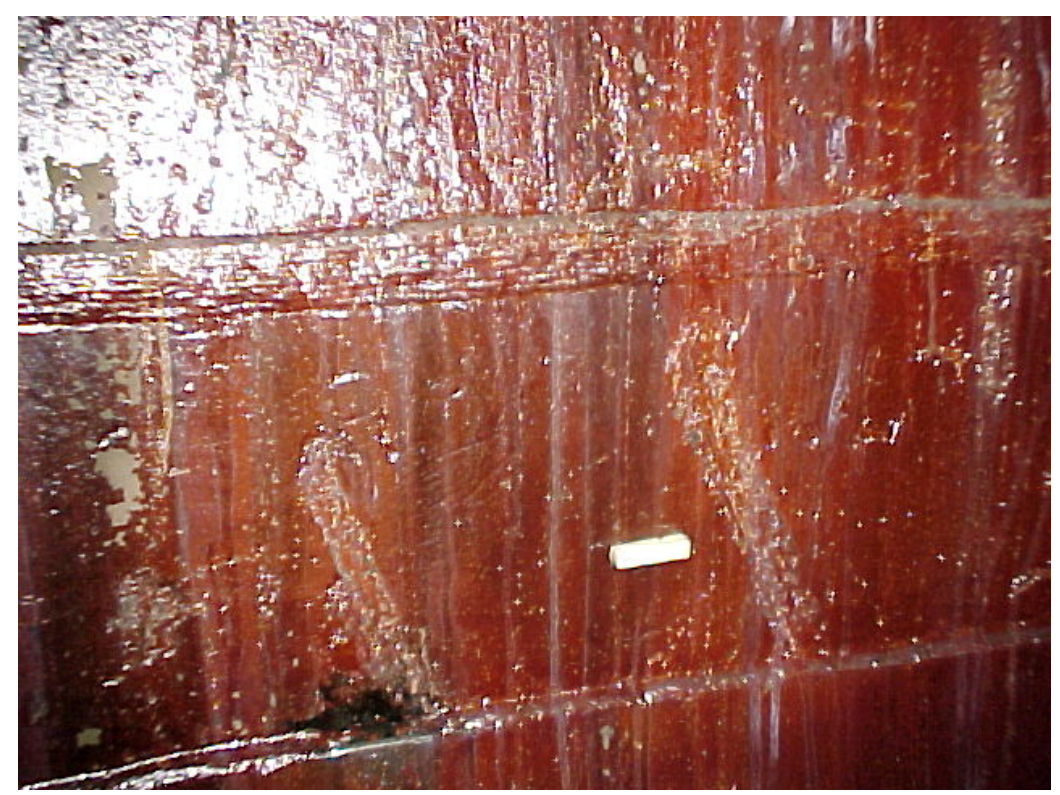

Fig. 6. Transition piece (ring 17) and the round seam weld H18 at the June 2003 inspection. Localized corrosion at this location was not previously documented. Pits near the white scale marker (3.5 cm long) are generally 60-75 mils deep.

The stainless steel screens and mild steel dummy plates that separate the upper and lower cooking screens appeared smooth and unattacked. The mild steel surfaces behind the screens were not generally accessible for detailed inspection, but appeared to exhibit only light scattered round/smooth bottom pits to a depth estimated to be 20 mils.

Most of ring section 13 (just above the ring 12 probe) exhibited relatively shallow "oceansand-islands" pitting patterns on a fine/close spacing. The nominal shell thickness change from the top of the "island" to the bottom of the "ocean" was very abrupt and mostly at the higher end of a 45-60 mil range. While difficult to evaluate precisely, it is suspected that the thickness differential at these locations has increased slightly (from $\sim 25$ mils) compared to the previous inspection. Figure 7 contains representative photographs. 

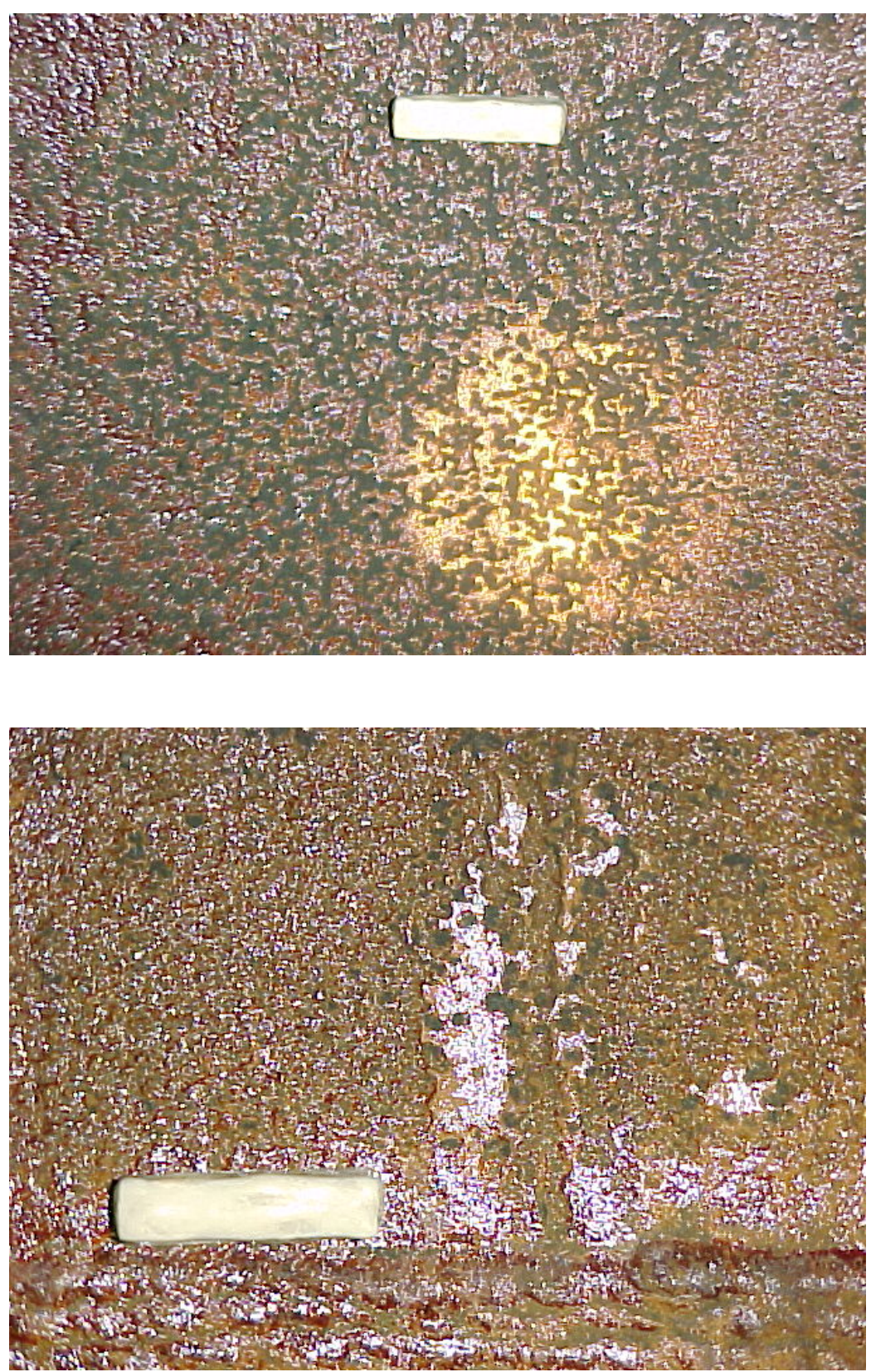

Fig. 7. Views of the ring 13 surface during the June 2003 inspection. Top: oceans-and-islands pitting on a relatively fine/close spacing. The flashlight beam spot improves contrast between the elevated surface (bright, "island") and the recessed (dark, "ocean") positions. Bottom: close-up view of a relatively large "island" at the bottom of ring section 14. In both photos, the white scale marker is $3.5 \mathrm{~cm}$ long. 
The oceans-and-islands pitting pattern was also observed on ring section 12. At this location (top of Fig. 8), the majority of the elevated surface is relatively smooth and the pits are relatively shallow ( 25 mils, similar to the previous year) and isolated. In one location that was not documented in previous inspections (shown at the bottom of Fig. 8), the pitted areas seem to have agglomerated in a pattern reminiscent of a former attachment weld location. Less specific patterns of agglomerated pits oriented mostly in a vertical "swath" were observed over several large areas of ring section 12. The area around the ring 12 probe was essentially unchanged from the previous year, and the probe itself was in good condition with no obvious signs of attack on the electrodes.

The stainless steel extraction screens and new blank plates in rings 8-10 looked smooth and unattacked. All of the test panels on the two blank plates at this elevation remained firmly attached. Despite the cleaning of the vessel for inspection, there were indications of a "mash" of residual pulp and black liquor behind most of the panels. Figure 9 shows one of the test plates with coupons from the middle row of section 9 (from the side of the vessel opposite the manway).

Just below the extraction screens, the 309LSi overlay covers the digester shell surface all the way down to almost the wash screens. The overlay was applied in two campaigns - the first in June 2001 included about 20 feet below the extraction screens, and the second covered the shell from the terminus of the initial application down to the manway on ring 3. All of the overlay looked pristine - largely a very shiny surface with weld ripples and original heat tint remaining, and there were no signs of erosion, pitting, or general wastage. Further, the ring 6 and ring 3 probes appeared visually to be in good condition with no obvious attack. 

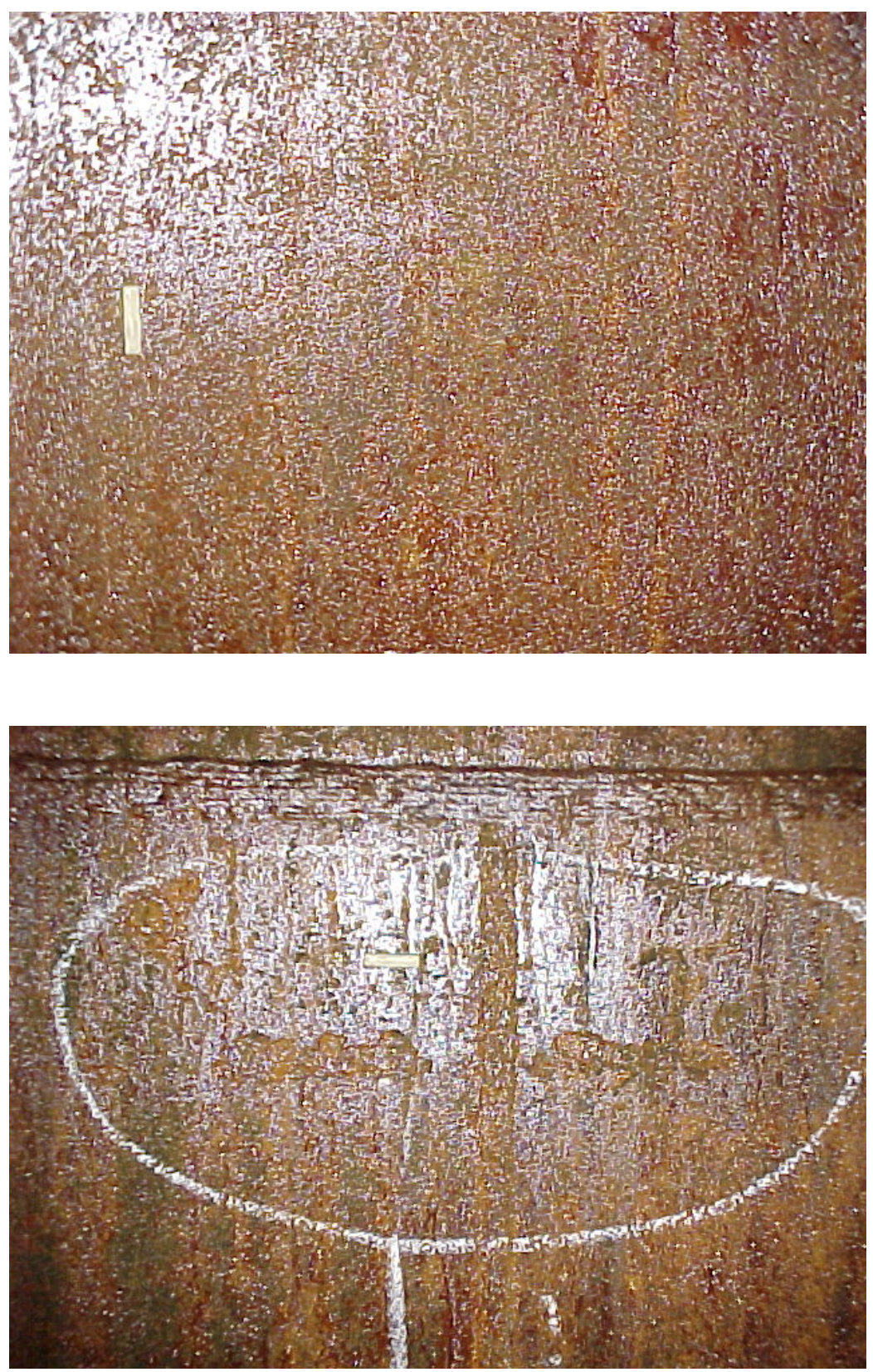

Fig. 8 Views of ring section 12 at the June 2003 inspection. Top: general appearance, showing shallow pits scattered in a mostly unattacked surface. Bottom: some pits appear to have agglomerated in patterns suggesting the location of a former bracket just below the H13 seam weld. White scale marker is $3.5 \mathrm{~cm}$ long. 


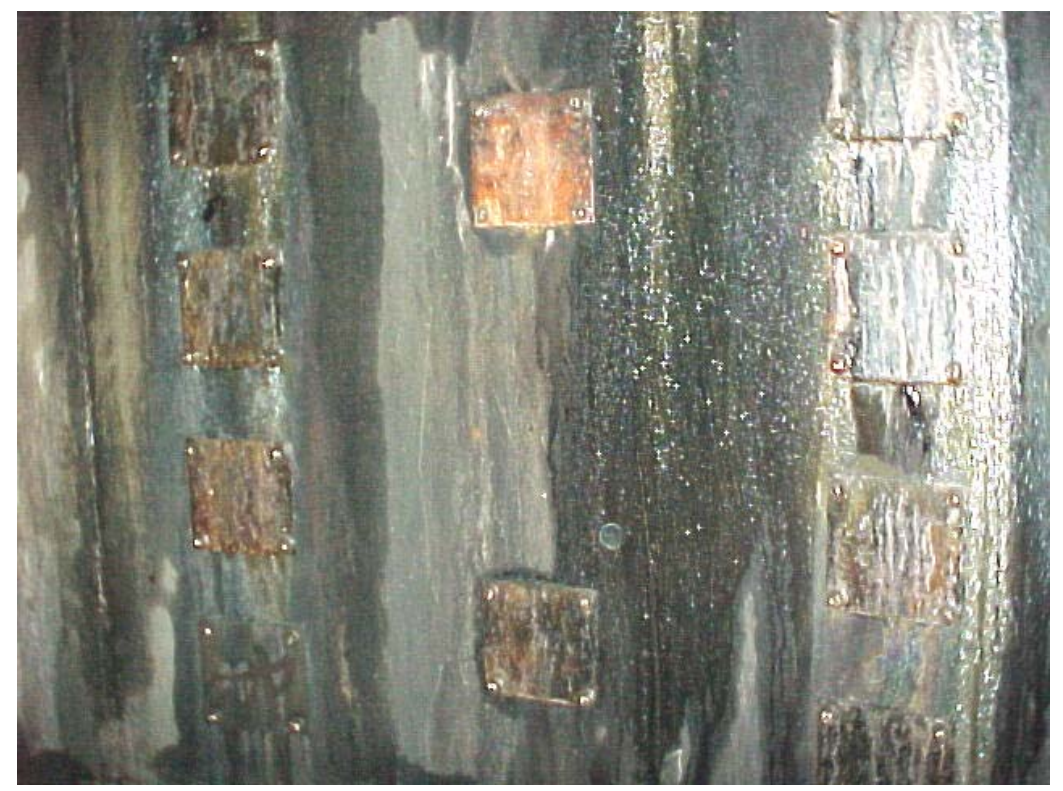

Fig. 9. Stainless steel blank plate with steel test panels after one year of exposure.

The strip of steel between the wash screens and the bottom dome was mostly smooth but there were isolated pits observed in some locations. Nominally, the pits were approximately 6070 mils deep, but one particular eroded/corroded area adjacent to the weld seam was measured to be about 120 mils deep. Past inspections did not reveal the density or depth of pitting in this location that was observed in the June 2003 inspection. There was also shallow pitting on the stainless clad bottom dome - mostly hemispherical, smooth, and very shallow. However, one unusually large indication was about a half inch in diameter and 100 mils deep. The dome cladding also appeared to have a long circumferential scrape in a path suggesting it was caused by movement of the rake arm or perhaps when the outlet device was removed during the previous maintenance effort.

\subsection{EN PROBES}

The basic design of the probes used in the second year at Spring Grove was identical to that used in the previous year, including an adjustable working length so that the surface of the probe could be placed precisely flush with the vessel ID at each probe location (see Fig. 10). However, rather than using electrodes representing mild steel and 309LSi overlay, there were electrodes of 
309LSi and 312 overlay embedded in the teflon header along with a silver rod to function as a reference electrode.
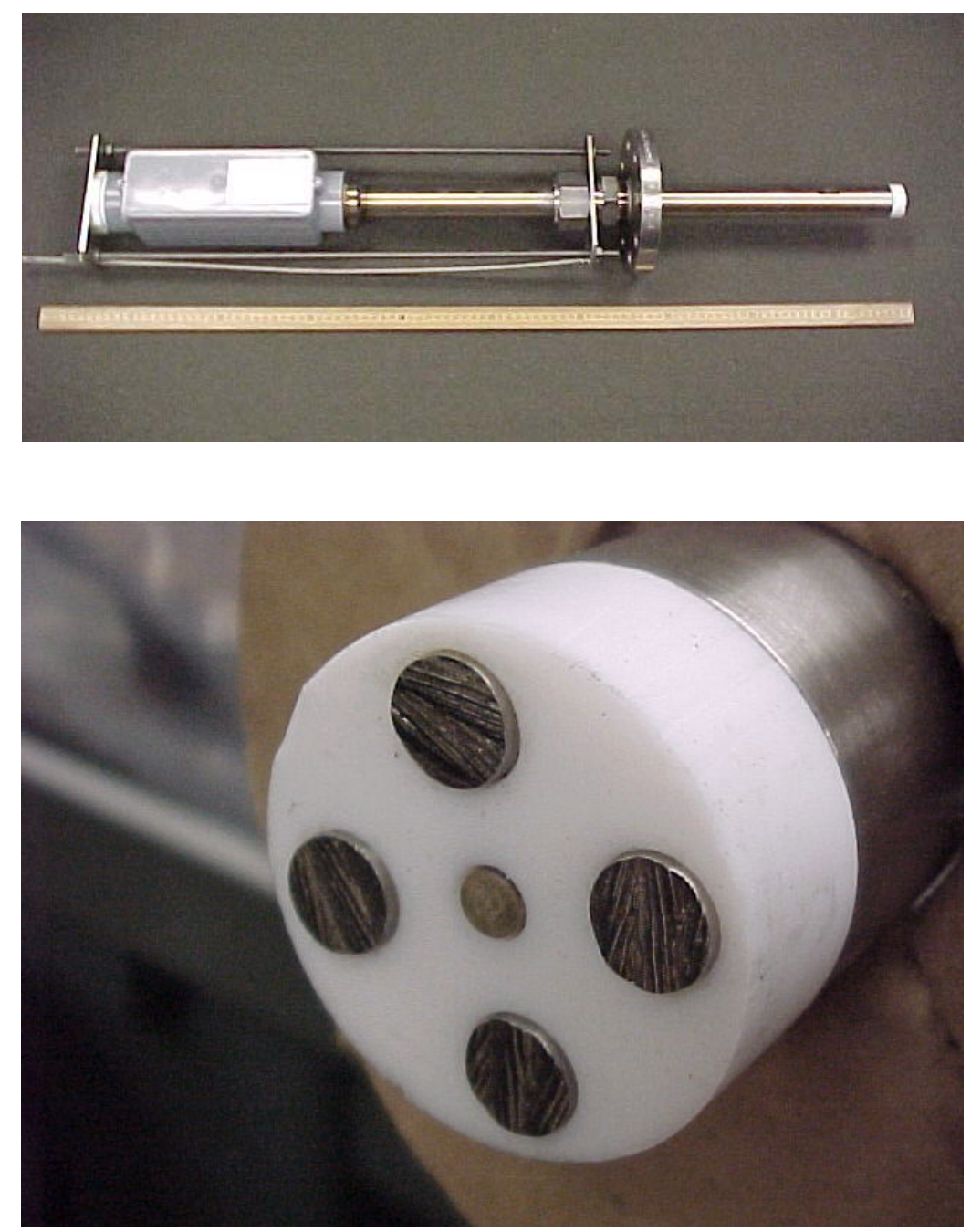

Fig. 10. Adjustable length dual probe used in the Spring Grove digester experiment.

The original design for the EN probes included a sheathed thermocouple placed in the teflon header of the device. However, due to manufacturing difficulties, the thermocouple was instead placed in the stainless steel housing about 3 in. behind the probe face that was exposed flush with the vessel ID to the process. The probe port was slightly larger in diameter than the probe body, so process solution and wood chips no doubt reached this location, but at a temperature somewhat lower than the temperature at the working end of each probe. As a result, the temperatures 
reported for each probe track changes in the vessel but underestimate the actual values by approximately $30-35^{\circ} \mathrm{C}$. [For additional details, see Ref. 2.]

The 309LSi and 312 overlay electrodes were fabricated from actual overlay material. Type 309LSi meeting the same composition specification as that used in the field at Spring Grove was used to deposit 3/16 in. thick overlay on a substrate of mild steel, and an identical technique was used to fabricate a deposit of 312 overlay on substrate steel. Electrode specimens were then machined from the actual overlay material, leaving the as-deposited surface intact so that the electrode surface mimicked the actual overlay surface as well as possible. Table 2 gives the asdeposited composition of the electrode materials determined using the average of nine determinations with an alloy analyzer via x-ray fluorescence. For comparison, the actual asdeposited composition of the field 309LSi overlay in the digester is also given. In particular, note that the Cr content (and thus, the ferrite content) of the laboratory 309LSi overlay is somewhat higher than the field overlay counterpart. Figures 11 and 12 give representative photomicrographs of the mid-thickness region of the overlay materials.

Table 2. Composition of overlay materials (weight \%, average of at least nine determinations). No Si was detected for either overlay with the alloy analyzer. Ferrite number determined by average of 20 determinations with a calibrated magnetic gage.

\begin{tabular}{|c|c|c|c|}
\hline Element & $\begin{array}{l}\text { 309LSi overlay } \\
\text { made in laboratory }\end{array}$ & $\begin{array}{l}\text { 309LSi overlay as- } \\
\text { deposited in vessel }\end{array}$ & $\begin{array}{l}\text { 312 overlay } \\
\text { made in laboratory }\end{array}$ \\
\hline $\mathrm{Fe}$ & 57.9 & 63.6 & 60.3 \\
\hline $\mathrm{Cr}$ & 24.3 & 21.3 & 28.4 \\
\hline $\mathrm{Ni}$ & 12.1 & 9.7 & 7.3 \\
\hline $\mathrm{Mo}$ & 0.19 & 0.16 & 0.16 \\
\hline $\mathrm{Mn}$ & 3.9 & 3.8 & 2.4 \\
\hline $\mathrm{V}$ & 0.17 & 0.23 & 0.11 \\
\hline $\mathrm{Ti}$ & 0.09 & --- & 0.06 \\
\hline $\begin{array}{c}\text { avg. ferrite } \\
\text { number }\end{array}$ & 9 & 2 & 42 \\
\hline
\end{tabular}



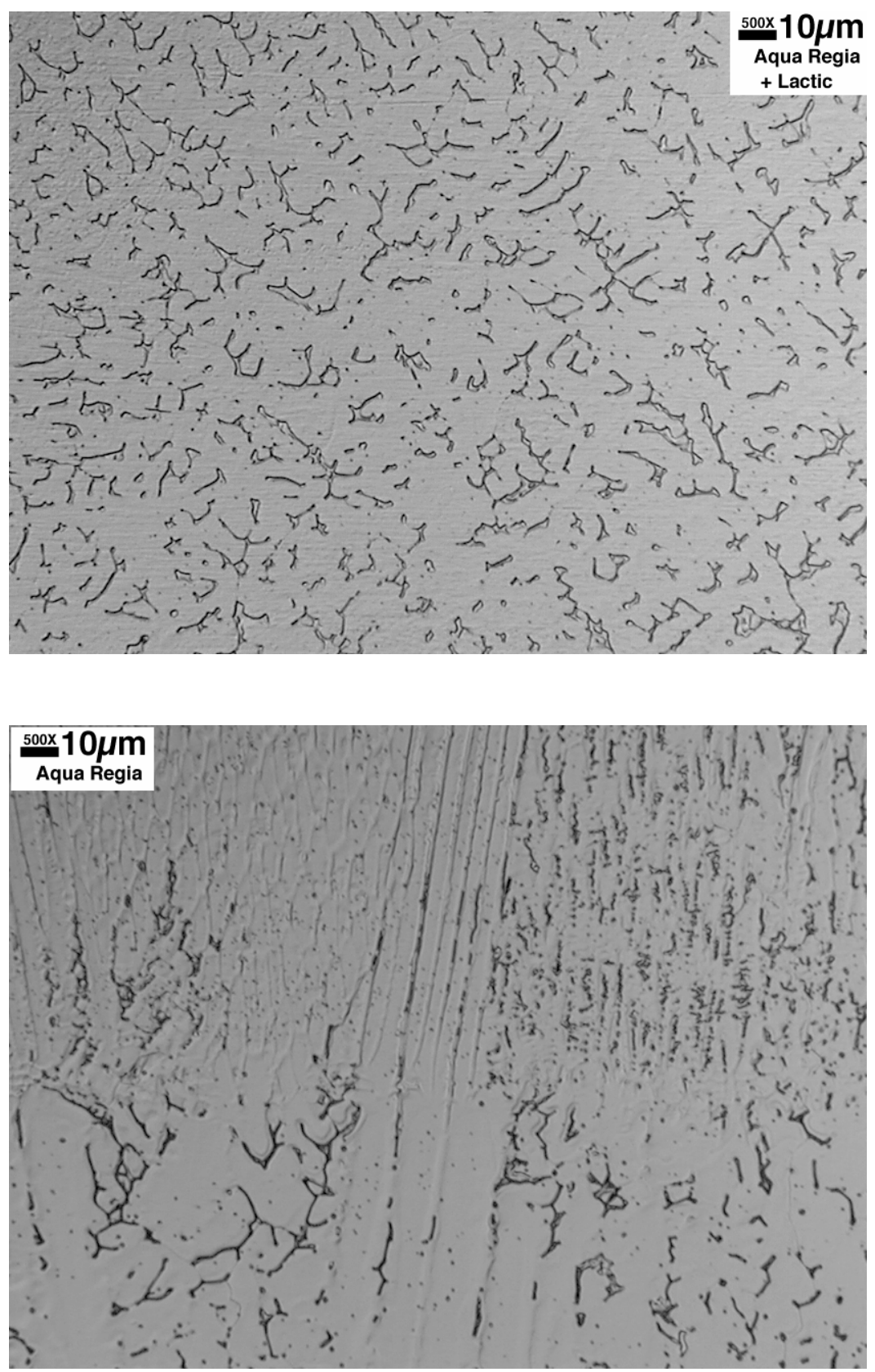

Fig. 11. Photomicrographs of the 309LSi overlays. Top: representative of the laboratory applied overlay. Bottom: representative of the 309LSi field overlay in the digester. 


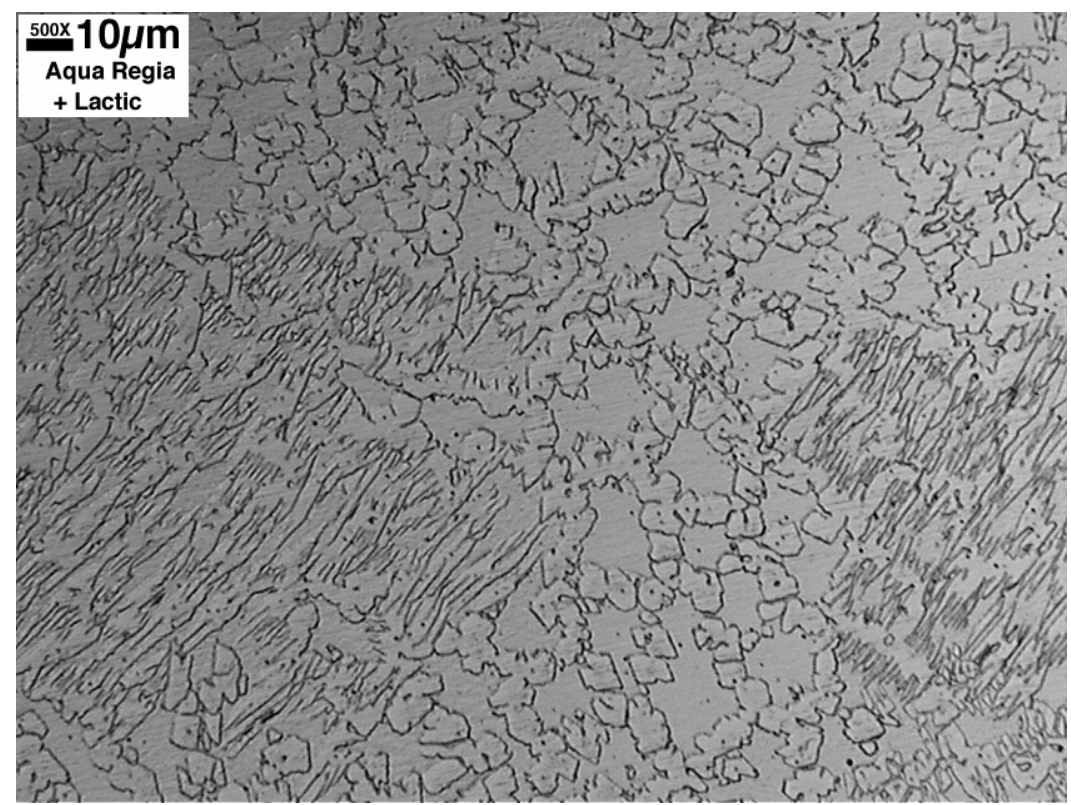

Fig. 12. Photomicrograph of 312 overlay applied in the laboratory.

\subsection{EN DATA GATHERING}

Data collection from the probes commenced in late June 2002 during start-up following the major maintenance outage, and continued with only minor exception until the following major maintenance outage at the beginning of June 2003. The gaps in data gathering occurred during a planned mill shutdown of about two weeks during late December 2002 and early January 2003 as well as a few brief, unplanned periods early in the experiment in which the data gathering and transfer routine experienced a few problems. Gaps in the data stream were kept to a minimum by real-time monitoring of the data and rapid support at the mill.

As previously, current and potential values were collected at intervals of one second for each probe. The system hardware included an 8-channel monitoring $\operatorname{rack}^{(*)}$ with a standard laptop computer using data logging software ${ }^{(\dagger)}$ designed for this type of data collection. Statistical parameters (averages, standard deviations, root-mean-square values) were calculated at five-

(*) CIS400 control unit with CIS502 current-potential logging and zero-resistance ammeter modules from Petroleum Research and Production, Ltd., in England, and ADAM 4018 8-channel temperature loggers, from Advantech, USA.

$(\dagger)$ Amulet software system, from Corrosion and Condition Control, Ltd. in England. 
minute intervals. Raw data was discarded immediately and only the calculated parameters were saved. The analysis discussed here uses only five-minute averages calculated from current and potential noise for each time interval. The probe thermocouples gathered data on 60 -second intervals. In addition, bulk process data (for example, flow rates, temperatures, pump speeds, and liquor composition) from 23 sensors was collected on approximately 15-30 minute intervals over the duration of the experiment. Particularly for liquor chemistry, measurements were sometimes gathered only 2-3 times per 8-h shift, but some process data was recorded continuously (many times per minute).

The probe at ring 12 was not used to monitor EN during the second year of this experiment. Temperature was monitored on a regular basis at this location, but corrosion in the area of ring 12 was very minor in the year \#1 exposure (both mild steel and the stainless overlay electrodes) in confirmation of historical trends, so this probe remained off-line in favor of the others throughout the second year.

\subsection{STEEL COUPONS ON DUMMY PLATES}

Some corrosion patterns observed in digesters suggest that mill scale (or its absence) may be an important factor in localized attack [1,2]. For example, the selective attack described as "oceans-and-islands" pitting, in which regular pits are scattered on an otherwise very smooth steel, often exhibits a mill scale coloration on the smooth portions of the surface. Similarly, pitting of this type tends to agglomerate into roughly geometric shapes (L-shapes, circles, parallel straight lines) suggesting association with the former location of weld bracket - or heat affected zones related to these - or the grinding to prepare a surface for welding. To examine the possibility that mill scale might prevent/delay corrosion on mild steel, a variety of test panels were placed on two new dummy plates that were installed on opposite sides of the digester at the extraction screen level.

Three types of mild steel were included in the test matrix, with a major compositional variable being silicon content, which is known to influence corrosion rates of mild steel in digester liquors [3]. The composition of the mild steels, along with the composition of the 304L panels included for comparison, appears in Table 3. In addition to the as-received condition (120-grit finish, ambient air formed oxide only), panels were given heat treatments to simulate mill scale formation on the surface. About 45 minutes in lab air at $305^{\circ} \mathrm{C}$ formed a bright blue 
film, and about 135 minutes in lab air at $305^{\circ} \mathrm{C}$ formed a light blue/gray film sometimes referred to as gun-metal blue.

Table 3. Composition (wt. \%) of the test panels attached to dummy plates at the extraction level and exposed to the process for one year.

\begin{tabular}{|c|c|c|c|c|}
\hline & A285-C & A516-70 & Corten-A & 304L SS \\
\hline $\mathrm{C}$ & 0.19 & 0.20 & 0.08 & 0.016 \\
\hline $\mathrm{Mn}$ & 0.44 & 1.05 & 0.45 & 1.71 \\
\hline $\mathrm{P}$ & 0.006 & 0.010 & 0.092 & 0.031 \\
\hline S & 0.018 & 0.005 & 0.006 & 0.005 \\
\hline $\mathrm{Si}$ & 0.18 & 0.27 & 0.42 & 0.31 \\
\hline $\mathrm{Cu}$ & 0.29 & 0.25 & 0.27 & 0.34 \\
\hline $\mathrm{Ni}$ & 0.09 & 0.12 & 0.19 & 8.55 \\
\hline $\mathrm{Cr}$ & 0.07 & 0.08 & 0.68 & 18.13 \\
\hline Mo & 0.03 & 0.03 & --- & 0.35 \\
\hline
\end{tabular}

The 5 in. $x 5$ in. $x 0.125$ in. panels (with holes machined near each corner) were cleaned and degreased in acetone and dried with forced air. Panels were weighed to the nearest $0.5 \mathrm{~g}$ and wrapped in inhibitor paper until they were installed on the dummy plates using teflon shoulder washers and stainless steel hardware. Figure 2 shows an array of test panels on a dummy plate; each dummy plate had at least one panel of A285-C steel in each heat treat condition, at least one panel of A516-70 steel in each heat treat condition, one panel of Corten A in each of the asreceived and $135 \mathrm{~min} / 305^{\circ} \mathrm{C}$ conditions, and a mill-annealed 304L panel. Following the yearlong exposure, the panels were removed from the dummy plates, cleaned in inhibited hydrochloric acid (ASTM G-1 procedure C.3.5) to remove corrosion products, rinsed in water, rinsed in acetone, air dried, and reweighed.

\subsection{AUTOCLAVE TESTING}

In addition to the steel coupons exposed at the extraction screen level, a brief series of laboratory autoclave tests was also performed for coupons of the same compositions and heat treatments. The autoclaves used in these experiments were 2205 duplex stainless steel, as were all of the metallic auxiliary components except the 316 stainless steel all-thread and bolting 
hardware. Tests were run undisturbed for 14 days at $165^{\circ} \mathrm{C}$. Three different synthetic liquors, made with reagent grade chemicals and distilled/demineralized water, were examined:

- Extraction liquor $\# 1=20 \mathrm{~g} / 1 \mathrm{NaOH}+20 \mathrm{~g} / 1 \mathrm{Na}_{2} \mathrm{~S}$

- Extraction liquor $\# 2=5 \mathrm{~g} / \mathrm{l} \mathrm{NaOH}+20 \mathrm{~g} / 1 \mathrm{Na}_{2} \mathrm{~S}$

- White liquor $=100 \mathrm{~g} / 1 \mathrm{NaOH}+35 \mathrm{~g} / 1 \mathrm{Na}_{2} \mathrm{~S}$

A high purity nitrogen purge was used to minimize/eliminate oxygen from the head space of the autoclave prior to the commencement of heating and testing. Pressure was essentially constant at $100 \mathrm{psi}$ for the simulated extraction liquor tests. The pressure was initially the same for the white liquor tests, but it tended to drift slowly upward to 140 psi over the two-week test duration. 


\subsection{RESULTS AND DISCUSSION}

\subsection{EN DATA ANALYSIS AND INTERPRETATION}

The EN data collected over the entire year-long experiment were examined in an attempt to find specific events or periods of time in which probe activity - and therefore potentially digester shell corrosion - changes from the nominal level. Ultimately, the goal of the effort is to correlate changes in corrosion activity with specific operational characteristics of the digester and identify conditions contributing significantly to accelerated corrosion.

For the present experiment, the data was evaluated for such changes/events in two ways. Primarily, the electrode potential and current activity were examined graphically as a function of time (generally 6-10 week segments) to look for significant/sustained changes in electrode potential or current activity. Time periods in which these changes were detected were compared to graphical representations of each of the operational variables (temperatures, flow rates, liquor composition, etc.) that are tracked and recorded by the mill. In this fashion, an attempt was made to correlate periods of relatively high electrochemical activity - as indicated by changes in current and potential noise - with specific operational variables. In addition to using graphical trends to identify periods of corrosion activity corresponding to changes in operational parameters, the data was also evaluated via correlation coefficient analysis for all pairs of process variables with several delay times considered.

The value of current noise generated by the EN probes is a complex - and not necessarily straightforward - number. The current value in any sampling interval is the net current detected flowing through the zero-resistance ammeter (ZRA) connecting the nominally identical working electrodes. Depending on which electrode is momentarily active compared to the other electrode, current can flow from electrode A toward electrode B as well as in the opposite direction. As a result, EN current can be either "positive" or "negative" with - for the present discussion - no particular significance attached to the sign of the current flow.

Several factors influence the magnitude of the current detected by the ZRA. For example, in any corrosion reaction, there are necessarily areas of both anodic and cathodic activity. If an individual working electrode is sufficiently large, at least some of the corrosion current will be consumed on the surface of the electrode (discreet anodes and cathodes on a single electrode surface) and thus a portion of the corrosion current does not pass through the ZRA and is not 
detected by the system. In principle, electrode size is an important design feature of an EN system, with some balance required between the advantages of relatively large electrodes and very small ones. Larger electrodes come closer to representing real surfaces (inclusions, surface roughness, surface deposits/films, composition gradients, etc.) than do small electrodes, but as the surface area of the electrodes increases, the likelihood that the corrosion current self- terminates (anodes and cathodes on the same surface) also increases. Further, the expected signal-to-noise ratio may influence electrode size requirements; for example, a strongly passive system might require a very large electrode surface to generate the required signal. Finally, for pulping liquor corrosion, another electrode size/condition factor might be how readily various reactions which do not directly contribute to the corrosion reaction take place. For example, reduction/oxidation reactions (termed redox, hereafter) involving sulfur species may contribute some electrons detected by the ZRA without directly participating in electrode corrosion. As long as the electrodes are reasonably similar to the structure they are to simulate (similar roughness, composition, film catalytic effects), the amount of indirect contribution should be essentially constant and thus in the "white noise" of current activity (meaning equal probability of happening on either electrode and thus a factor that largely "cancels" from the current measurement). If the electrode surfaces were to become biased (polarized) relative to each other, current from corrosion or redox reactions will preferentially flow in one direction rendering the quantity or magnitude of current noise less valuable as a semi-quantitative tool.

Ultimately, there is no known relationship to determine a precise electrode size that is most appropriate for a given system. The literature is replete with examples of successful EN applications with electrode diameters between 0.5 and $5 \mathrm{~cm}^{2}$ and there is no reason to expect that such a size is inappropriate for the present experiments. The electrode size chosen for the EN probes deployed at Spring Grove represents the largest collection of working surfaces (four working electrodes and a reference electrode) that could be fit onto a $1.5 \mathrm{in}$. (38-mm) diameter probe that mated into a flanged port cut into the digester.

In this research, the EN current is sometimes analyzed/plotted as the absolute value of the current detected by the ZRA. Nominally, the EN current signal oscillates in a largely random fashion about the value of zero (net current flows back and forth between nominally identical electrode surfaces). However, as the magnitude (not the sign) of current activity is of prime importance to identify operational parameters causing increases in general corrosion activity, the absolute value of current is often plotted for ease of presentation. In particular, when the EN 
signals suggest a uniform corrosion mechanism, the relative sign of the current has no significance. In contrast, in the case of pitting or stress-corrosion cracking, the sign of the current (indicating a particular electrode) can be part of the data interpretation.

The sums of absolute current over a specific period of time can be related - albeit in a somewhat crude fashion - to the corrosion rate experienced by the probes (and, in principle, the nearby digester wall). In order to develop such a relationship, certain simplifying assumptions are required. First, the total current must be consumed uniformly over the entire exposed surface area of each pair of electrodes (in this case, $1.24 \mathrm{~cm}^{2}$ of 309LSi overlay and $1.24 \mathrm{~cm}^{2}$ of 312 overlay for each probe). Essentially, this assumes that no localized corrosion - such as pitting or stress-corrosion cracking - is occurring (confirmed with post-test analysis of probes) and therefore net current flow between electrodes is related directly to thinning via general corrosion. In order to relate the current to mass loss and uniform thinning, it was assumed that the iron oxidizes from $\mathrm{Fe}$ to the $\mathrm{Fe}^{+2}$ state in all cases. [For stainless steel corrosion, $\mathrm{Cr}$ oxidation is also involved; the atomic mass difference between $\mathrm{Fe}$ and $\mathrm{Cr}$ is $\sim$ negligible, but trivalent oxidation to $\mathrm{Cr}+3$ involves $50 \%$ more electrons than oxidation to $\mathrm{Fe}+2$, and this must be considered in any quantitative estimate. However, in the present case, only very crude generalizations are required to interpret the data.] Using these assumptions, the total current flow (summed in absolute value) over any period can be related to corrosion rate via Faraday's Law (see Appendix A in Ref. 1 or 2). Since not all the current for any reaction passes through the ZRA, and some amount of the current that does pass through the ZRA is related to redox reactions, the value so calculated essentially represents only a fraction, or a qualitative estimate, of the actual corrosion rate experienced by the probe materials.

\subsection{POST-TEST EVALUATION OF ELECTRODE MATERIALS}

Following the year-long experiment, the stainless steel overlay electrode materials appeared to be in essentially pristine condition. Visually, the stainless electrodes showed no sign of corrosion or erosion and retained the surface relief detail and slight heat tint resulting from the original overlay operation to fabricate the electrodes. No dimensional changes (diameter or height) were detected for any of the stainless steel electrodes as a result of the year \#2 exposure.

Metallographic examination revealed the 309LSi electrodes to be smooth and unchanged from the unexposed condition. Independent of position in the digester, all of the 312 electrodes 
suffered similar shallow attack as shown in Fig. 13, which shows the post-test surface of two of the 312 electrodes. The attack is very shallow - on the order of $5 \mu \mathrm{m}$ or less - and limited study of etched microstructures suggests that the attack initiates at interdendritic regions in the cast structure, with perhaps some tendency to attack austenite preferentially. The appearance of the unexposed 312 electrodes (Fig. 14) included a very thin (1-2 $\mu \mathrm{m})$ surface oxide, and perhaps dissolution of the oxide is a part of the apparent surface roughening observed for the 312 electrodes. In any case, the extent of "attack" appears inconsequential for practical concerns.
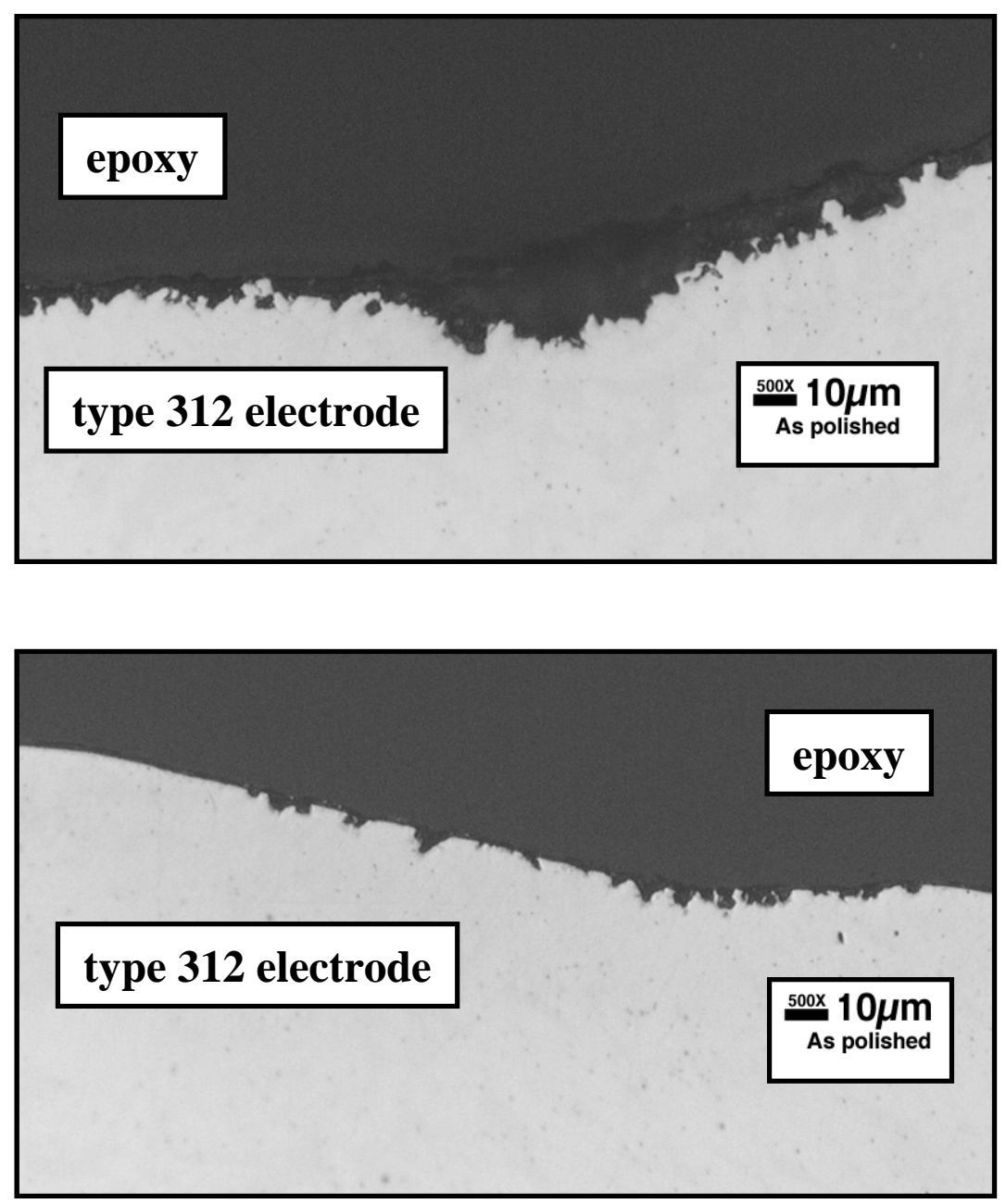

Fig. 13. Post-test cross-sections of type 312 stainless steel electrodes after exposure for one year. Top: from the ring 12 probe. Bottom: from the ring 3 probe. 


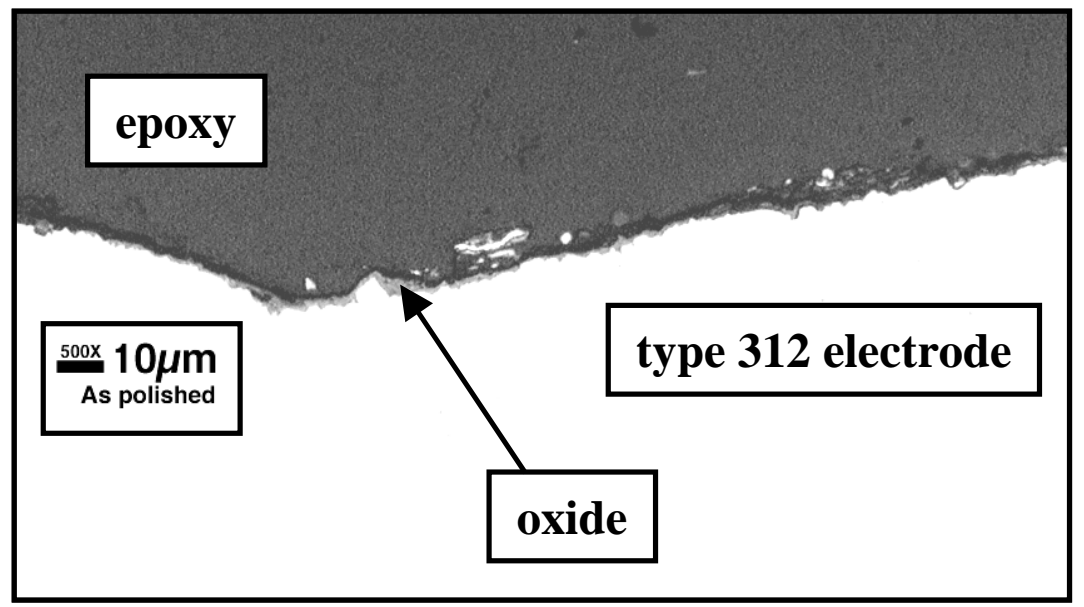

Fig. 14. Unexposed cross-section of type 312 stainless steel electrode. This specimen was prepared form material remaining following fabrication of the test probes.

Metallographic examination of the silver electrodes was also performed, and the extent of dissolution/attack of the silver varied substantially with position in the digester. Figures 15-18 are representative of the range of post-test conditions observed for the silver electrodes. In Figure 15, the cross-section of silver electrode shown was exposed in the probe at ring 12, and the working end (exposed to the process) is at the right. A relatively adherent layer of dark gray $\mathrm{Ag}_{2} \mathrm{~S}$ can be seen on the sides (relatively thick) and on the working face. At the time the silver electrode was removed from the probe header after the exposure, the amount of $\mathrm{Ag}_{2} \mathrm{~S}$ on the working face was very similar to that observed on the sides of the electrode in Fig. 15; however, in an attempt to gage its relative adherence, some amount of grinding - while recording progressive thickness measurements - was attempted on this surface. The "notch" in the silver, roughly in the middle of the photograph, is the location of the elastomeric o-ring that was squeezed between the silver and the teflon probe header to help prevent in-leakage at the interface. The discontinuity in the center of the Ag rod (far left center of Fig. 15) is the end of the threaded connection to the electrometer. The silver electrode from the probe at ring 12 , as well as that from the flash tank probe, exhibit only very minor dimension changes (loss of 25-30 mils of Ag on the radius and length) compared to the original dimensions prior to installation. 


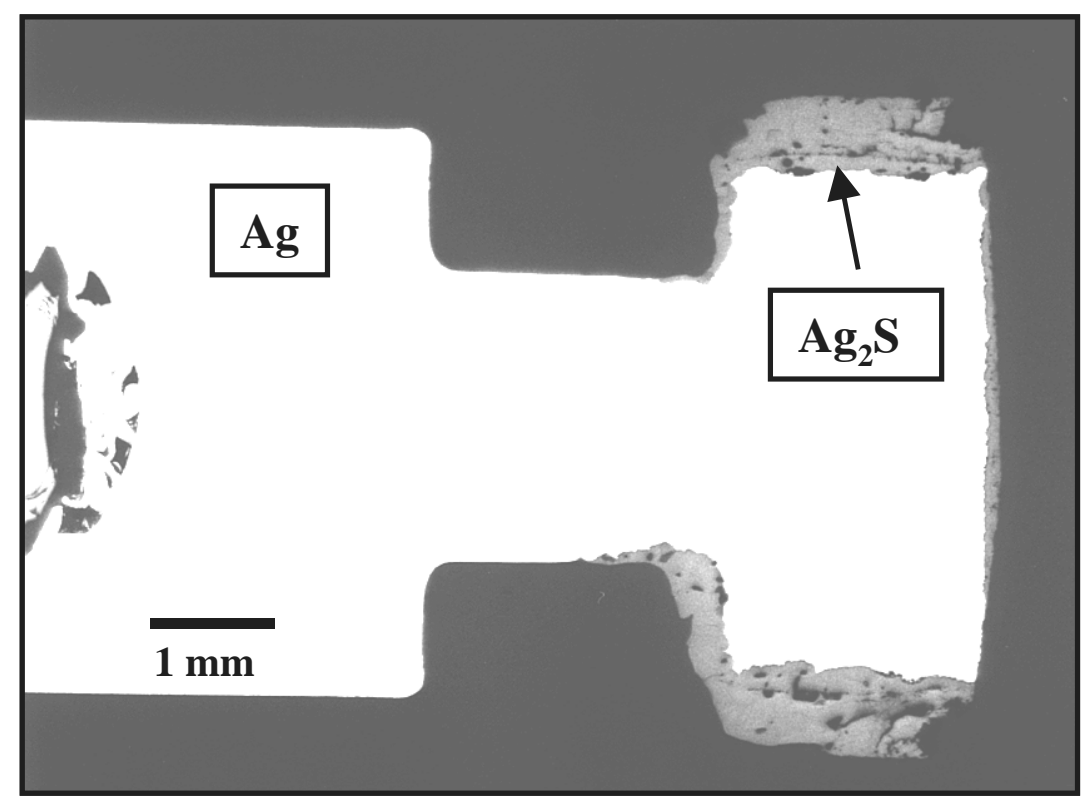

Fig. 15. As-polished cross-section of the approximate mid-plane of the Ag electrode from the ring 12 probe.

Figure 16 shows the post-test silver electrode from the ring 3 probe in cross-section. The extent of interaction with the process is more severe than indicated in Fig. 15, and approximately one third of the original working length and radius have been converted to $\mathrm{Ag}_{2} \mathrm{~S}$. Yet more extreme is the silver from the ring $6 \mathrm{~N}$ probe (Fig. 17), which was almost completely consumed during the exposure period. Finally, Fig. 18 shows the ring 6S probe silver, which was essentially completely consumed. [There was actually a sliver of metallic silver remaining after the exposure, but polishing to the center of the cross-section went slightly too deep and the remaining metallic silver was lost.]

In theory, the silver rod can function as a pseudo-reference as long as metallic silver remains in intimate contact with $\mathrm{Ag}_{2} \mathrm{~S}$ (porous) and the environment. While there is some question about the precise utility of silver for a reference in the digester environment [4], it appears that the $\mathrm{Ag} / \mathrm{Ag}_{2} \mathrm{~S}$ junction was maintained throughout the exposure for each rod of silver, and as a result the silver rods probably functioned as an acceptable pseudo-reference throughout the year-long exposure. (An approximate conversion [5] is $\mathrm{mV}\left(\mathrm{Ag} / \mathrm{Ag}_{2} \mathrm{~S}\right)=\mathrm{mV}(\mathrm{SCE})+880$.) 


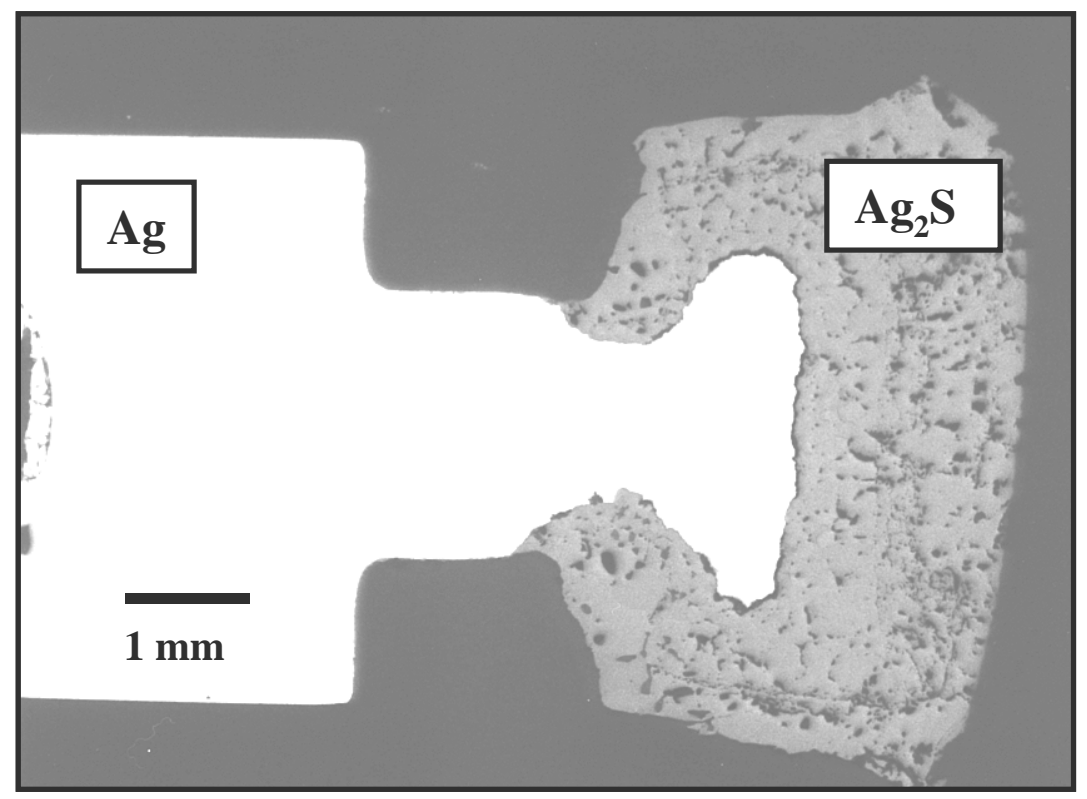

Fig. 16. As-polished cross-section of the approximate mid-plane of the Ag electrode from the ring 3 probe.

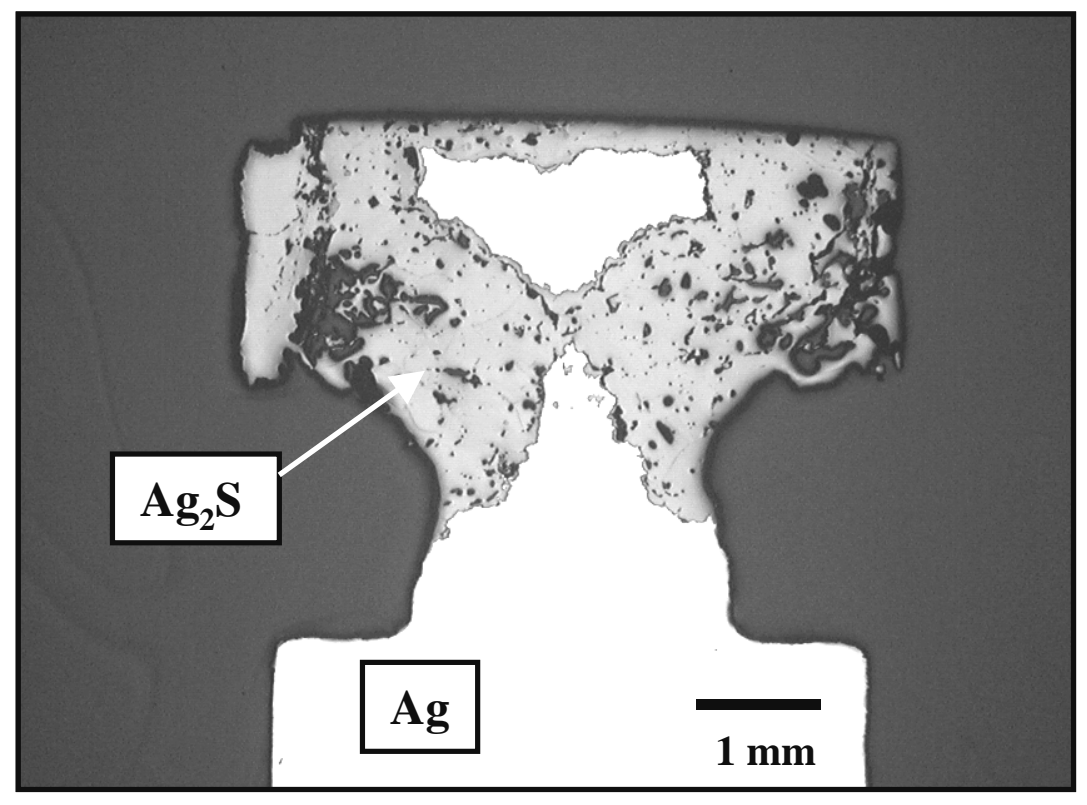

Fig. 17. As-polished cross-section of the approximate mid-plane of the Ag electrode from the ring $6 \mathrm{~N}$ probe. 


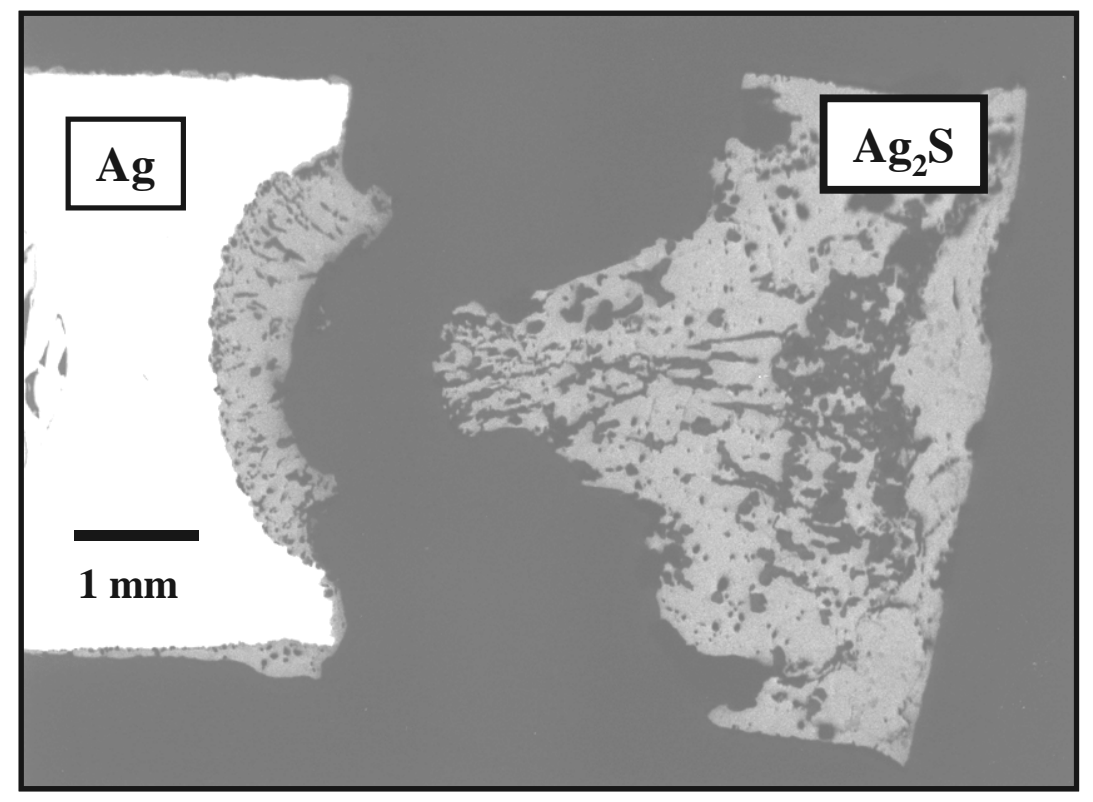

Fig. 18. As-polished cross-section of the approximate mid-plane of the Ag electrode from the ring $6 \mathrm{~S}$ probe.

The $\mathrm{Ag}_{2} \mathrm{~S}$ from several electrodes was examined by energy-dispersive $\mathrm{x}$-ray analysis in the scanning electron microscope, and it was determined that essentially all of the corrosion product was $\mathrm{Ag}$ and $\mathrm{S}$ in the atom ratio 2:1. Small particles likely to be manganese sulfides were found throughout most of the $\mathrm{Ag}_{2} \mathrm{~S}$ matrix, as well as small particles of undissolved silver. Traces of $\mathrm{Na}$ and $\mathrm{Ni}$ (presumably from the process) and $\mathrm{Si}$ (from the specimen polishing treatment) were also detected.

The silver reference electrodes from the year \#1 experiment at Spring Grove yielded a similar range of interaction of the silver with the process as a function of position. Curiously, however, the interaction was much less for ring $6 \mathrm{~S}$ in year \#1 compared to ring $6 \mathrm{~N}$ in year \#1 or ring $6 \mathrm{~S}$ in year \#2, suggesting a potentially significant chemistry change that is undetected by the standard mill measurements. 


\subsection{GENERAL ECN CHARACTERISTICS}

Table 4 compares the absolute value current sums for each electrode pair over the entire year exposure (extrapolated to a full year to account for brief periods - generally $2-5$ days at a time and a three-week stretch in April - in which either the data collection or archiving scheme temporarily failed). Also shown in Table 4 are the data from the 309LSi electrodes from year \#1 at Spring Grove, a few trends deserve comment.

Table 4. Comparison of corrosion rates (mils/y) calculated from the sum of the absolute values of current averages on five-minute intervals for the 309LSi and 312 stainless steel overlay probe materials. List includes data for the 309LSi from year \#1 at Spring Grove for comparison with the present data.

\begin{tabular}{|l|c|c|c|}
\hline Probe Location & $\begin{array}{c}\text { Type 309LSi } \\
\text { year 1 }\end{array}$ & $\begin{array}{c}\text { Type 309LSi } \\
\text { year 2 }\end{array}$ & $\begin{array}{c}\text { Type 312 } \\
\text { year 2 }\end{array}$ \\
\hline Ring 6 - north & 1 & 0.1 & 0.8 \\
\hline Ring 6 - south & 10 & 0.9 & 1.1 \\
\hline Ring 3 & 9 & $\sim 0$ & $\sim 0$ \\
\hline Flash Tank & 9 & 6.5 & 10.6 \\
\hline
\end{tabular}

Following the year \#1 and \#2 exposures, each stainless steel electrode was - within measurement precision - the same height and diameter as the pre-exposure dimensions. This result is consistent with the previous inspections of the vessel indicating that the 309LSi overlay appeared to be in pristine condition (no apparent thinning, original weld ripples and heat tint remain) following two years of service. Therefore, any positive current sums on the stainless steel electrodes would appear to be related to redox reactions that do not occur with equal intensity/frequency on each electrode in a pair. It is not clear what sources of bias might be present at the electrode surfaces, but as a general rule, the current noise for each electrode pair remained roughly "centered" on zero throughout the duration of the exposure, indicating no substantial/extended polarization.

Table 4 indicates that for the 309LSi electrodes, there is more of the apparent redox activity at the ring $6 \mathrm{~S}$ position than at the equivalent $6 \mathrm{~N}$ probe position on the opposite side of the digester by a factor of about 10 in both years ( $10 \mathrm{v} .1$ in year 1 and $\sim 1$ v. 0.1 in year 2$)$. It is not possible to determine what chemical(s) are involved in the redox reaction(s) that are indicated here, but it is potentially significant that the corrosion rate of mild steel (both the digester steel 
prior to the overlay campaign and the electrodes at this position in year \#1) was substantially higher at the $6 \mathrm{~N}$ position compared to the $6 \mathrm{~S}$ position. This observation suggests a strong role of localized chemistry influenced by non-uniform flow, and in this particular case the chemicals/conditions present to cause increased redox activity at the ring $6 \mathrm{~S}$ probe apparently inhibit corrosion relative to the ring $6 \mathrm{~N}$ probe environment.

Although the calculation does not particularly justify two significant figures in the result, note that the redox activity was slightly higher for type 312 compared to type 309LSi stainless steel overlay in all three locations with a non-zero sum. It is possible that this result suggests that there is a characteristic of the passive film on type 312 (significantly higher $\mathrm{Cr}$ content and much more ferrite phase than 309LSi) that renders it somewhat more "supportive" of a redox reaction. In addition, it was an observation in the $\mathrm{EN}$ data that brief periods of current noise bias were present for all the type 312 electrodes, but very rarely for any of the 309LSi electrodes. In any case, based on the similar appearance of the 309LSi and 312 electrodes following the exposure, there seems to be no particular significance to increased redox activity on the type 312 electrodes, but this will be discussed further in a subsequent paragraph.

The redox activity on the probes in the flash tank was relatively high in both years and for both stainless overlay materials. In the flash tank, the digester pressure is let down on black liquor, and it is quite likely that the resulting violent flashing of the liquor generates very unusual chemical environments, including the possibility of separating small amounts of organic acids from the strongly basic liquor chemistry. However, no specific redox reactions can be identified from the EN data.

\subsection{REPRESENTATIVE EN DATA}

Figure 19 shows a histogram for the EN potentials for each probe during the first three months of the year \#2 exposure. The data indicate the similarity in potentials between type 309LSi and type 312 at each probe position, with a nominal range of potentials only $15-20 \mathrm{mV}$ wide for each probe/material except the flash tank. The median potential values (the "peak" in each histogram) for the stainless alloys in the ring $6 \mathrm{~N}$, ring $6 \mathrm{~S}$, and ring 3 probes shifted only slightly over the year \#2 exposure, tending to drift upward by 5-10 $\mathrm{mV}$ each over the 12-month experiment. No systematic change in current activity was associated with the slight drift of potential with time for these three probe positions. 


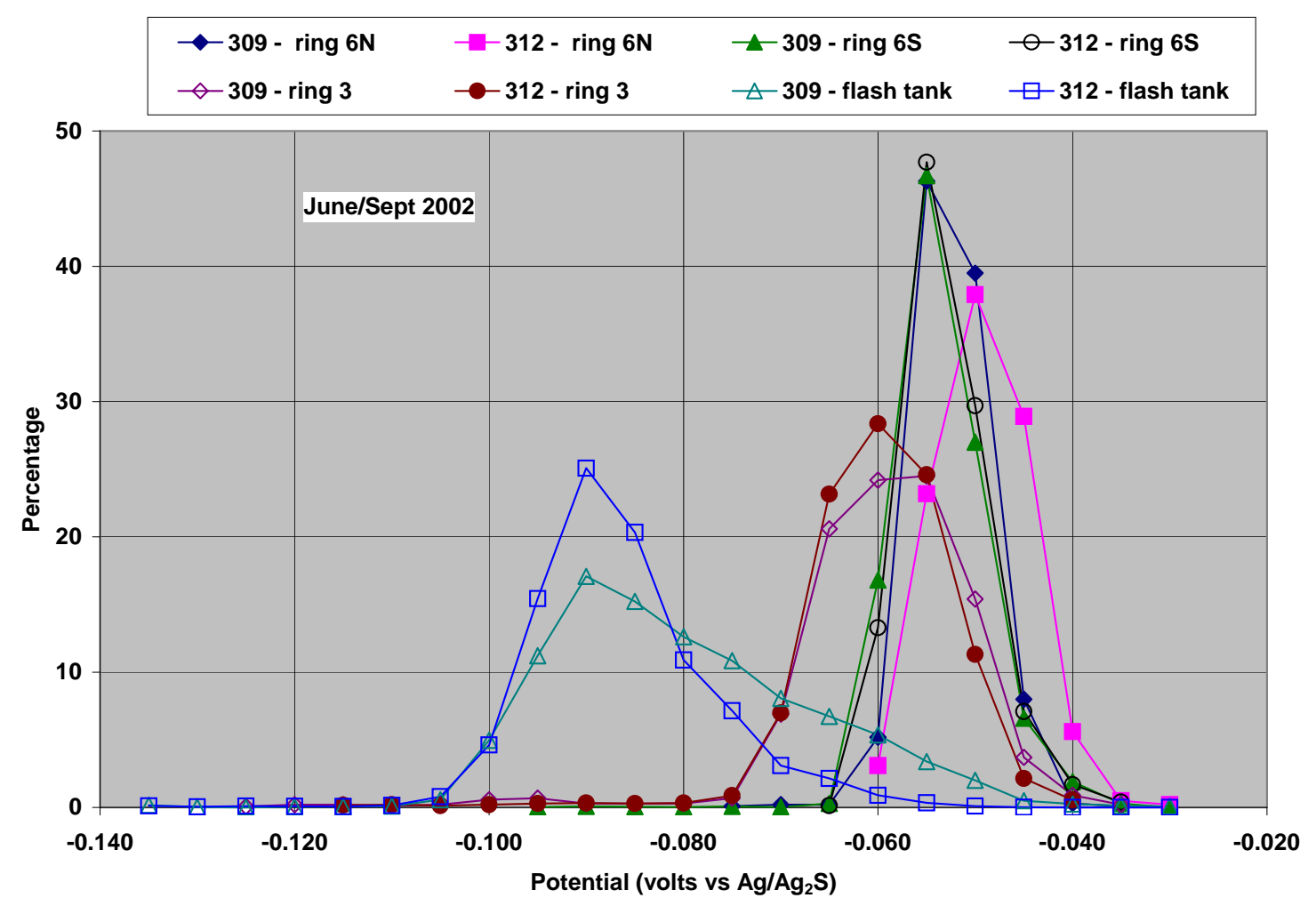

Fig. 19. Histogram representing the EN potential data for each probe position and electrode material for the period June-September 2002.

Figure 20 shows an EN potential histogram for the 309LSi probe materials during an early portion of the year \#1 exposure. Comparison with potentials of the type 309LSi electrodes from the year \#2 exposure indicates a significant difference for the nominal value for the ring $6 \mathrm{~N}$ probe (value of $-30 \mathrm{mV}$ early in year \#1) and particularly the ring $6 \mathrm{~S}$ probe (value of $+45 \mathrm{mV}$ early in year \#1) compared to early in year \#2. The potential of the 309LSi at the ring 6S probe in year \#1 drifted slowly toward the value exhibited by the 309LSi at this position in year \#2, and this data suggests that the digester chemistry at the ring 6 position may have changed substantially from early in year \#1 to year \#2. However, no significant change in the chemistry data routinely collected by the mill was recorded. 


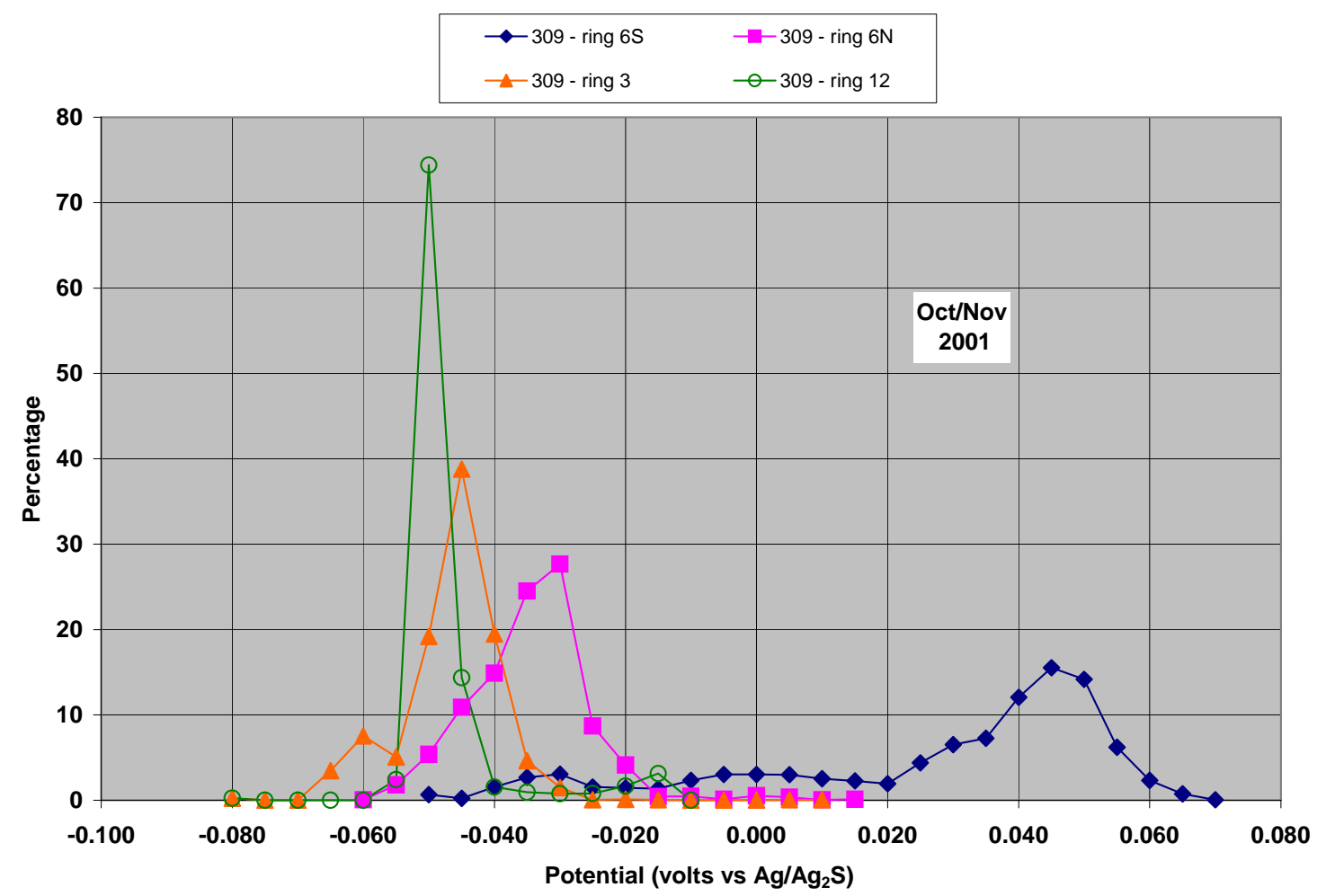

Fig. 20. Histogram representing the EN potential data for 309LSi electrodes early in the year \#1 experiment.

\subsection{DATA FOR RING 6S}

Representative potential data as a function of time specific to the 309LSi stainless steel electrode in the ring $6 \mathrm{~S}$ probe for year \#2 is shown in Fig. 21. Consistent with the histogram in Fig. 19, the potential of the 309LSi electrode varies only about $\pm 10 \mathrm{mV}$ or so around the median value of $-55 \mathrm{mV}$ for weeks at a time, and the potential of the 312 electrode is essentially indistinguishable from that of the 309LSi. During the entire year of exposure, there were eight relatively large potential excursions ( $>25 \mathrm{mV}$ out of the nominal range of -45 to $-65 \mathrm{mV}$ ), two of which are represented in Fig. 21. All eight of the large potential excursions can generally be described as very brief (six hours or less is typical) and associated with a sudden temperature decrease of more than about $20^{\circ} \mathrm{C}$ at the probe $6 \mathrm{~S}$ location. 


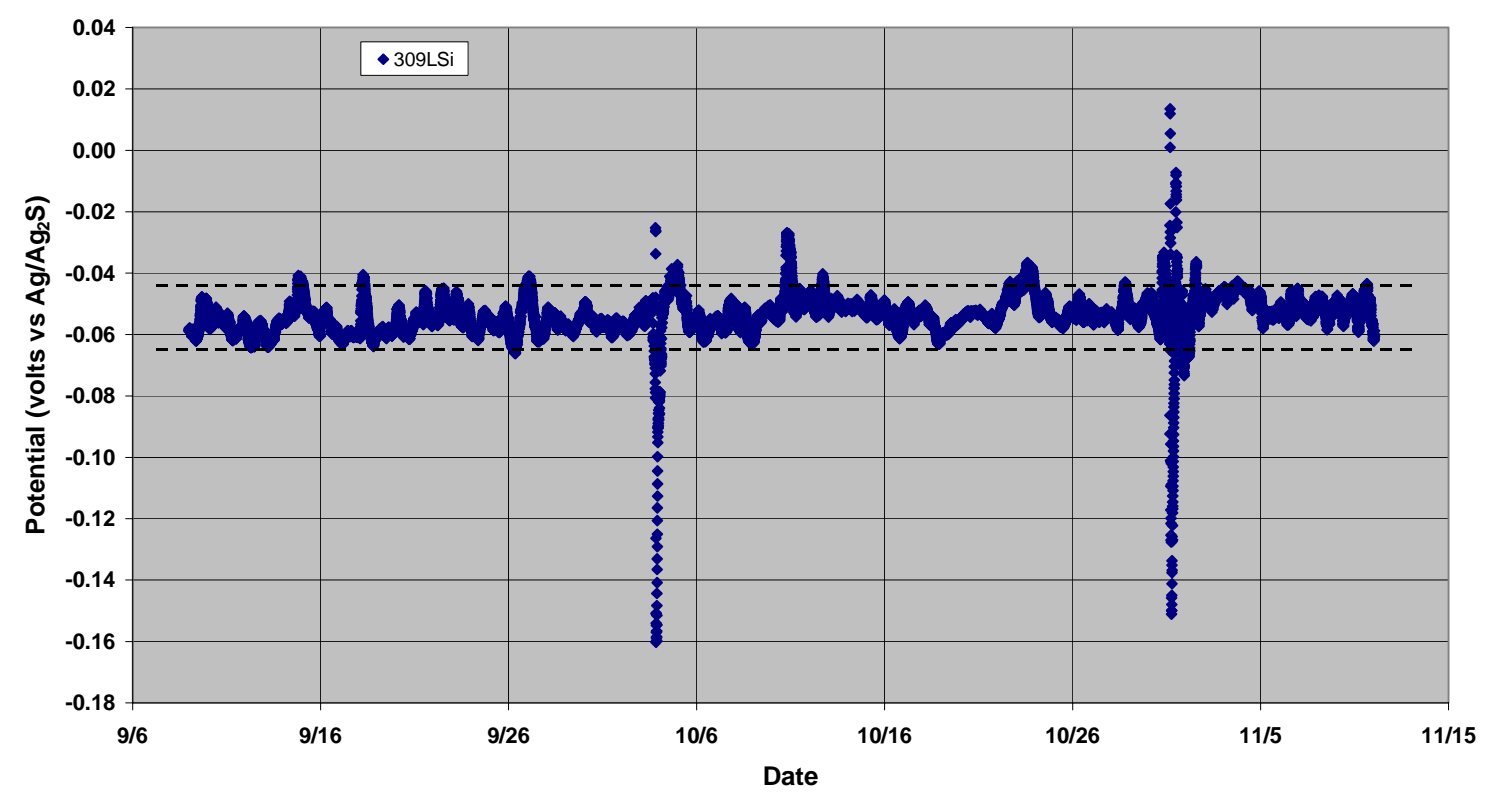

Fig. 21. Representative EN potential data for the 309LSi electrodes in the ring 6S probe. The dashed lines represent the $\pm 10 \mathrm{mV}$ boundary around the median potential of $-55 \mathrm{mV}$.

Figure 22 provides more detail of the potential excursion on/about October 4. Note that there is a modest temperature decrease of about $30^{\circ} \mathrm{C}$ (no associated potential variation outside normal scatter) just prior to a larger temperature drop that coincides with the potential excursion. Further, note that the potential recovery is essentially complete prior to the return of the temperature to the normal range.

The temperature decrease shown in Fig. 22 is related to a process interruption which is reflected in most of the major process parameters that are routinely tracked at the mill. For example, Fig. 23 plots the white liquor flow (as representative of the continuity of the process) along with the ring $6 \mathrm{~S}$ probe temperature as a function of time. [The actual process data for white liquor flow indicated a few small negative numbers on October 3; these were assumed to be an artifact of a very low flow rate measured by a device calibrated to much higher values of flow. 


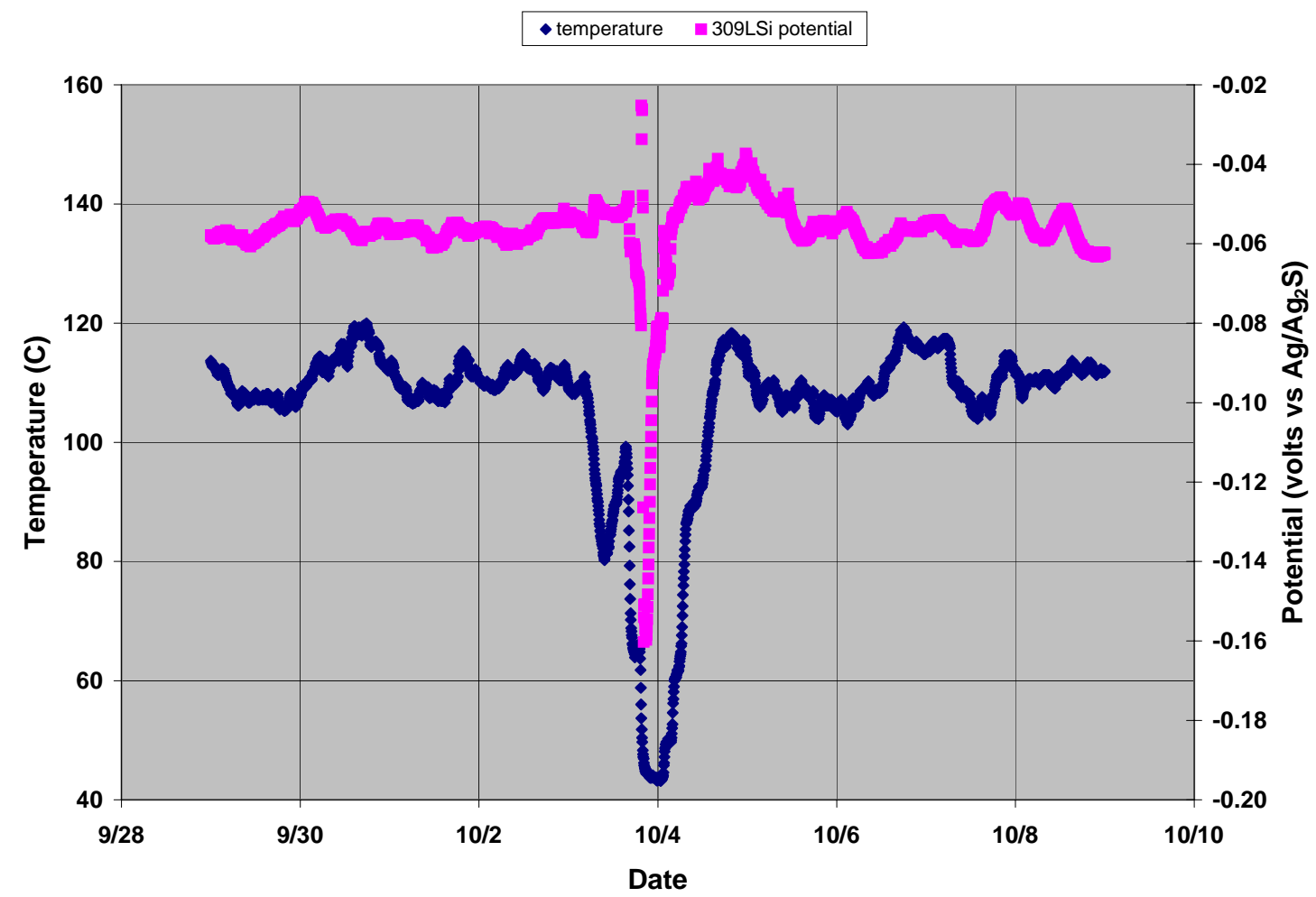

Fig. 22. EN potential data along with probe temperature for the ring 6S 309LSi electrode surrounding the October 4 event in the digester.

Here, all rates less than 1 gpm were arbitrarily set to $1 \mathrm{gpm}$ for ease of graphing.] It is clear that the disruption in the process (white liquor flow decrease) and the temperature are closely related, but note in particular that the temperature decrease that begins coincident with the halt in white liquor flow is not continuous - there appears to be a brief recovery in the temperature before a plunge toward room temperature. It is not clear why the digester temperature would behave in this fashion (no apparent clues in the other process data), but it is possible that the slightly occluded position of the probe thermocouple (recessed slightly in the probe port rather than positioned on the probe face) is involved. In any case, the resumption of white liquor flow is followed by a return to the nominal process temperature at this location. Again, a time lag between the resumption of white liquor flow and the probe temperature may be related to the thermocouple position in the probe port, but this document will also cite examples where the probe temperature tracks a process upset simultaneously with the event. 


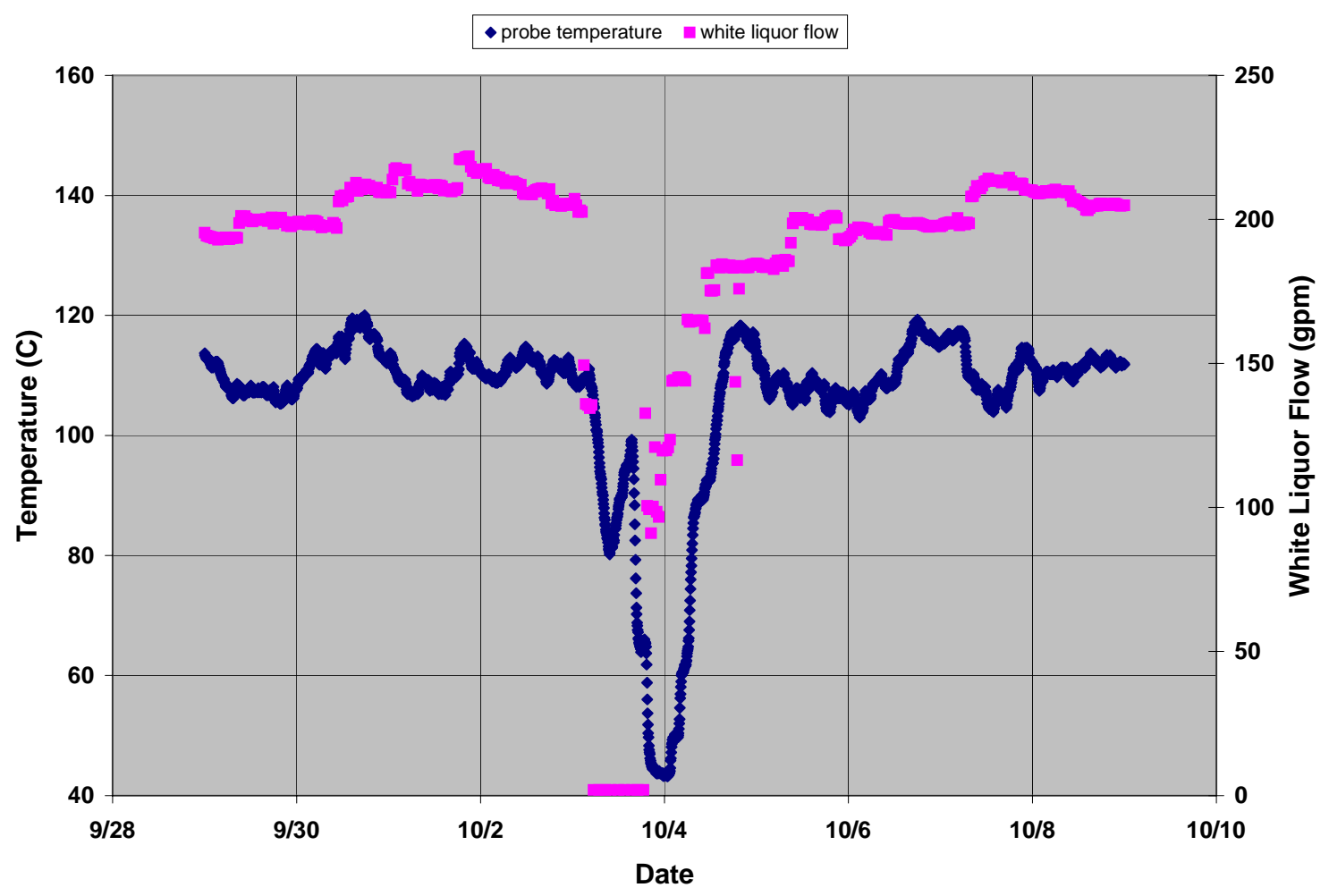

Fig. 23. Relationship of ring $6 \mathrm{~S}$ probe temperature and the white liquor flow to the digester surrounding the October 4 event in the operation.

Further detail is shown in Fig. 24, which includes the process white liquor flow plotted along with the corresponding potential for the October 4 event. This plot reveals that the potential change (and presumably the associated liquor chemistry change) occurs after the white liquor flow has been stopped for a few hours, and in fact the potential drop and subsequent recovery each seem to happen during the resumption of white liquor flow. That the potential change occurs after the decrease in white liquor flow may indicate a time-dependent chemistry change (e.g., consumption of a species; leaching a species) resulting from overcooking chips in black liquor. 


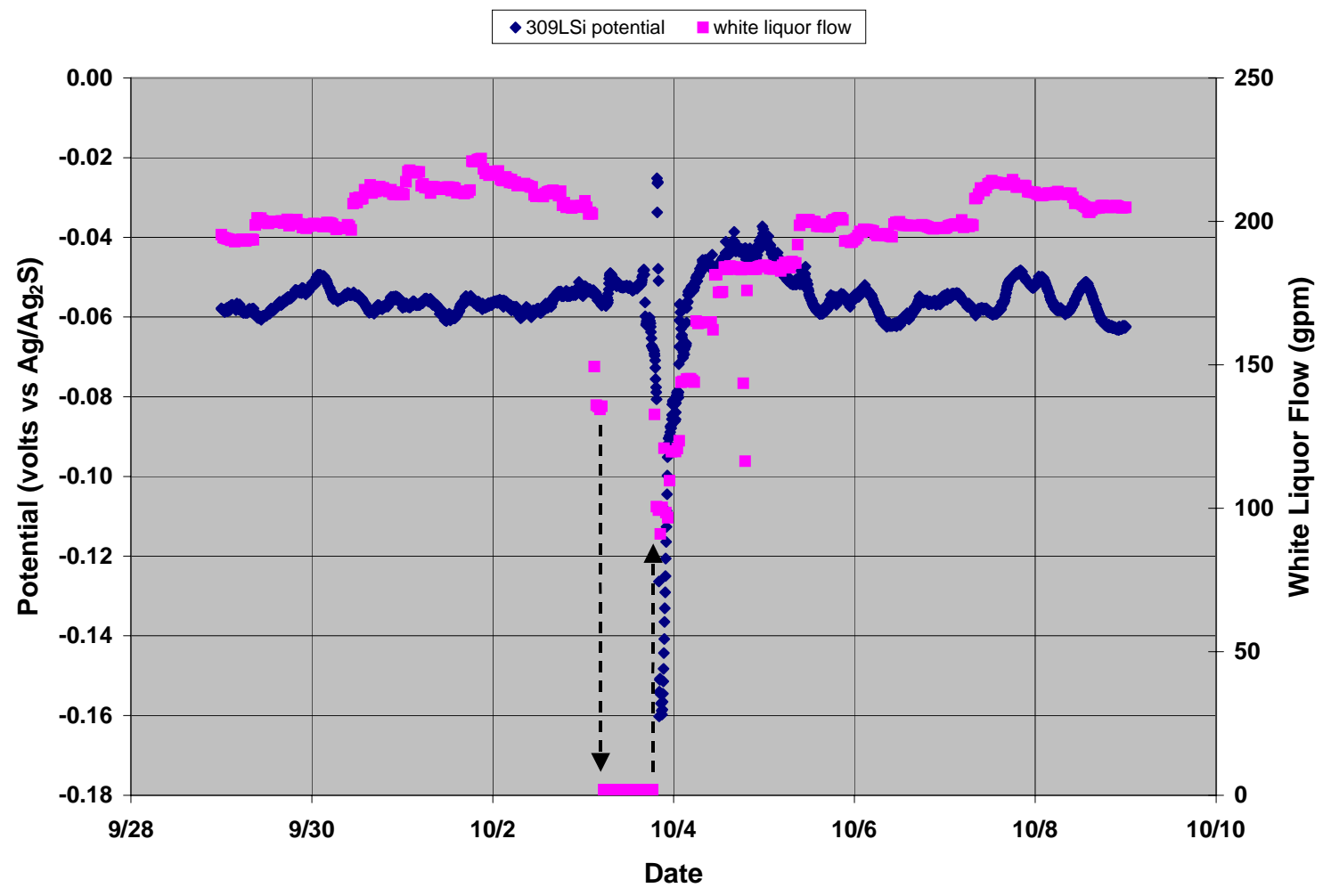

Fig. 24. White liquor flow plotted with 309LSi potential data for the ring 6S probe surrounding the October 4 event in the digester. The dashed vertical lines represent the boundaries of the $\sim$ zero white liquor flow period.

Figure 25 shows the October 4 potential excursion along with the corresponding electrochemical noise current for the 309LSi probe. In this instance, as in five of the eight overall large potential excursions at Ring 6S during the year, there is only a very minor/brief current change (inconsequential to current sums) associated with the potential excursion.

This general behavior observed at Ring 6S is consistent with previous results at Spring Grove in that process disruptions were closely associated with large/sudden changes in the temperature and electrochemical noise patterns. However, the stainless steel electrode materials appear resistant to corrosion, independent of the upsets and fluctuations where the carbon steel electrodes suffered at least periodically high corrosion rates [2]. No significant liquor chemistry changes 


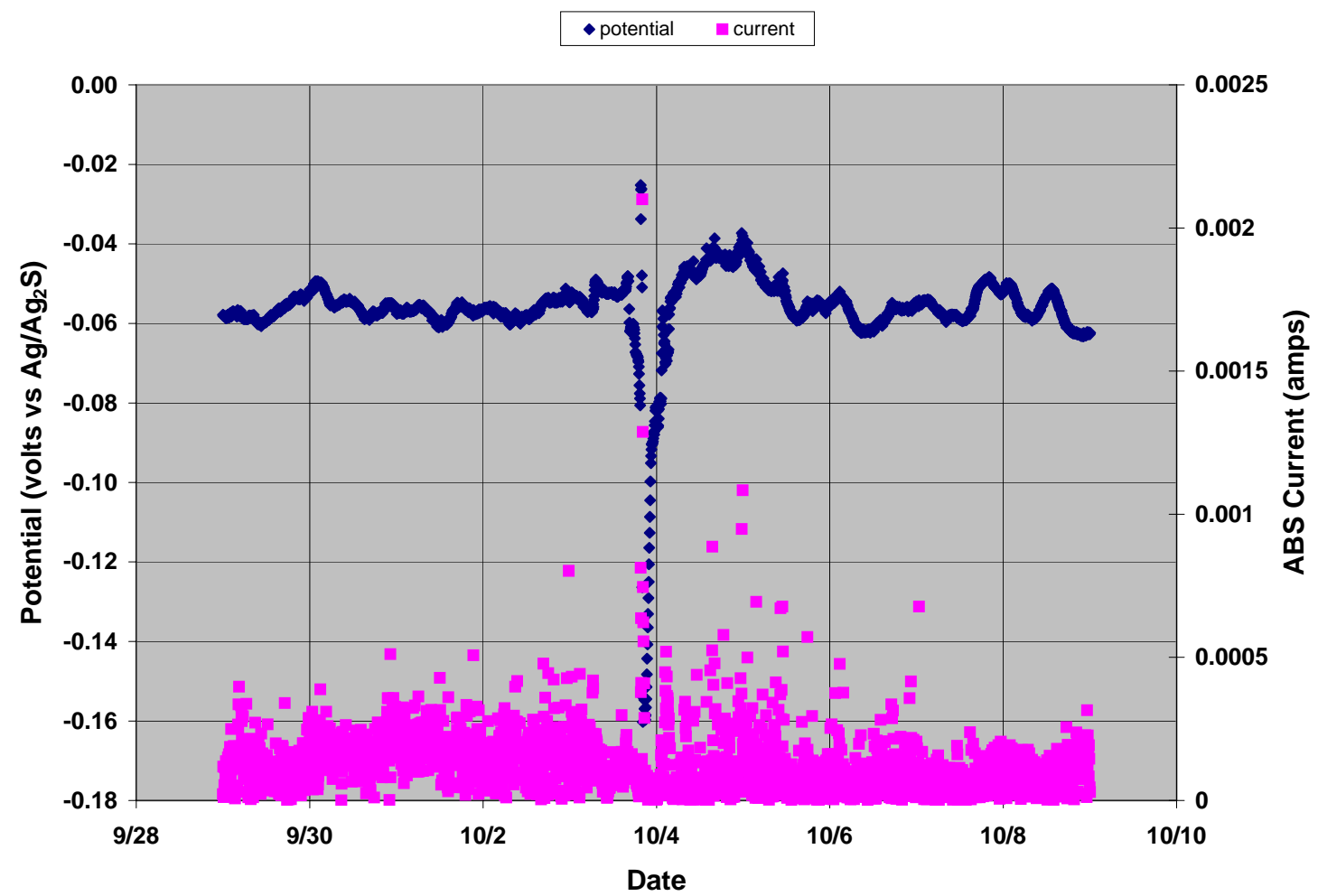

Fig. 25. Relationship of current and potential noise for the 309LSi electrodes on the ring 6S probe for the October 4 event in the digester.

were detected by the routine mill sampling that occurs across/during these excursions, which further highlights the critical need to include real-time chemical sampling capability with future probe installations in order to more fully appreciate the type/magnitude of the environmental changes that occur.

While also caused by an interruption in the digester process, the other potential excursion in Fig. 21 (Oct. 31) has somewhat different characteristics than the Oct. 4 excursion. Figure 26 plots probe temperature and potential as a function of time for the October 31 event. In this case, the potential excursion and the temperature drop are coincident, but the potential seems to recover to the nominal range many hours prior to a return to normal operation temperature at this location. [The potential excursion for 312 at this time was even larger, with bounds of about +40 and $-220 \mathrm{mV}$ vs. $\mathrm{Ag} / \mathrm{Ag}_{2} \mathrm{~S}$.] Unlike the previous example, the probe temperature tends to track white liquor flow in the present case (see Fig. 27). Also unlike the previous example, there is a 
substantial change in current noise associated with the Oct. 31 process upset, which lingers for almost three days following the initial potential drop (Fig. 28). The increase in current noise roughly coincides with the temperature decrease, and unlike many other similar excursions, seems to be related also to the total filtrate flow (Fig. 29).

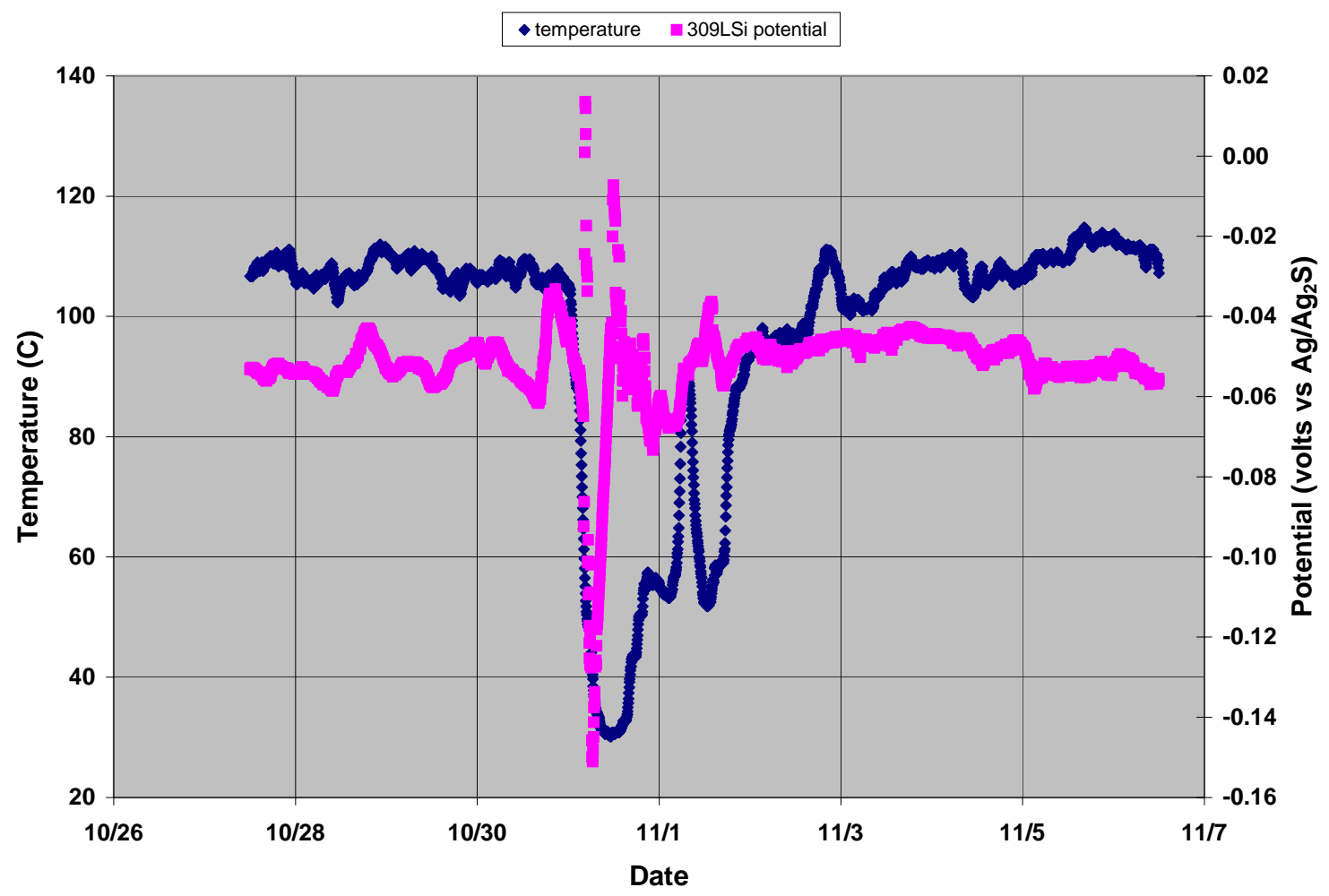

Fig. 26. Probe temperature and 309LSi potential at the ring $6 \mathrm{~S}$ probe associated with the October 31 event in the digester. 


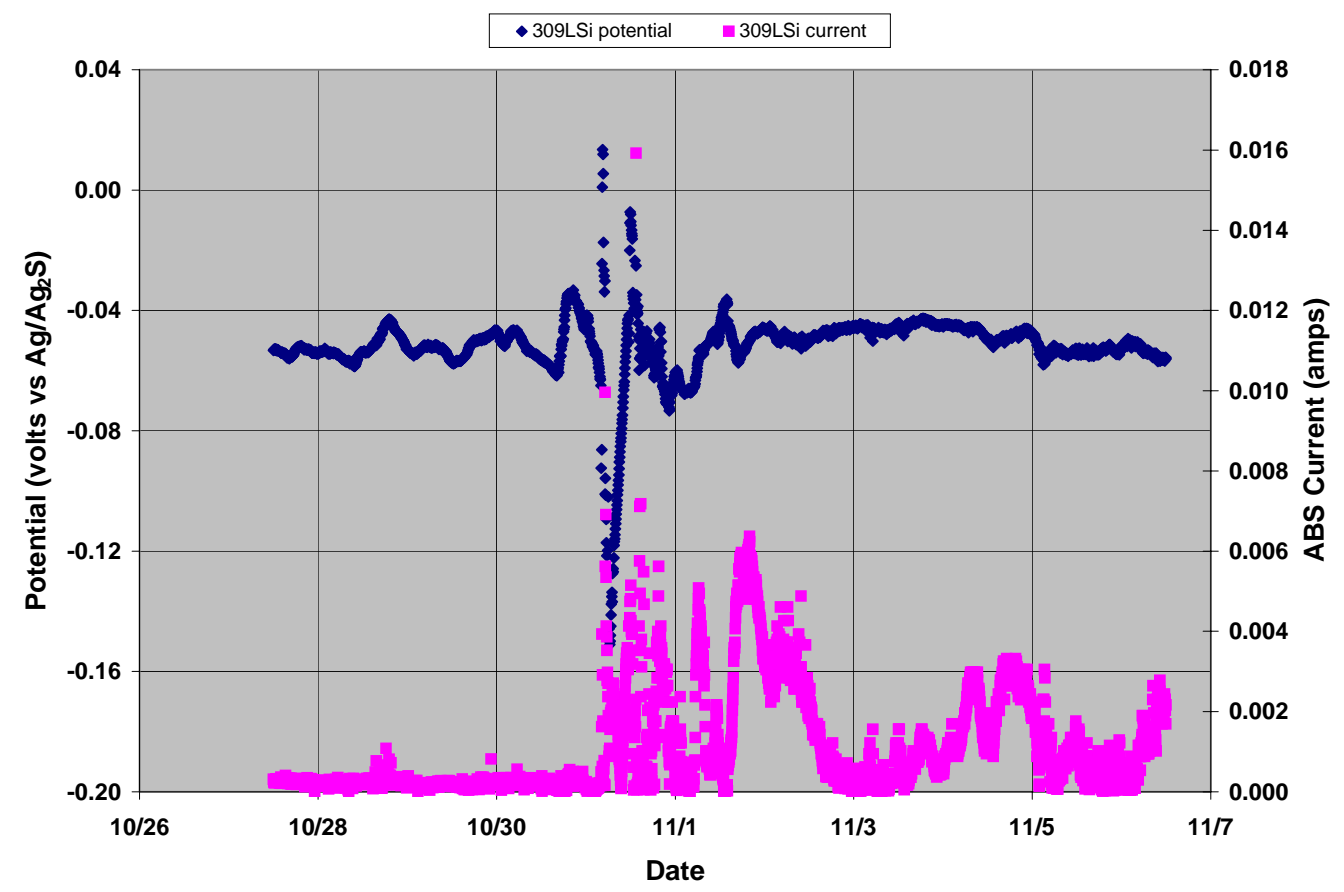

Fig. 27. Relationship of current and potential noise data for the ring 6S 309LSi electrodes associated with the October 31 event in the digester.

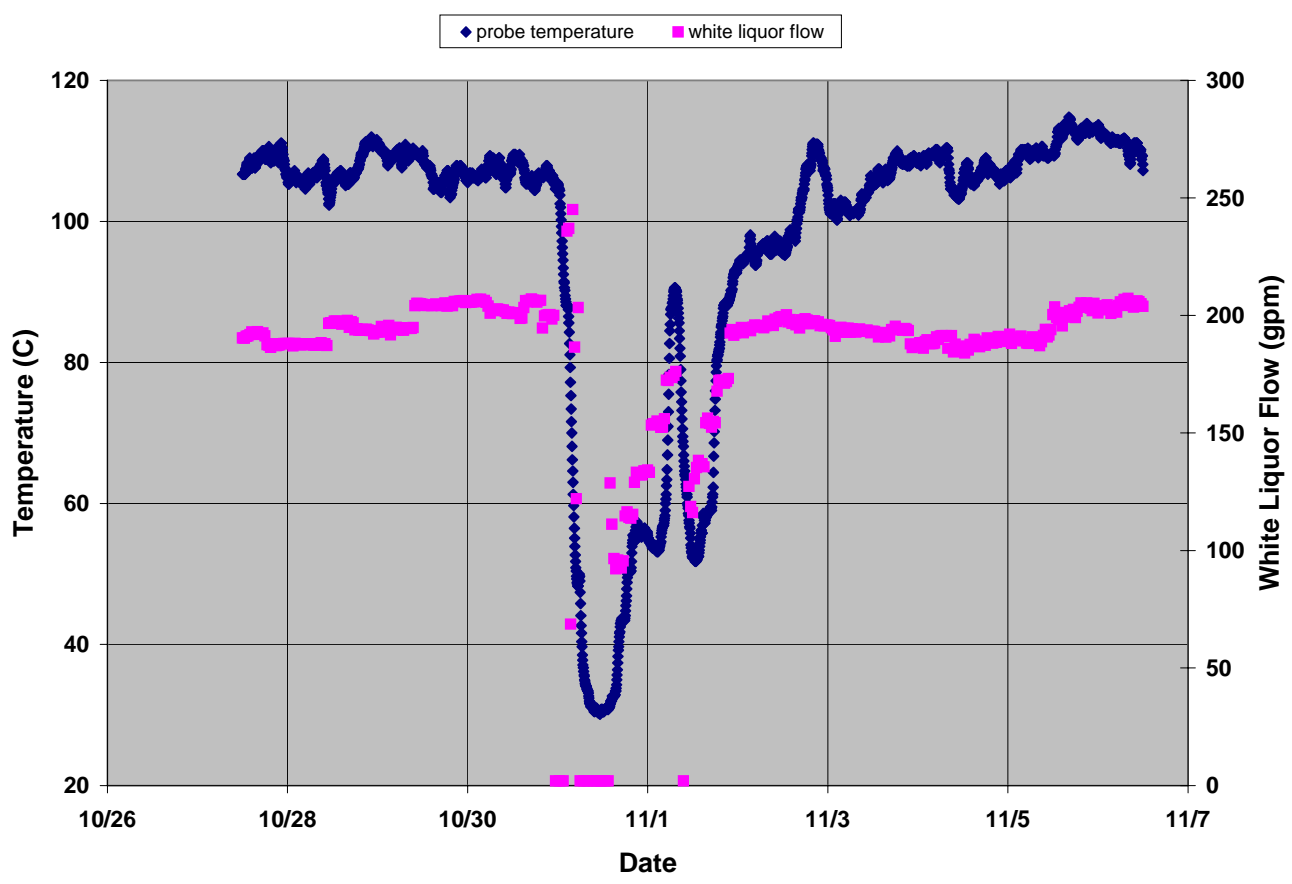

Fig. 28. Ring $6 \mathrm{~S}$ temperature and white liquor flow plotted together for the October 31 event in the digester. 


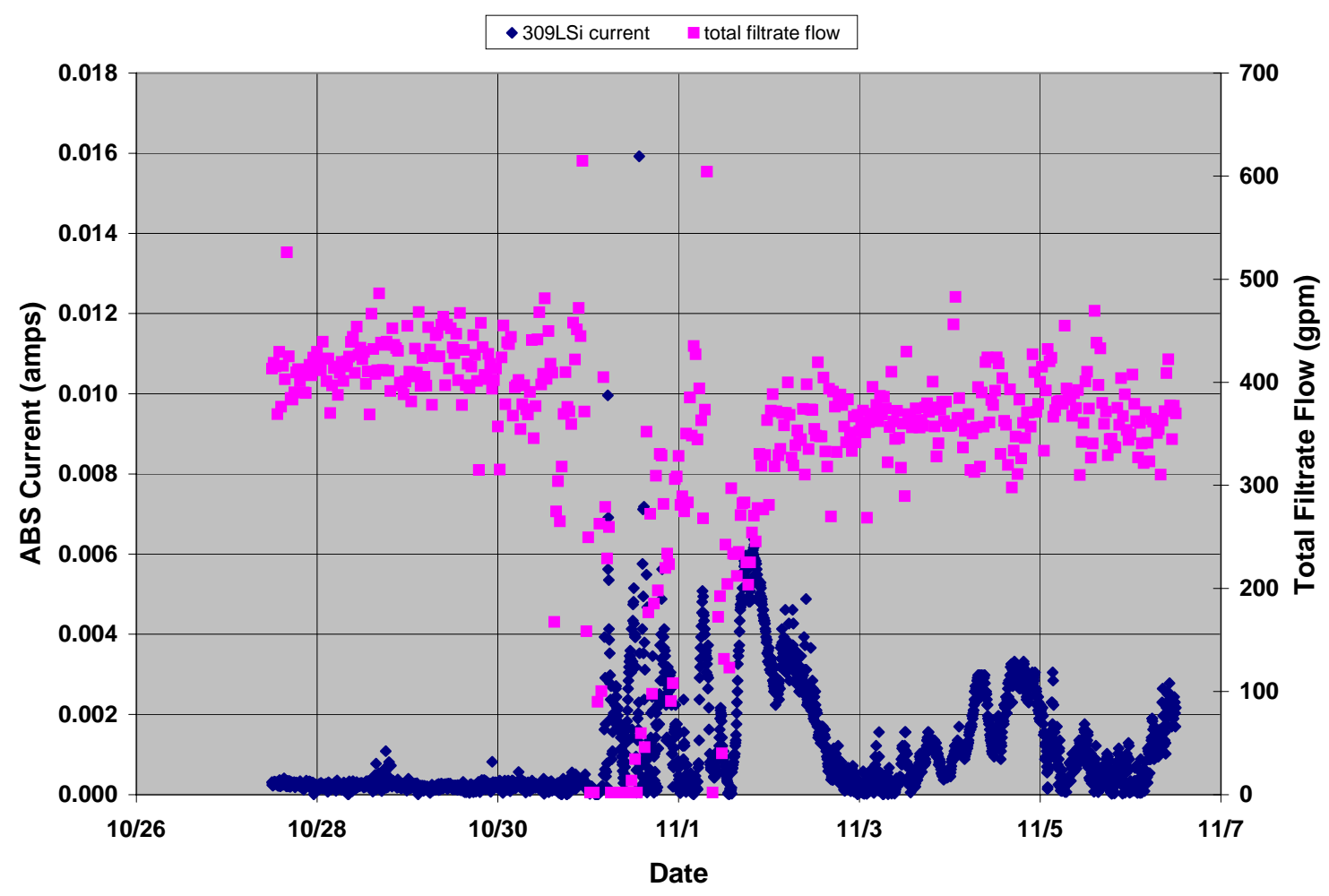

Fig. 29. Current noise for the ring 6S 309LSi electrodes plotted with the total filtrate flow associated with the October 31 event in the digester.

While neither potential excursion discussed above had a negative impact on the corrosion of the Ring 6S electrode materials, it is perhaps significant to note that simply measuring the potentials would not distinguish them as different events with different current noise, perhaps having different process causes or different liquor chemistry changes. As discussed previously [1], monitoring only potential changes seems inadequate for assessing process corrosion in digesters and possibly leads to incorrect conclusions.

Yet a different example of electrochemical noise changes associated with a temperature drop is shown in Fig. 30. The data here show the potential noise and temperature leading up to and including the vessel shutdown in June 2003. In this case, the potential noise is from the 312 electrode pair in the ring $6 \mathrm{~S}$ probe (but the data from the 309LSi electrode pair was similar). On June 13, when the operation was halted and the temperature at Ring 6 drops precipitously, the potential of the 312 increases approximately $100 \mathrm{mV}$ above the median value for the previous 12 


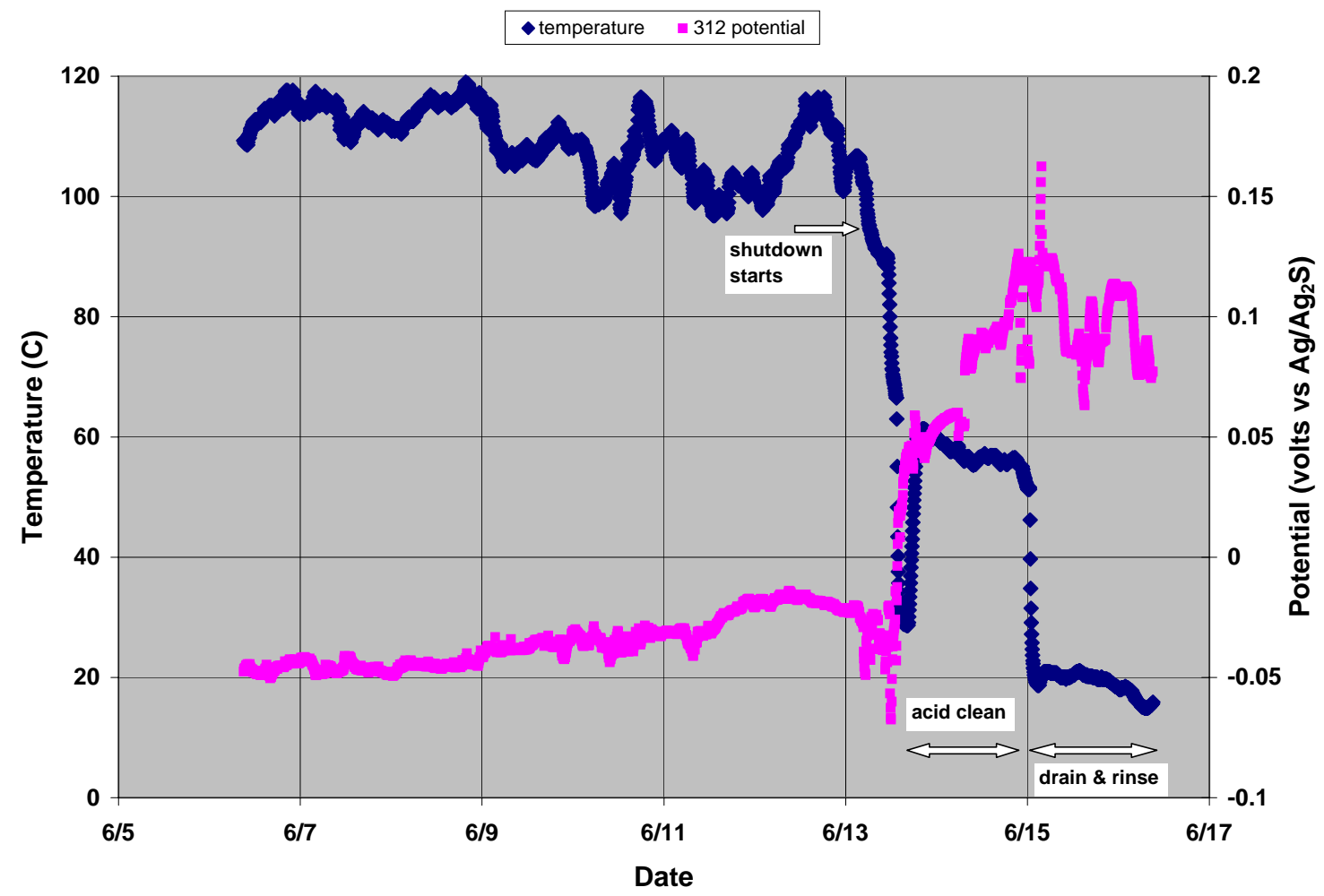

Fig. 30. Potential noise of the 312 electrodes along with the shutdown temperature excursion at ring $6 \mathrm{~S}$.

months. Shortly after the initial shutdown, the temperature again rises from near ambient up to about $60^{\circ} \mathrm{C}$ reflecting the beginning of the approximately 24-h acid cleaning step. [Vessel cleaned with 3\% formic acid inhibited with rhodine.] During the acid cleaning step, the 312 potential remained near $+50 \mathrm{mV}$ for a period, then increased further to $+125 \mathrm{mV}$ (and, briefly, even higher potential). Subsequently, the vessel was drained and rinsed, causing the temperature to drop but the potential remained quite elevated. As has been observed in previous digester investigations [1,2], there is an irregular but substantial increase in the current noise corresponding to the shutdown and cleaning of the vessel (see Fig 31). In the case of the stainless steel overlay materials at Spring Grove, this is not a corrosive condition but perhaps is quite aggressive toward mild steel construction materials. 


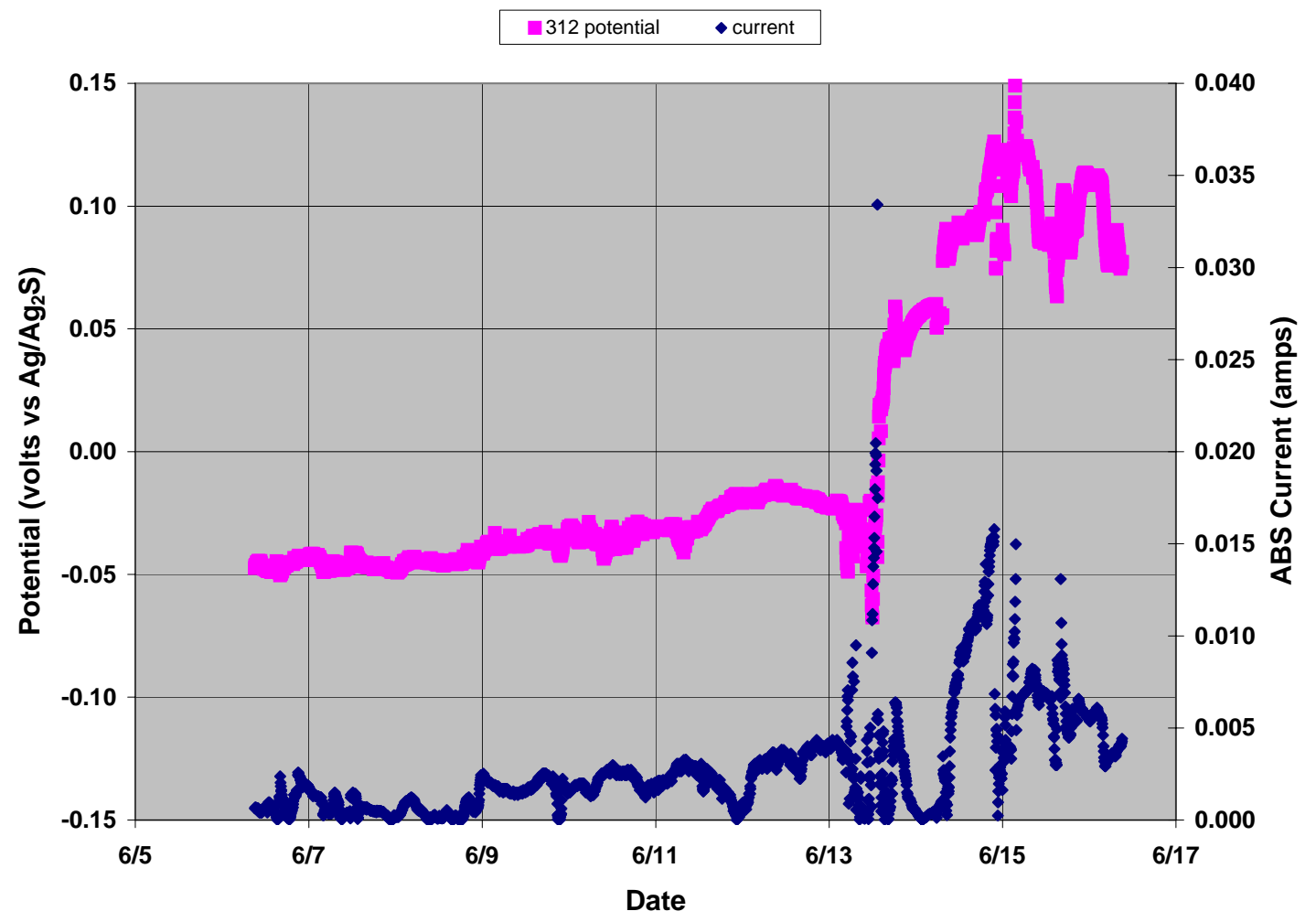

Fig. 31. Potential and current noise for the 312 electrodes of the ring $6 \mathrm{~S}$ probe during the shutdown transient.

It is also interesting to note that, even after draining the vessel, measurements of the current and potential noise continued until the data-gathering system was deactivated, indicating that the probe surface retains a sufficient film of residual black liquor that continuity between the electrodes is maintained. Note that this same film, while not necessarily aggressive toward the stainless steel overlay materials, is likely very aggressive toward carbon steel (contains thiosulfates), even when the vessel appears to be empty.

\subsection{DATA FOR RING 6N}

It was noted previously [2] that the digester temperature and chemistry conditions varied sufficiently at the elevation of Ring 6 that the corrosion rate of carbon steel could vary significantly on opposite sides of the digester at this height. Although wastage corrosion was 
essentially nil for the stainless steel electrodes, the current noise data indicated significant differences in temperature and EN behavior for stainless steel on opposite sides of the vessel as well. In the year \#2 exposure at Spring Grove, the EN difference between the Ring $6 \mathrm{~S}$ and $6 \mathrm{~N}$ probes was somewhat less than in the year \#1 exposure, at least based on current noise and potential transients for 309LSi, but nevertheless, some differences in behavior suggest significant flow and chemistry gradients.

For example, in the year \#1 exposure at Spring Grove, the temperature of the ring $6 \mathrm{~S}$ probe was routinely about $15^{\circ} \mathrm{C}$ higher than that of the ring $6 \mathrm{~N}$ probe. [See Fig. 53 in Reference 2.] However, as shown in Fig. 32, in the year \#2 exposure the temperature profile was largely reversed at the ring 6 elevation, with the temperature of the ring $6 \mathrm{~N}$ probe frequently $7-8^{\circ} \mathrm{C}$ higher than that of the ring $6 \mathrm{~S}$ probe. [Thermocouple location was precisely the same for each probe and exposure year.] Certainly, $7-8^{\circ} \mathrm{C}$ is a modest difference, but it represents a potentially significant (uncontrolled) change in the pattern of liquor flow from the prior year of operation. Also, although both probe locations respond similarly during major process disruptions, the temperature of probes $6 \mathrm{~S}$ and $6 \mathrm{~N}$ do not particularly track each other on a day-to-day basis - frequently, one temperature is increasing while the other is decreasing - which is also different than the previous year at the ring 6 elevation.

Another indication of possible differences in chemistry on opposite sides of the vessel at ring 6 is the comparison of the ring $6 \mathrm{~S}$ and $6 \mathrm{~N}$ potential and current noise associated with major process disruptions. Unlike the ring $6 \mathrm{~S}$ probe, for which $100 \%$ of the potential excursions greater than $25 \mathrm{mV}$ from the nominal range were associated with a large temperature decrease, only about half of the ring $6 \mathrm{~N}$ potential excursions were associated with a substantial temperature decrease. [Similarly, only about half of the low temperature excursions at ring $6 \mathrm{~N}$ were accompanied by a substantial change in potential.] An example of the potential noise on the ring $6 \mathrm{~N}$ probe is shown in Fig. 33. Note that there are several brief increases in potential $(40-60 \mathrm{mV}$ above nominal) in the period shown, only one of which was accompanied by a large temperature excursion. [The 312 stainless steel electrodes at ring $6 \mathrm{~N}$ behaved similarly, with potential excursions corresponding precisely in time and generally in magnitude to those for 309LSi.] Changes in potential (by 40-60 mV) that occur for modest periods of time (30 minutes to several hours) on the $6 \mathrm{~N}$ probe are not observed by the probe on the opposite side of the vessel, and it seems reasonable to speculate that flow/chemistry gradients are responsible. 


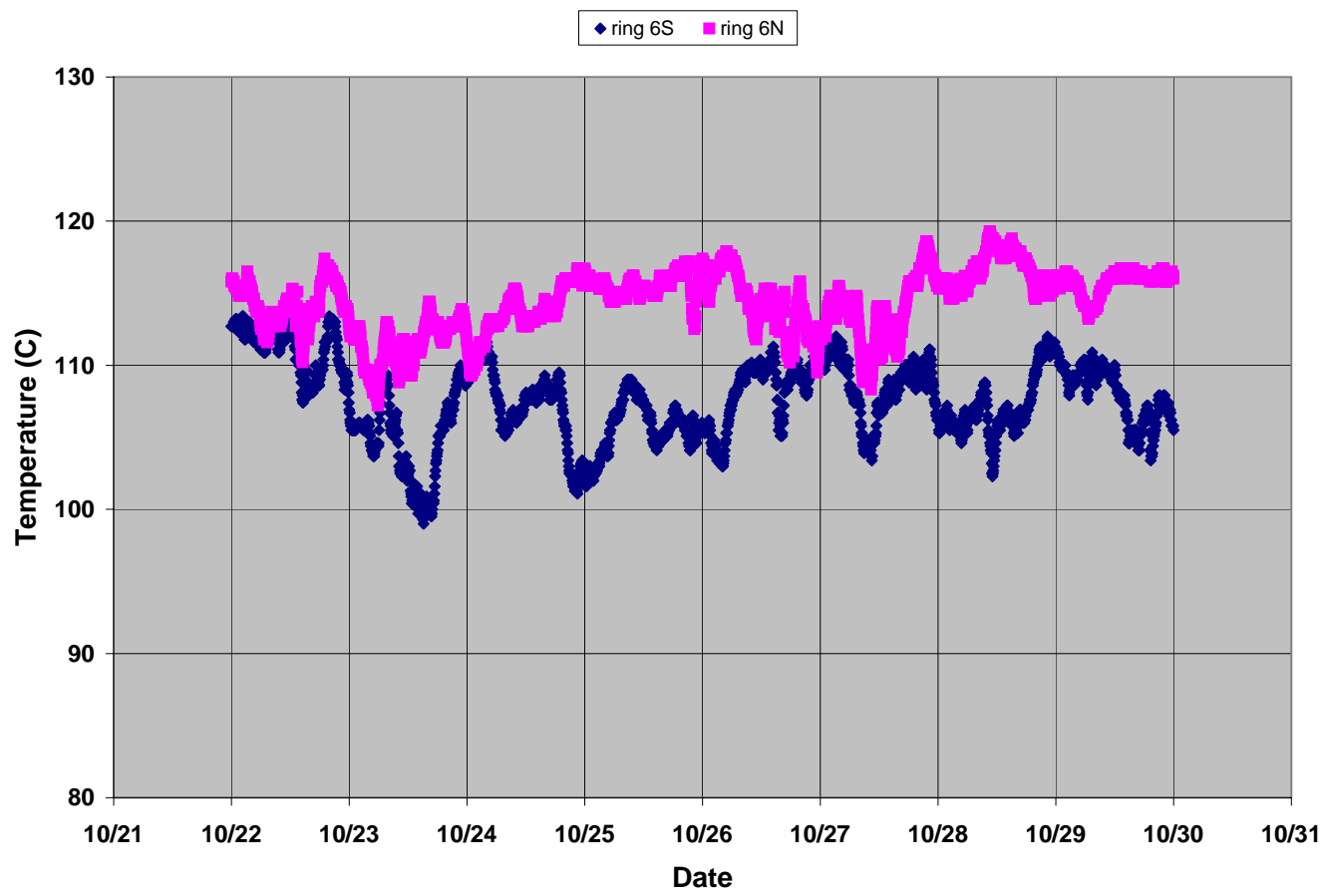

Fig. 32. Representative temperature data as a function of time at the ring 6 elevation.

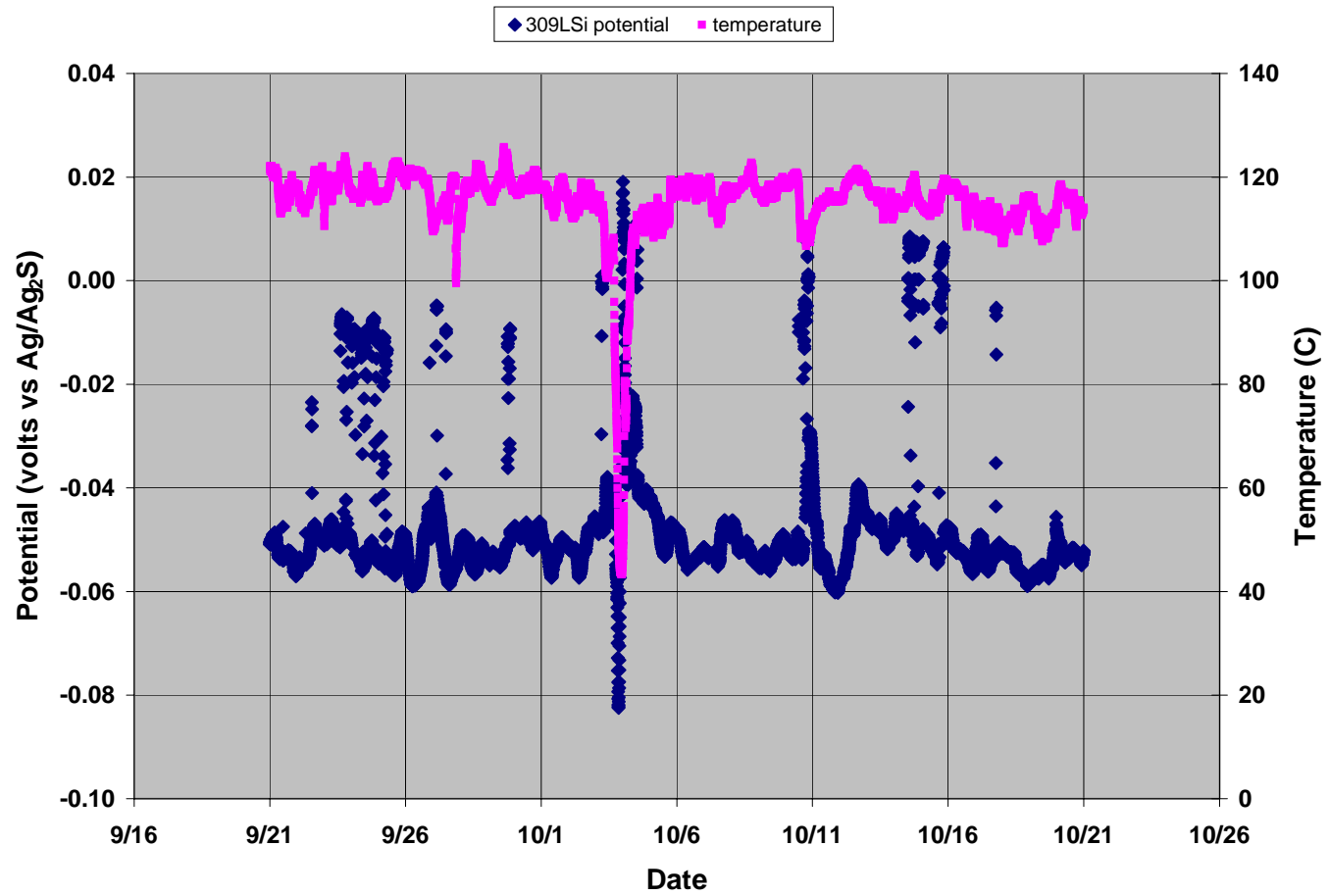

Fig. 33. Representative potential noise for 309LSi electrodes along with temperature data for the ring $6 \mathrm{~N}$ probe. 
It could perhaps be argued that the relative degradation of the silver electrodes at the ring 6 position calls the potential measurements into question. On an absolute basis, that is no doubt true; however, the silver in both probes was similarly degraded at the end of year $\# 2$, and the data shown in Fig. 33 represent a period relatively early in the exposure. Further, the similarly degraded silver at ring $6 \mathrm{~S}$ did not detect a large number of relatively brief potential transients during the period shown in Fig. 33 (or any other period), suggesting that the different behavior at probe $6 \mathrm{~N}$ is a result of short-lived but significant chemistry gradients at the ring 6 level.

The significant result, in any case, is that differences in EN behavior of the electrodes in probes $6 \mathrm{~S}$ and $6 \mathrm{~N}$ are not predictable in any of the various predictive models that depend upon circumferential symmetry. Clearly, unbalanced flow and related issues will have to be incorporated to eventually understand and predict variable behavior at a specific elevation in the process.

For both electrode alloys, there was only one substantial current noise transient from probe $6 \mathrm{~N}$ in the period shown, which was coincident with the largest potential transient (see Fig 34). Also note in Fig. 34 that the current noise is relatively unbiased ("centered" on, or very near, zero - neither electrode dominant in direction of current flow), which is generally representative of all the current noise data for the year \#2 experiment. The main exceptions were observed mostly for the 312 electrodes, which periodically - for days or even a few weeks at a time - exhibited a slight drift toward positive current, meaning the same electrode was favored for the oxidation portion of the redox reaction each time bias was observed. During the period shown in Fig. 34, the average current noise for the 312 electrodes is perhaps a factor of six higher than that for 309LSi, with some significant bias. 


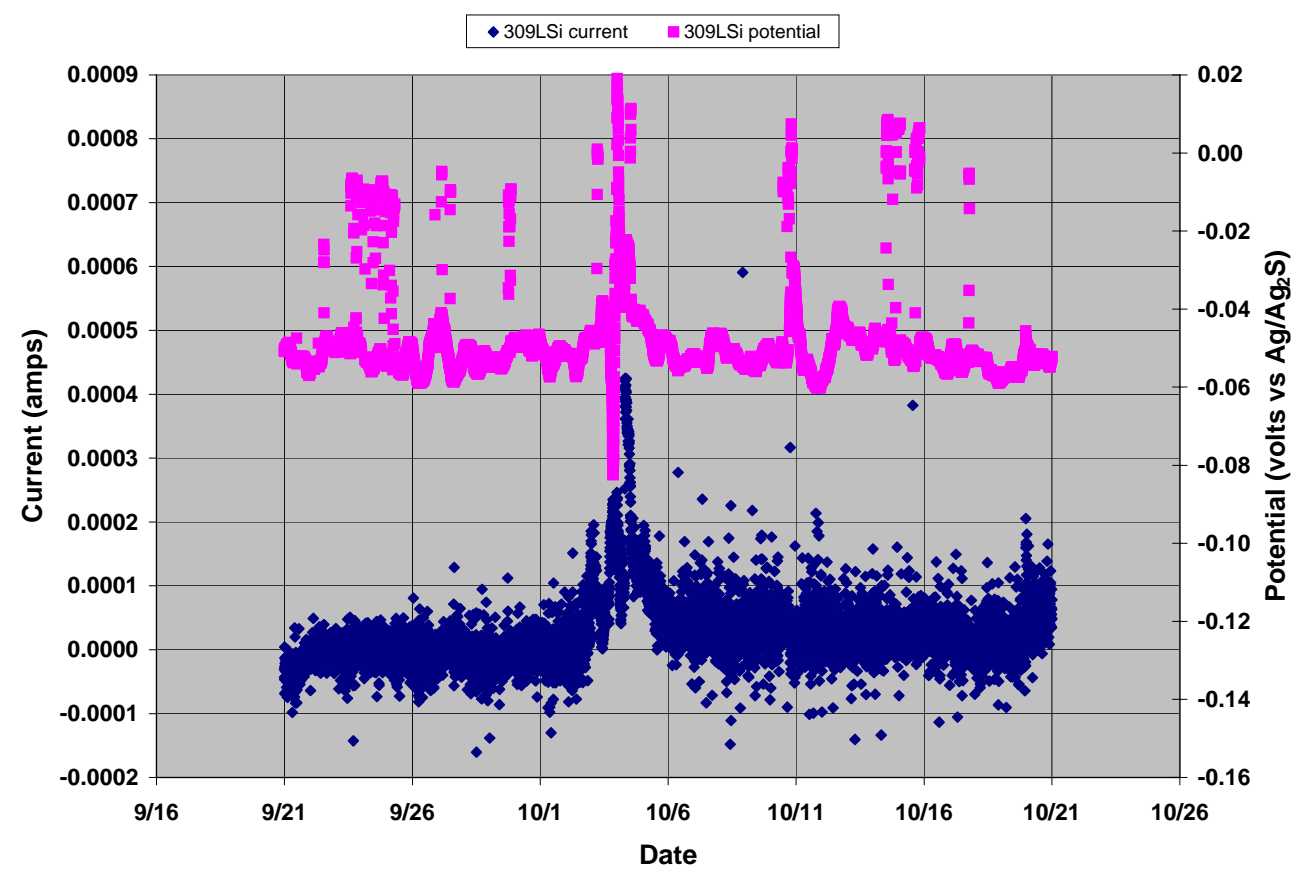

Fig. 34. Current and potential noise for the 309LSi electrodes in the ring $6 \mathrm{~N}$ probe surrounding the early October event in the digester.

\subsection{DATA FOR RING 3}

The behavior of the current and potential noise of the stainless steel electrodes in the Ring 3 probe was very similar to that at Ring $6 \mathrm{~S}$ and $6 \mathrm{~N}$. Generally, the potential noise was very modest, with potential variations from the nominal value greater than about $20 \mathrm{mV}$ relatively rare and short-lived. Most, but not all, substantial potential transients coincided with operational upsets (and the associated large temperature decrease). Generally, current noise was unbiased and very low/quiet, with only brief transients associated with the largest temperature/potential excursions.

\subsection{DATA FOR THE FLASH TANK}

For the flash tank electrodes, the nominal potential range (see Fig. 19) also seemed to be about $15-20 \mathrm{mV}$ wide in the first few months of exposure, but there was significant scatter toward higher potentials for each material. During the course of the year \#2 experiment, the median potential of the flash tank probe materials drifted about $50 \mathrm{mV}$ toward higher values, and by late Fall of 2002 the nominal peak value of the potential histogram had shifted to about -40 or $-45 \mathrm{mV}$ 
for each of type 309LSi and 312 electrodes. In a general sense, the EN current activity of the flash tank electrodes was much more substantial during the periods in which the potential hovered near $-90 \mathrm{mV}$ than during similar time frames with a nominal potential near $-45 \mathrm{mV}$, suggesting the development of stable passivity with increasing exposure time. (The nominal potential of the 309LSi in the flash tank was -50 to $-70 \mathrm{mV}$ vs. $\mathrm{Ag} / \mathrm{Ag}_{2} \mathrm{~S}$ during year \#1 [1].) However, the EN current and potential activity in the flash tank is unusual in other ways, as discussed below.

Figure 35 shows a representative period of current noise for the flash tank probe plotted along with the probe temperature. While the data given are for type 312 stainless steel, the current noise in Fig. 35 is largely indistinguishable from the behavior of type 309LSi in this or any other time period. In particular, note that the current noise frequently seems to fluctuate between two value ranges - a modest positive number and a smaller negative number (or near zero) with a distinct gap frequently apparent between the two current ranges. In this particular period, $72 \%$ of the current values in Fig. 35 are greater than zero, suggesting slight but consistent bias. The potential noise data for this period (and others) also reveals a small gap between distinct values/ranges.

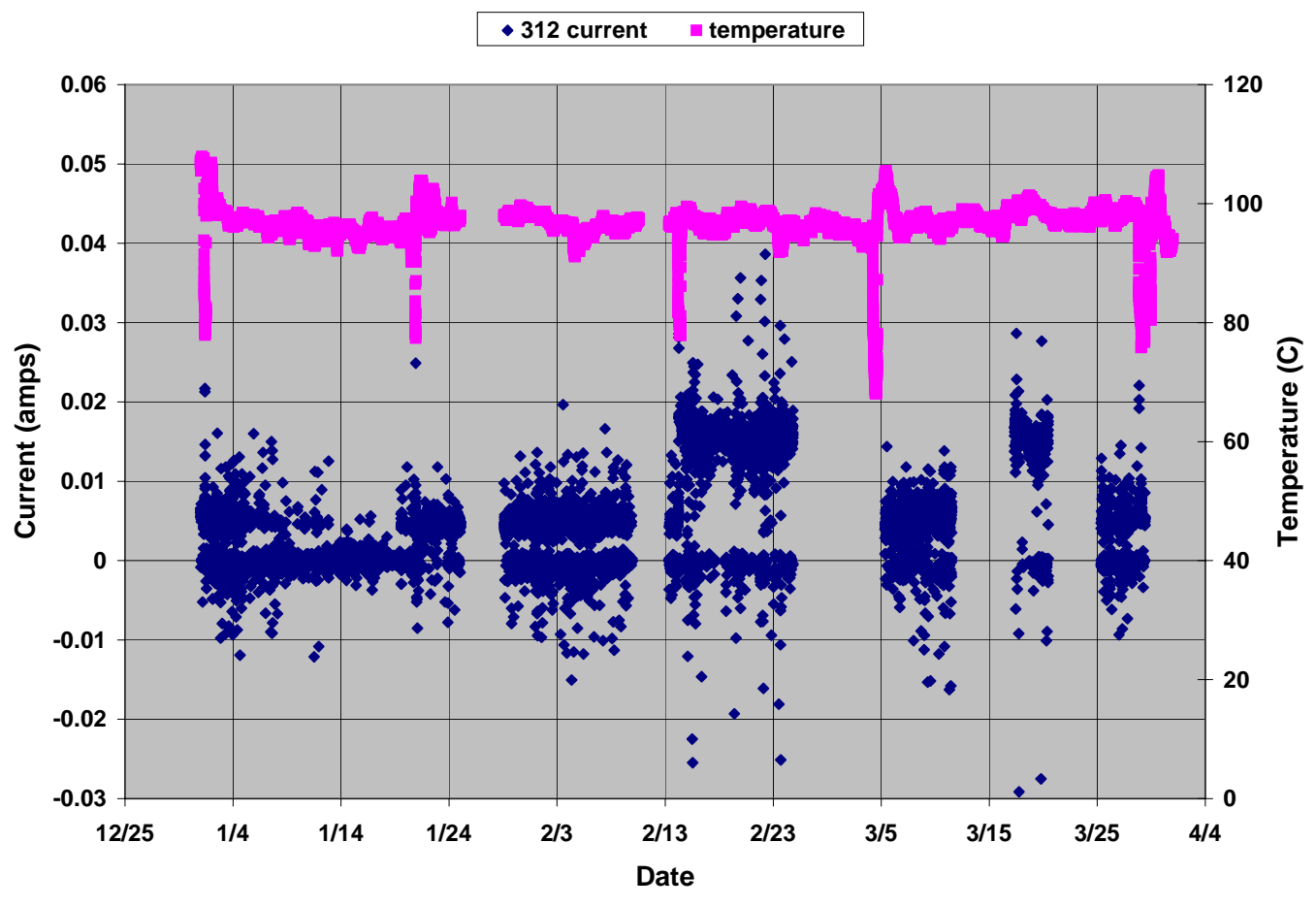

Fig. 35. Representative current noise for the 312 electrodes plotted with temperature of the flash tank probe. 
There are five substantial temperature perturbations $\left(>20^{\circ} \mathrm{C}\right.$, related to upsets in digester operation) in the period shown in Fig. 35, and it is clear that none of these alter the basic character of the current noise pattern. It might be argued that the gap in the current noise becomes more distinct immediately following some of the temperature transients, and there are several examples where this is true, but there are also a few counterexamples in which the size of the gap changes without a corresponding temperature change.

Figure 36 plots the current noise for the February 15 segment of the data shown in Fig. 35. During this period, the maximum temperature variation is less than $2^{\circ} \mathrm{C}$, so temperature swings are not likely to be responsible for the distinct current fluctuations shown here. Further, note that Fig. 36 plots the current noise distinguished by relative potential. The average value of the "high current" noise in the period shown in Fig. 36 is $1.60 \times 10^{-2}$ amps, while the average (absolute value) of the "low current" range is about an order of magnitude less at $2.08 \times 10^{-3}$ amps. As shown in Fig. 37, the nominal potential difference generating the current noise range is only about $10 \mathrm{mV}$. (A similar, but perhaps even larger, fluctuation in current was noted for the 309LSi electrodes in the flash tank in year \#1 of the Spring Grove experiment [2] although the year \#1 data was not plotted in the fashion shown here.) In consideration of a standard active-passive polarization curve for stainless steels, the only location where a $10 \mathrm{mV}$ increase in nominal potential corresponds to a decrease in current activity by approximately an order of magnitude is near the passivation (Flade) potential, but the current activity indicated is likely to be entirely related to redox reactions. Among aqueous sulfur chemistry reactions, for example, it is not apparent what reaction may participate in the potential range -30 to $-60 \mathrm{mV}$ vs. $\mathrm{Ag} / \mathrm{Ag}_{2} \mathrm{~S}$ (approximately -905 to $-935 \mathrm{mV}$ vs. saturated calomel electrode) of interest in Fig 37. 


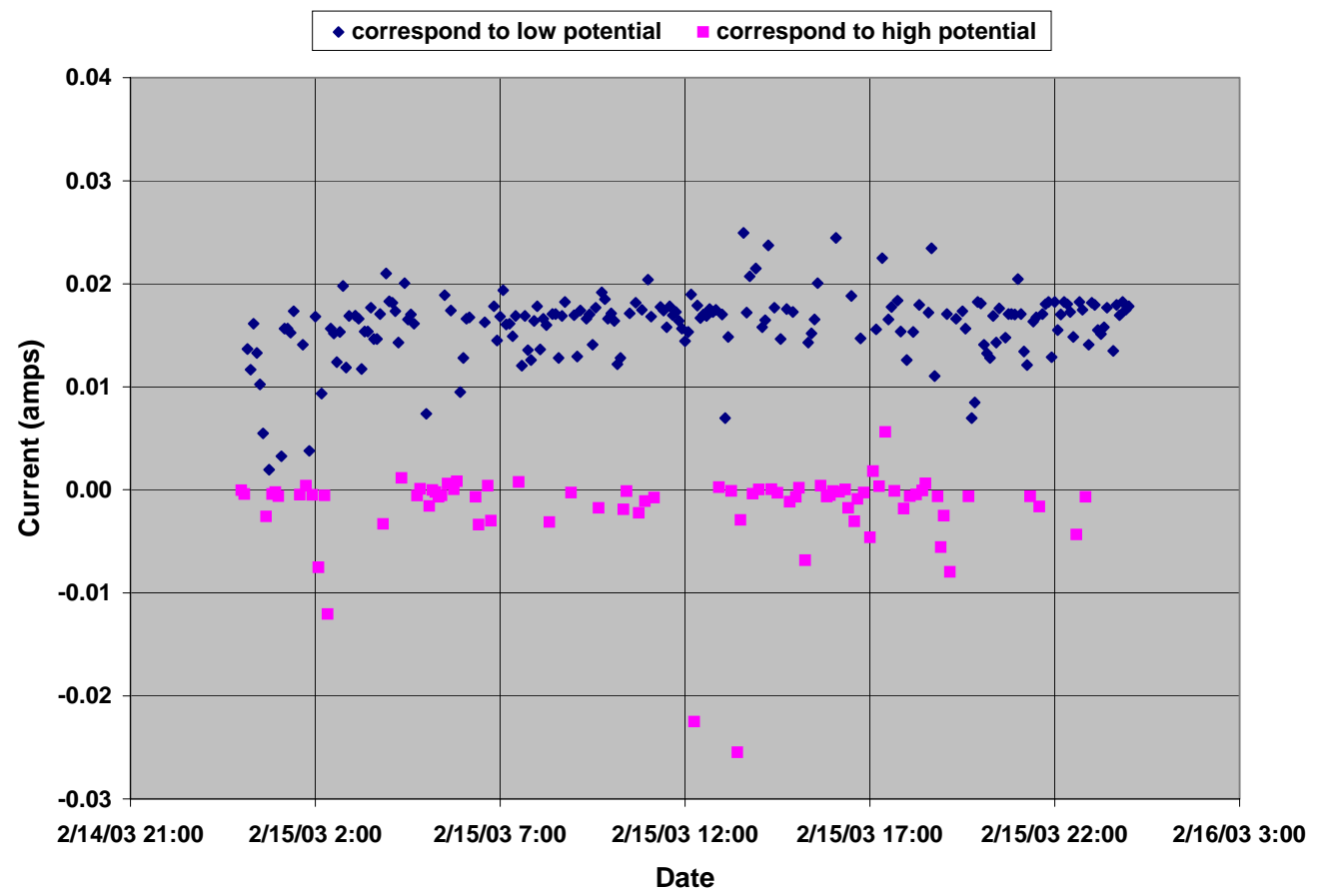

Fig. 36. Current noise for the February 15 portion of the general current noise recorded in Fig. 35. Data points are coded corresponding to the relative potential associated with each.

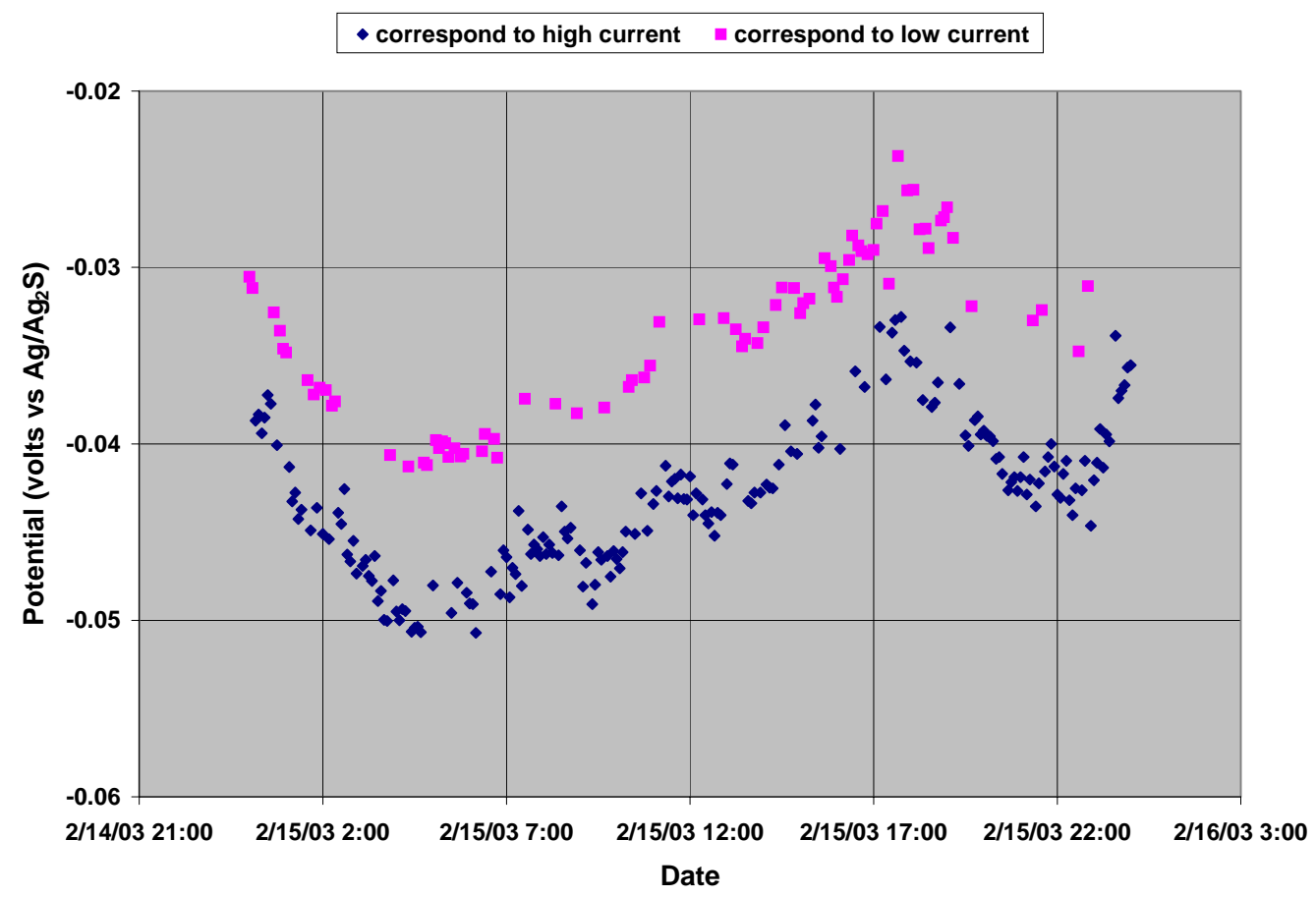

Fig. 37. Potential noise corresponding to the current noise data plotted in Fig. 36. 
Although not always observed, it was relatively common that a digester operation upset tended to change the current noise behavior in the flash tank. Generally, the digester upsets were associated with a halt of continuous operation (or at least a significant production rate decrease) and the temperature in the flash tank (and other locations) drops for a few hours or even a day. These changes in temperature/operation tend to increase the gap between the flash tank current ranges that tend to decay slowly with extended time. Examples from Fig. 35 where this is so can be seen on approximately January 2 and 21 and February 14. EN current data along with probe temperature is shown for the type 309 electrodes in Fig. 38 for the event associated with approximately January 21 . While the data for 312 (Fig. 35) imply the change in current activity may very slightly precede the temperature drop, it is clear that, at least for type 309LSi in Fig. 38, the temperature drop and change in redox activity coincide.

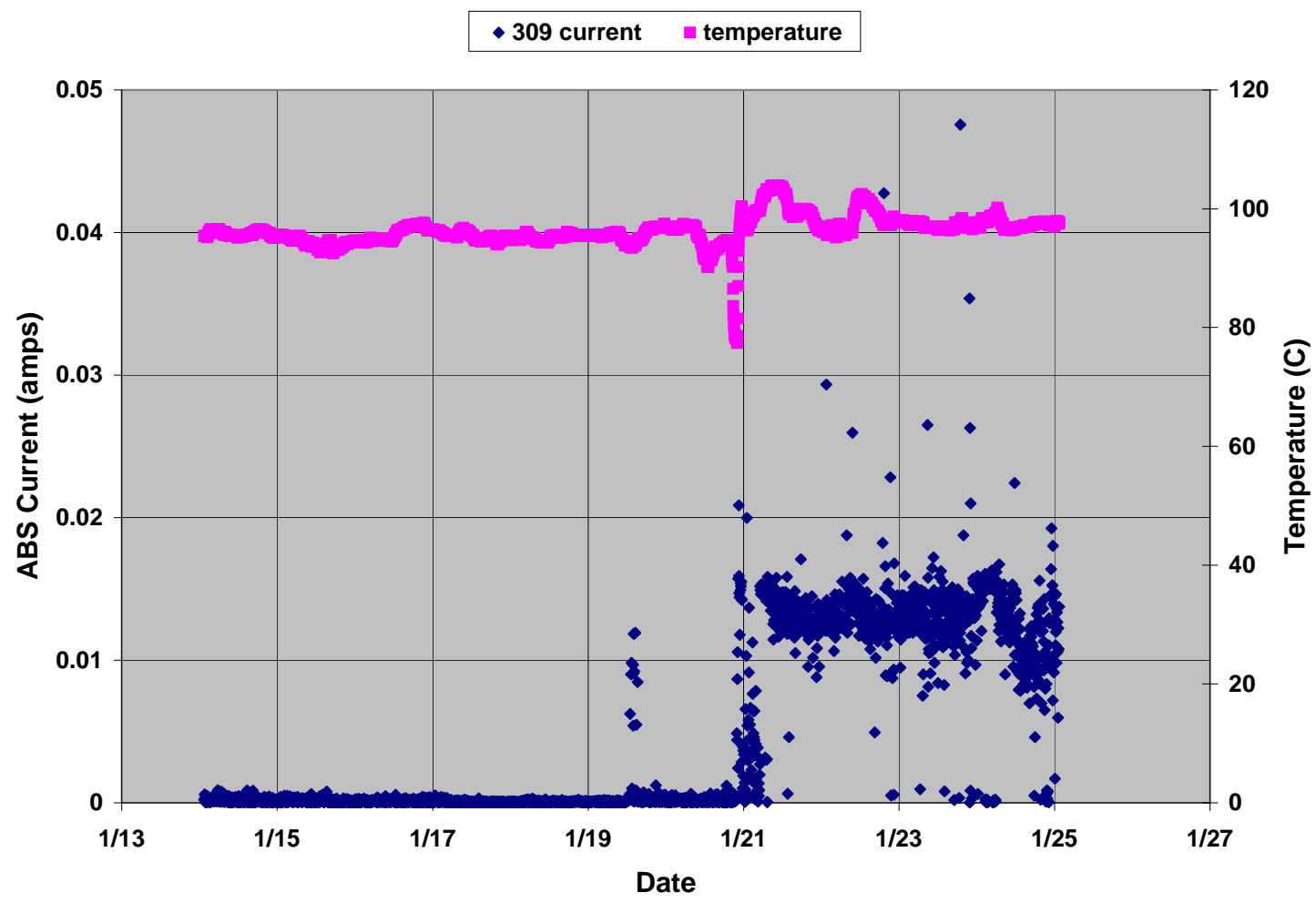

Fig. 38. Current noise transient associated with a digester upset (temperature excursion) near January 21. 
While these details of the changes in redox activity appear to be inconsequential for the performance of the 309LSi and 312 overlay materials, they do imply that there are unknown/untracked changes in process chemistry that occur regularly. These changes perhaps are much more significant to the performance of mild steel in continuous digester service.

\subsection{PROCESS DATA CORRELATION}

Once the corrosion parameters were determined, simple correlations to the process data were investigated. There are 23 process parameters (for example, liquor composition at specific sampling points, chip feed rate, heater temperatures), 5 probe temperatures, and 56 corrosion parameters (for example, EN current, EN potential, and calculated parameters from these) available. Correlation coefficients were calculated between each pair of parameters in the following manner. Start with two time series $x_{i}$ and $y_{i}$. The average values are then $\mu_{x}$ and $\mu_{y}$ and the standard deviations are $\sigma_{x}$ and $\sigma_{x}$. The correlation coefficient ranges between -1 and +1 and is calculated from

$$
R_{x y}(0)=\frac{1}{N} \sum_{i=1}^{N} \frac{\left(x_{i}-\mu_{x}\right)\left(y_{i}-\mu_{y}\right)}{\sigma_{x} \sigma_{y}}
$$

In this equation, $N$ is the number of data points, and $R_{x y}$ is the linear correlation coefficient between variables $x$ and $y$. An $R_{x y}$ value of -1 means complete negative linear correlation, a value of zero means no correlation, and a value of +1 means complete direct linear correlation. Correlation coefficient is often included in least-sum-of-squares curve fitting to evaluate the "goodness of fit" of the resulting linear equation. For data which exactly match the linear equation $y=m x+b$, the correlation coefficient will be $+/-1$. The calculation of cross-correlation coefficients between the process variables should give some idea of what process variables are most closely related. However, as was evident for previous attempts of this type [1,2], no regular correlation was found between process variables and EN parameters. The largest correlation coefficients were approximately 0.6 (or -0.6 ), with the vast majority falling in the range \pm 0.1 . [Related efforts were also employed including slight delay times in the coefficient analysis these permit the possibility of a time lag between when a process variable is changed and a response within the digester, as indicated by EN parameters. However, no correlations of significance were determined in this fashion.] 
The lack of correlation seems to imply that the parameters tracked by the mill are either not relevant to the corrosion processes or perhaps are measured as average/bulk values rather than at the locations where corrosion is occurring. In addition, it may simply be that the relationships between process parameters and EN activity are more complex than can be revealed by assessments for linear correlations. Additional discussion on this topic can be found in Ref. 2.

\subsection{RESULTS FROM STEEL PANELS ON DUMMY PLATES}

Following cleaning in inhibited acid along with rinsing and drying, the panels were evaluated for appearance as well as weight and dimensional changes. The $304 \mathrm{~L}$ stainless steel panels were essentially immune to attack, exhibiting only a slight change toward a dull luster from the original surface, no dimensional change, and a weight loss of less than $0.5 \mathrm{~g}$. Based on the entire surface area of the coupon, the weight loss corresponds to a uniform corrosion rate of less than $0.1 \mathrm{mils} / \mathrm{y}$.

The mild steel panels, however, exhibited significantly greater corrosion in all cases. Typically, these exhibited a dark luster with several hues (golden-brown to brown, even dark reddish), but the surfaces were relatively smooth - not rough or etched looking - suggesting a significant component of erosion along with general corrosion. The steel panels did not exhibit pitting or crevice corrosion at any location, but the general corrosion rate (plus erosion component) varied with position across the panels. As a general rule, the panels retained their pre-test thickness only directly beneath the contact area with the teflon shoulder washers. Immediately adjacent to the washer contacts, however, the panel thickness was typically reduced about 100 mils. As position moved from adjacent to the washer contact toward the center of the panel, the decrease in thickness became less pronounced, and over large areas of panel surface, the loss in thickness was only 40-60 mils. Three of four edges on the steel coupons (the exception being the edge facing down in the digester) were corroded to a near knife-edge profile over about $0.25 \mathrm{in}$.

As a rule, the appearance, thickness, and weight loss of the steel panels was not influenced significantly by heat treatment condition. Further, weight loss was not influenced significantly by position (side of the digester) - it was routinely only about $5 \%$ higher on the $6 \mathrm{~N}$ side. However, weight loss from the steel panels was a relatively mild function of steel composition. Corrosion rate cannot be precisely calculated from the panel weight loss because the corrosion was not entirely uniform and it may in fact be essentially one-sided (so area is uncertain), but the average 
corrosion rate can be estimated for comparison purposes in this fashion. The resulting estimate indicates a corrosion rate of approximately 19 mils/y for A285-C, 26 mils/y for A516-70, and 30 mils/y for Corten-A, which follows closely the change in Si content among the alloys (increasing Si increases weight loss).

\subsection{AUTOCLAVE TESTING}

In advance of seeing the results from the panel testing at Spring Grove, a limited set of autoclave tests to examine the potential role of mill scale were performed in the laboratory. Coupons for autoclave testing were fabricated from the same heats of material (see Table 3) used to fabricate the panels discussed above, and were also given the same range of heat treatments. Figure 39 shows the coupons arranged on an all-thread probe with teflon shoulder spacers of the type used in the autoclaves.

Following testing, the coupons were cleaned in the same fashion as the panels exposed on the dummy plates. Since corrosion was in every case very general and uniform, the weight losses were used to calculate annualized corrosion rates (see Table 5). In the solution termed extraction liquor \#1, the corrosion rates for A285C and A516-70 steel with the oxide treatments are approximately an order of magnitude lower than without an oxide, while there is little effect of the oxide for Corten A. A similar effect, but smaller in magnitude, was observed in the somewhat less aggressive solution termed extraction liquor \#2.

In the highly aggressive simulated white liquor, oxide treatments slightly reduced the corrosion rate for A285 C and A516-70 steels but oxide again had little or no effect on the Corten A steel. However, corrosion rates were so extreme in this solution that the oxide role, if any, may have been only to slightly delay the onset of rapid dissolution of the metal. Generally, the coupons experienced remarkably uniform corrosion product development - so much so that the growth of the corrosion product on each of the original flat/rectangular faces of the coupon retained sharp right angles between all the coupon faces. Figure 40 shows an example of the extreme corrosion rates experienced in the simulated white liquor environment, as well as a closeup of a partially cleaned coupon. Note that on the individual coupon shown, the corrosion product is extremely thick and approximates the original coupon thickness. However, the corrosion process is also sufficiently uniform that the original specimen ID number stamped onto the surface is still visible on the outer surface of the corrosion product. 

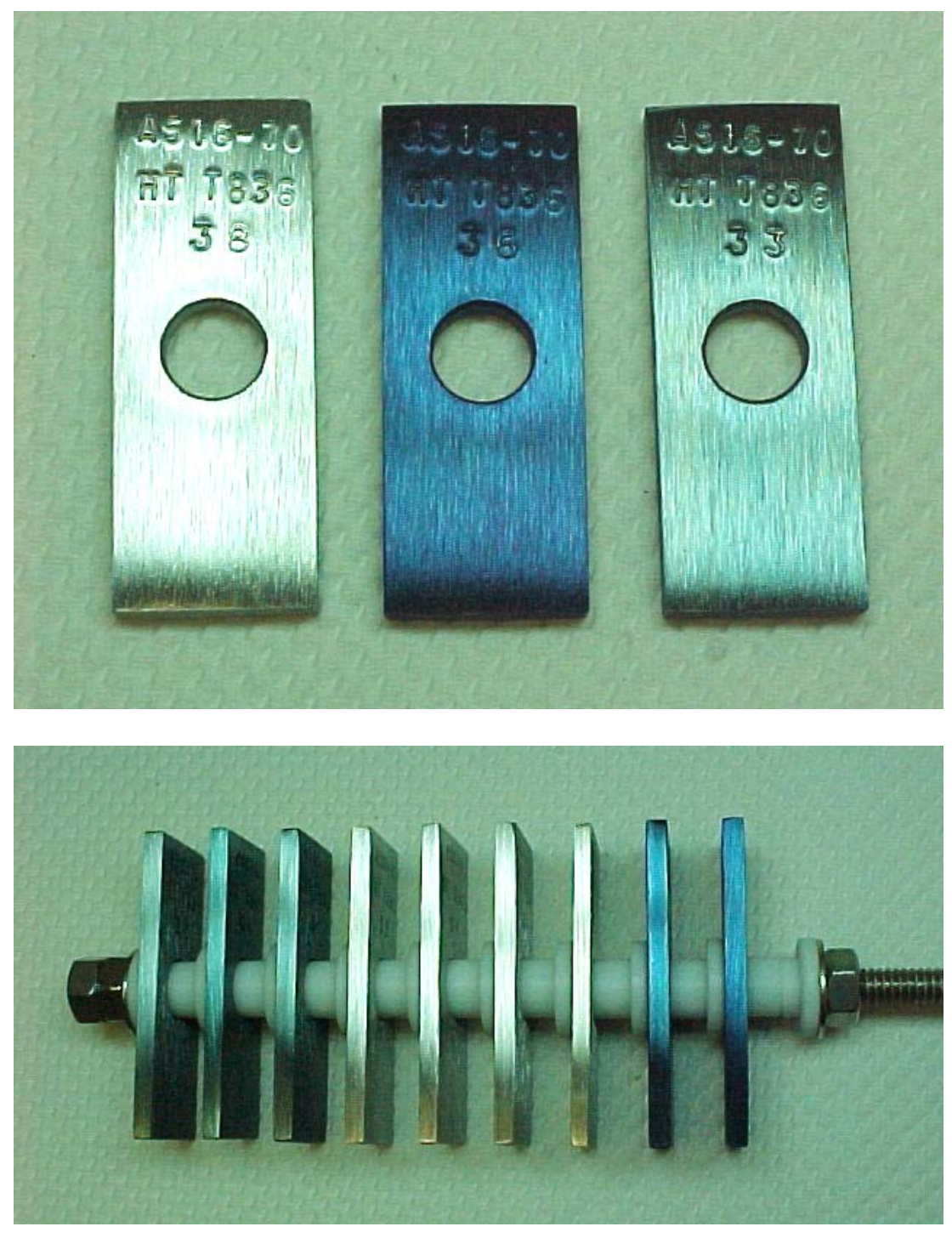

Fig. 39. Coupons used in autoclave testing. Top: A series of A516-70 panels with a 120 grit finish, $45 \mathrm{~min} / 305^{\circ} \mathrm{C}$ scale, and $135 \mathrm{~min} / 305^{\circ} \mathrm{C}$ scale, from left-to-right, respectively. Bottom: A series of coupons (one of each material and heat treatment) arranged on a piece of all-thread for exposure in the autoclave. 
Table 5. Corrosion rates (mils/y) calculated from weight loss of coupons exposed to synthetic liquors in autoclaves for 14 days at $165^{\circ} \mathrm{C}$ under nitrogen.

\section{EXTRACTION LIQUOR \#1}

\begin{tabular}{|c|c|c|c|}
\hline no oxide & 10.4 & 10.8 & 6.2 \\
\hline $45 \mathrm{~min} / 305^{\circ} \mathrm{C}$ & 0.9 & 1.6 & \\
\hline $135 \mathrm{~min} / 305^{\circ} \mathrm{C}$ & 1.3 & 1.4 & 5.7 \\
\hline
\end{tabular}

\section{EXTRACTION LIQUOR \#2}

no oxide

$45 \mathrm{~min} / 305^{\circ} \mathrm{C}$

$135 \mathrm{~min} / 305^{\circ} \mathrm{C}$

no oxide

$45 \mathrm{~min} / 305^{\circ} \mathrm{C}$

$135 \mathrm{~min} / 305^{\circ} \mathrm{C}$
$\frac{\mathrm{A} 285 \mathrm{C}}{3.0}$

1.5

1.8

\section{$\underline{\mathrm{A} 516-70}$}

2.8

1.6

2.1

\section{$\frac{\text { Corten A }}{2.8} \quad \frac{304 \mathrm{~L}}{0.3}$}

2.1

WHITE LIQUOR

$\begin{array}{lccc}\frac{\mathrm{A} 285 \mathrm{C}}{316} & \frac{\mathrm{A} 516-70}{251} & \frac{\text { Corten A }}{50} & \frac{304 \mathrm{~L}}{3.9} \\ 269 & 228 & & \\ 250 & 202 & 50 & \end{array}$



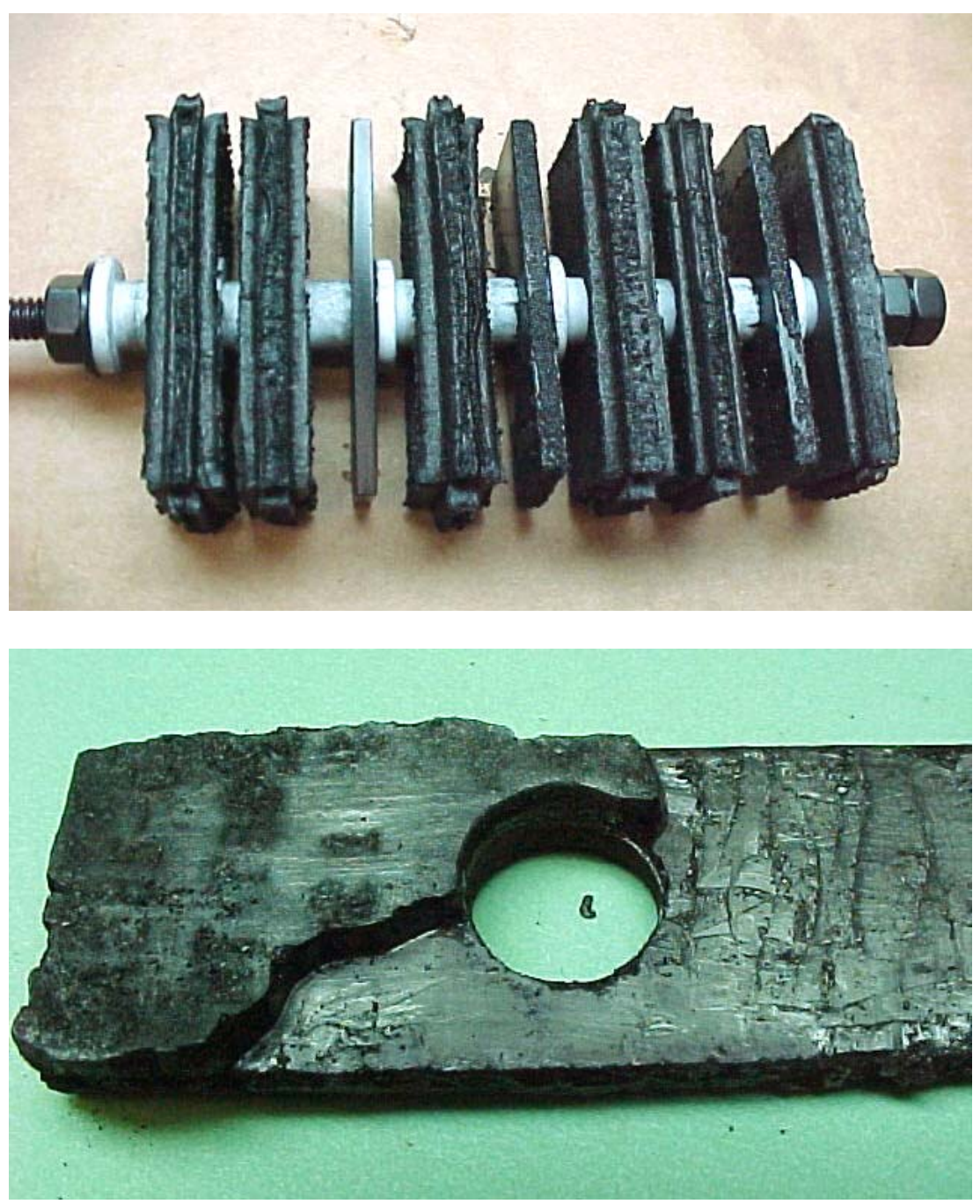

Fig. 40. Appearance of specimens following autoclave testing for 14 days at $165^{\circ} \mathrm{C}$ in synthetic white liquor solution. Top: specimen rod with all the specimens; the one with no corrosion product is the 304L coupon, and the two Corten A specimens have relatively less corrosion product. Bottom: A285C coupon with the corrosion product partially removed.

The 304L stainless steel coupons were largely immune to corrosion of any kind in the simulated extraction liquors. In the simulated white liquor solution, the coupon corrosion rate was very low, but the coupon experienced significant stress corrosion cracking at the coupon edges/corners (no doubt encouraged by the residual stress resulting from the shearing operation to fabricate specimens). 
As a result of the results in the simulated extraction liquors indicating some beneficial effect of the oxide, another set of autoclave experiments was performed to examine the possibility that if the oxide film were sufficiently protective - there could be a galvanic couple between bare and oxide-covered steel to accelerate corrosion locally as observed in some digesters where the oxide has clearly been removed by grinding or other methods. The same steels, heat treatments, and test solutions were used as previously but, in this instance, portions of the oxide films were removed by grinding. A representative photo appears in Fig. 41.

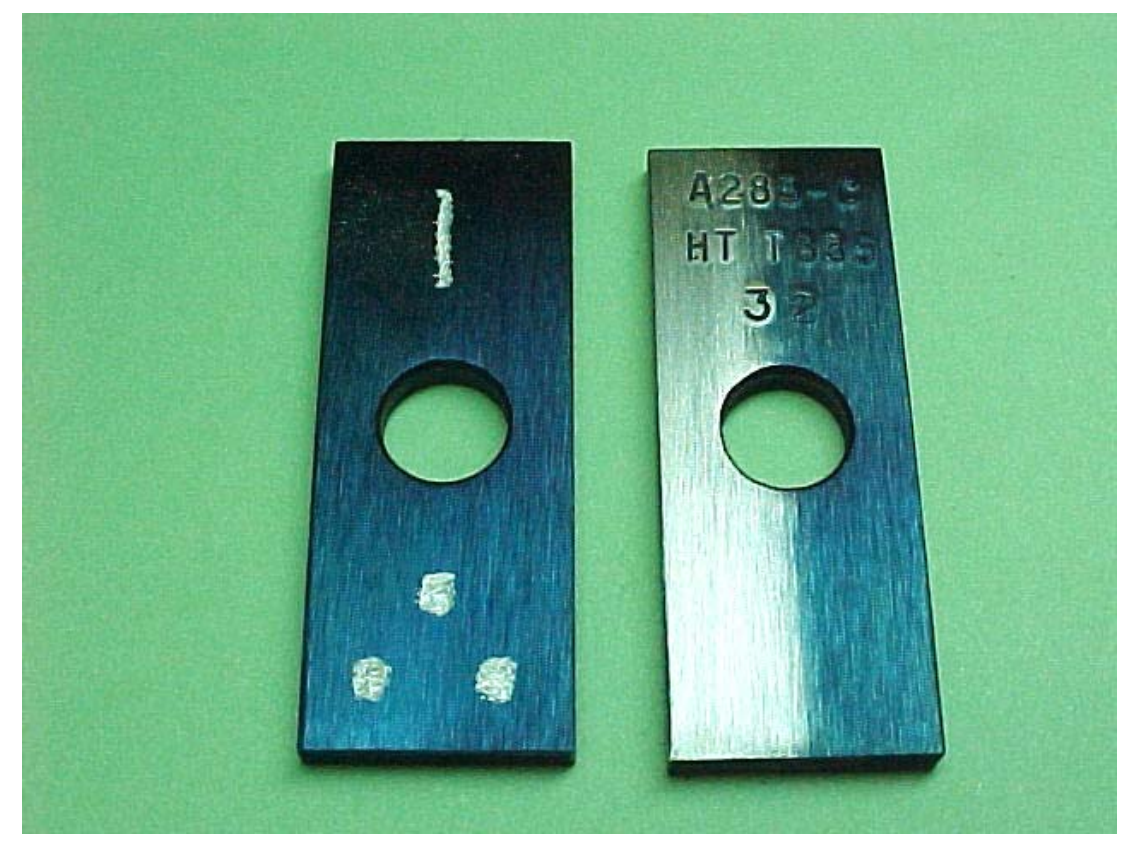

Fig. 41. Examples of oxide removal patterns to examine potential galvanic effects of the scale during autoclave testing. The dark/blue areas have scale formed in $45 \mathrm{~min} / 305^{\circ} \mathrm{C}$, and the shiny areas have been ground to 120 grit finish.

On coupons with oxide removed in both of the patterns shown in Fig. 41, there was no accelerated corrosion of bare material in any test environment. Further, general corrosion rates calculated from weight loss for coupons with no oxide (120 grit surface) and for full oxide (45 $\min / 305^{\circ} \mathrm{C}$ ) were not particularly reproducible compared to earlier results, indicating more effort is required for testing and interpretation of a possible effect of oxide on corrosion rate. 
This page

Intentionally blank 


\subsection{CONCLUSIONS}

The second set of probes in the digester at Spring Grove performed adequately over the yearlong exposure. No leaks or problems at any of the probe ports were observed, and all the probe materials survived the exposure. Brief gaps in the data stream due to computer problems and a failure of the data logging equipment were overcome by real-time monitoring of the data and rapid support at the mill.

By comparing present visual inspection data with similar information from the recent past, it is clear that corrosion conditions aggressive to mild steel persist in the digester. In the June 2003 inspection, localized corrosion of mild steel surfaces was observed in locations previously free of attack such as near the top of the vessel and below the wash screens. Further, there was evidence that the depth of pitting in some locations had increased during the prior year. Nevertheless, the type 309LSi overlay material continues to perform extremely well as evidenced by its near pristine appearance, including residual slight surface relief and heat tint resulting from the original deposition process. Consistent with this observation, the electrodes of 309LSi stainless steel in each probe exhibited no attack during the year \#2 exposure. Very slight interdendritic attack - insignificant in a practical sense - was observed on the type 312 stainless steel electrodes from all the probes.

The general results from the EN experiments remain somewhat inconclusive. By comparing current and potential noise activity from the probes on opposite sides of the vessel at the ring 6 elevation, it is clear that environmental conditions (chemistry, flow, temperature) can vary in ways that are not incorporated by various predictive models that depend upon circumferential symmetry. For example, the temperature gradient at this location was substantially different than for the prior year, suggesting flow and mixing in the digester have changed. In addition, potential excursions occur for the stainless steel electrodes on one side of the vessel and not the other, and also exhibit different excursion tendencies in response to the same event, indicating the possibility of periodic gradients/changes in the local chemistry within the vessel. Further, current sums vary regularly on opposite sides of the vessel and, since no wastage was observed on the electrodes, this indicates that redox chemistry/conditions vary by a significant amount on a consistent basis. 
The silver electrodes revealed various degrees of "consumption" to silver sulfide during the year-long exposure, but since some amount of silver remained in contact with silver sulfide throughout the experiment, it appears the silver performed as a suitable (pseudo) reference. However, the highly variable extent of transition of $\mathrm{Ag}$ to $\mathrm{Ag}_{2} \mathrm{~S}$, even at opposite sides of the vessel at ring 6 and in consecutive years, is further evidence of the highly variable local chemistry in the vessel that is not detected by standard mill analyses.

Mild steel test panels exposed in the digester to examine the role of mill scale in the observed localized pitting pattern revealed little or no influence of simulated oxides on the total corrosion/erosion or wastage patterns. All of the mild steel panels suffered significant general thinning, but extensive wastage along the corners/edges while not under the teflon shoulder washers indicated a significant component of erosion on material at this location near the extraction screens. Concurrent laboratory testing of the same steel/oxide specimens in simulated liquors indicated some benefit of oxide scales for reducing corrosion rate - particularly in extraction liquors - but the effect was not particularly reproducible. Partial coverage of coupons with an oxide film - intended to simulate possible galvanic effects at regions where scale had been ground/removed - was not a significant factor in the autoclave test results. Type 304L stainless steel test panels from the digester were essentially immune to attack, as were similar coupons in the autoclave tests with simulated extraction liquors. The stainless steel coupons exposed to simulated white liquor in the autoclave revealed some tendency to cracking. 


\subsection{FUTURE WORK}

The EN results point to the possible utility of a corrosion probe that can distinguish between corrosion reactions and redox activity. One potential design presently under consideration incorporates a standard EN design in which the electrode(s) also function as thin-layer activation specimens. Further improvement of the probes could include on-line chemical analysis capability, particularly for major components of the digester process, as the routine sampling at this (and other) mills is not capable of detecting localized changes/gradients in the process to which the probes appear to respond. 
This page

intentionally blank 


\section{ACKKNOWLEDGEMENTS}

This research was funded by the United States Department of Energy, Industrial Technologies Program, for the Agenda 2020 Program. The Oak Ridge National Laboratory Program Manager for this effort was P. Angelini. The industrial advisory board consisted of M. E. Gorog (Weyerhaeuser), W. B. A. Sharp and S. J. Lukezich (MeadWestvaco), and D. C. Crowe (International Paper). The entire staff at Glatfelter in Spring Grove was helpful making probe installation and data transfers seamless - in particular, D. E. Roy, H. E. Muller, R. C. Abel, and G. L. Wisner facilitated information exchange and technical support and were very available to ORNL. In addition, B. Keeney (formerly of Glatfelter) and T. Redding (Glatfelter) were instrumental in providing computer access to the digester process data. S. J. Lukezich (MeadWestvaco) provided material for fabrication of the 309LSi and 312 electrodes, and the probes were manufactured by Rohrback Cosasco Systems (Santa Fe Springs, CA). A. W. Willoughby operated the autoclaves used in these experiments. E. T. Manneschmidt and K. A. Choudhury provided computer graphics/image file support and H. F. Longmire provided metallography support. P. M. Singh (Georgia Institute of Technology) provided helpful discussions and, along with P. F. Tortorelli (ORNL), reviewed the manuscript. 
This page intentionally blank 


\section{REFERENCES}

1. S. J. Pawel, D. W. Townley, D. E. Roy, and D. F. Wilson, "Correlation of Process Data and Electrochemical Noise to Assess Kraft Digester Corrosion: Kamloops Experiment," Oak Ridge National Laboratory Report ORNL/TM-2002/33, April 2002.

2. S. J. Pawel, D. W. Townley, D. E. Roy, and D. F. Wilson, "Correlation of Process Data and Electrochemical Noise to Assess Kraft Digester Corrosion: Spring Grove Experiment," Oak Ridge National Laboratory Report ORNL/TM-2003/107, April 2003.

3. A. Wensley, "Corrosion and Protection of Kraft Digesters," Tappi Journal, Vol. 79, No. 10, p.153 (1996).

4. D. C. Crowe and D. Tromans, "The Silver Sulfide Reference Electrode for Use in Alkaline Sulfide Solutions," Corrosion, Vol. 42, No. 7, p.409 (1986).

5. The Silver/Silver Sulfide Reference Electrode for Use in Corrosion Studies in Kraft White Liquor," The Institute of Paper Chemistry, Project 3556, Report One, February 15, 1984. 
This page

Intentionally blank 


\section{INTERNAL DISTRIBUTION}

1. P. Angelini

2. E. E. Bloom

3. G. E. Giles

4. L. L. Horton

5. J. R. Keiser

6-15. S. J. Pawel (10)
16. P. F. Tortorelli

17-18. D. F. Wilson (2)

19-20. Central Research Library (2)

21. Document Reference Section

22. ORNL Laboratory Records - RC

23. Office of Scientific \& Technical Information

\section{EXTERNAL DISTRIBUTION}

24. D. C. Crowe - International Paper, Mfg. Tech. Center, 6285 Tri-Ridge Blvd., P.O. Box 7910, Loveland, OH 45140

25. M. E. Gorog - WTC1B40, Weyerhaeuser P.O. Box 9777, Federal Way, WA 98063-9777

26. S. J. Lukezich - MeadWestvaco Research Laboratory, 232 Eighth St., P. O. Box 1700, Chillicothe, $\mathrm{OH} 45601-5700$

27-28. D. E. Roy - Glatfelter Company, 228 South Main St., Spring Grove, PA 17362

29. M. Salcudean - 1938 Western Parkway, Vancouver, V6T 1V5, British Columbia, Canada

30. D. Salem - DOE, Office of Industrial Technologies, EE-20, 1000 Independence Ave. SW, Washington, DC 20585-0121

31. W. B. A. Sharp - MeadWestvaco, Laurel Technical Center, 11101 Johns Hopkins Rd., Laurel, MD 20723-6006

32. D. A. Singbeil - Paprican, Vancouver Laboratory, 3800 Wesbrook Mall, Vancouver, British Columbia V6S 2L9, Canada

33. P. M. Singh - Institute of Paper Science and Technology, $50010^{\text {th }}$ Street, Atlanta, GA30318-5794

34-35. D. W. Townley - M. J. Schiff and Associates, 431 W. Baseline Rd., Claremont, CA 91911

36. D. A. Wensley - D. A. Wensley Consulting Engineering Services, 15397 Columbia Ave., White Rock, British Columbia V4B 1K1, Canada 